\title{
LA CASA Y LA MESA DE LA REINA BLANCA DE NAVARRA
} (1433)

\author{
FERNANDO SERRANO LARRÁYOZ \\ Universidad Pública de Navarra
}

\section{SUMARIO}

1. Introducción.- 2. El Hostal de la reina Blanca en 1433: 2.1. Los departamentos tradicionales. 2.1.1. La Panadería. 2.1.2. La Botellería. 2.1.3. La Cocina. 2.1.4. La Frutería. 2.1.5. La Escudería.- 3. En la mesa con la reina: 3.1. La vajilla de mesa. 3.2. Los ritmos alimentarios. 3.3. Aspectos religiosos. 3.4. Beneficiarios de los alimentos. 3.5. Prácticas culinarias en la Corte navarra.- 4 . Conclusiones.

\section{INTRODUCCIÓN ${ }^{1}$}

El estudio de la alimentación no sólo debe consistir en una enumeración descriptiva de las conductas de nuestros antepasados, sino que ésta debe ser entendida como un fenómeno socio-cultural que nos puede aportar una cantidad considerable de información sobre el funcionamiento de una sociedad ${ }^{2}$. Hay que tener en cuenta que si el alimento por sí mismo no resulta ser más que un conjunto de nutrientes, éste, una vez que ha sido aceptado o rechazado, cuando se consume en un medio social determinado, llega a convertirse en un símbolo cultural.

\footnotetext{
${ }^{1}$ Siglas referentes al sistema monetario que se cita: libras/sueldos/dineros $=\mathrm{lbs} . / \mathrm{s} . / \mathrm{d}$.

2Para estos aspectos se puede consultar la obra de J. ConTRERAS HERNÁNDEZ, Antropología de la alimentación, Madrid, 1993, pp. 51-69.

"Anuario de Estudios Medievales", 30/1 (2000)
} 
El Medievo fue un periodo en el que el consumo de los alimentos estaba estrictamente regido por los ciclos estacionales y donde la riqueza económica se mostraba mediante fiestas esplendorosas. A partir de la segunda mitad del siglo XIII los pudientes elevaron cada vez más el listón de la distinción social. Ya no bastaba con comer mucho, como era costumbre desde la más temprana Edad Media, sino en comer mejor. El refinamiento en el sabor, aroma y color de la viandas y el nacimiento de las «buenas maneras» comenzaron a perfilarse como signos de diferenciación que ya no dependían solamente de la cantidad, sino también de la calidad y de las formas del consumo ${ }^{3}$.

La desigualdad que imperaba en la sociedad durante la Baja Edad Media, aunque en cierta medida mediatizada por el desarrollo de grupos sociales intermedios, quedaba claramente reflejada en las costumbres y en los hábitos alimentarios de los miembros de los diferentes grupos sociales ${ }^{4}$. En un extremo estaba la realeza y la alta nobleza con una alimentación que en la mayoría de los casos superaba las necesidades fisiológicas de cada persona, y cuya preocupación por comer no era ni mucho menos una obsesión diaria. En el otro extremo, incluidos en un ámbito más amplio (proletariado urbano, mendigos...), se encontraba el campesinado, con una dieta bastante más limitada tanto en cantidad como en calidad, basada principalmente en el autoconsumo de la producción familiar y complementada con alguna aportación suplementaria adquirida en los mercados locales y, posiblemente, por la caza y la pesca furtiva.

Debemos, por tanto, tener en cuenta que las conclusiones a las que podamos llegar en el presente estudio no se pueden ni se deben hacer extensibles a otros estratos de la sociedad bajomedieval ${ }^{5}$. Los miembros de

\footnotetext{
${ }^{3} \mathrm{M}$. MONTANARI, El hambre y la abundancia. Historia de la alimentación en Europa, Barcelona, 1993, pp. 63-64. Sobre el sistema alimentario de la nobleza en la Alta Edad Media podemos remitirnos a A. RIERA I MELIS, El sistema alimentario como elemento de diferenciación social en la Alta Edad Media. Occidente, siglos VIII-XII, en Representaciones de la sociedad en la historia: de la autocomplacencia a la utopía. Universidad de Valladolid, 1991, pp. 15-18; y del mismo autor Senyors, monjos i pagesos: alimentació $i$ identitat social als segles XII $i$ XIII, Discurs de recepció d'Antoni Riera i Melis com a membre numerari de la Secció Històrico-Arqueològica, llegit el dia 24 d'abril de 1997, Barcelona, 1997, pp. 11-18.

${ }^{4} \mathrm{~T}$. de CASTRO MARTÍNEZ, La alimentación en las crónicas castellanas bajomedievales, Granada, 1996, pp. 144-147.

${ }^{5}$ Las reflexiones sobre la marginalidad de la dieta de la alta sociedad ya fueron apuntadas por M. MIQUEL y A. Domingo, en La taula reial a finals del segle XIV, en "Ir Col.loqui d'Història de l'Alimentació a la Corona d'Aragó. Edat Mitjana", t. 2, Lleida, 1995, pp. 293294.
} 
la monarquía eran una minoría en el total de la sociedad, pero fueron ellos quienes marcaron los ejemplos de conducta a seguir por las demás capas de población. No debemos olvidar que su comportamiento en lo que a cuestiones alimentarias se refiere, se intentaba reproducir en las mesas con menos posibilidades aunque fuera en una escala mucho menor ${ }^{6}$.

El interés por estudiar la organización de la Corte y de forma especial la mesa de Blanca de Navarra, a pesar de que ya se ha realizado algún trabajo parcial ${ }^{7}$, no es fruto del azar, y todavía queda mucho por hacer. En primer lugar, la intención de este artículo es presentar de forma general el funcionamiento de la Corte navarra durante la primera mitad del siglo $\mathrm{XV}$, y en particular estudiar todas las cuestiones referentes a los modos, formas, gustos, prioridades alimentarias y un largo etcétera, características de la realeza. En segundo lugar, pretende ser un ejemplo más con el que se quiere comparar y contrastar toda una serie de temas relacionados con la alimentación, y que hasta el momento han sido poco cuestionados.

1433 es un año que podemos denominar de «madurez» en la vida de la reina. Un tiempo en el cual su frágil salud motivó la organización y el posterior viaje a Santa María del Pilar en Zaragoza ${ }^{8}$. Una fase en la que para gobernar tuvo que saber conjugar sus dotes de observación y de paciencia, y, por qué no, su mano femenina, ante los intereses personales de su esposo Juan II, quien utilizaba el reino como fuente económica para sus aspiraciones en Castilla y Aragón'. En este contexto pues, puede ser interesante desgranar el sistema alimentario de la Corte y por extensión de todos los aspectos que esto conllevaba, poniéndolo en relación cuando sea posible con los estudios - pocos-, que sobre el mismo tema se han realizado en Navarra hasta el momento.

\footnotetext{
${ }^{6} \mathrm{~A}$. RIERA I MELIS, Estructura social y sistemas alimentarios en la Cataluña bajomedieval, "Acta Historica et Archaeologica Mediaevalia", 14-15 (1993-1994), p. 195.

${ }^{7} \mathrm{~F}$. SERRANO LARRÁYOZ, La alimentación de la realeza navarra en el siglo XV: las cuentas del Hostal de la reina Blanca durante una romería a Zaragoza (1433), en J. I. de la Iglesia Duarte (coord.): "La vida cotidiana en la Edad Media" ("VIII Semana de Estudios Medievales de Nájera"), Logroño, 1998, pp. 305-336.

${ }^{8}$ Siempre que se ha estudiado la romería de Blanca a Santa María del Pilar, en Zaragoza, se ha aludido a la mala salud de la reina. Sin embargo, no debemos olvidar que una de las funciones de las reinas, ante el pueblo, era ser ejemplo de virtud y de piedad cristiana.

${ }^{9}$ Sobre este periodo de la vida de Blanca debemos mencionar el trabajo de E. RAMíREZ VAQUero titulado La reina Blanca y Navarra, "Príncipe de Viana", 60 (1999), pp. 323-340.
} 


\section{El Hostal DE La REINA BlanCA EN 1433}

Con el nombre de «Hostal Real» tradicionalmente se ha designado al conjunto de servicios y servidores, que se dedicaban a satisfacer las necesidades personales de los miembros de la familia reinante. El rey y la reina tenían el suyo propio, mientras que por lo general los infantes y la infantas dependían del de la madre hasta que se hacían mayores ${ }^{10}$.

La introducción del Hostal como forma de organización interna de la Casa Real navarra se debe al linaje de los Evreux, descendientes de la realeza francesa. Éste alcanzó su máximo desarrollo durante el reinado de Carlos III (1387-1425) ${ }^{11}$. Tras su muerte el esplendor y la magnificencia de la Corte fue poco a poco declinando. Durante el reinado de Blanca (14251441) se ha podido comprobar un carácter más sobrio, que de ninguna manera está reñido con la concepción del gusto y de la exquisitez imperante en la época. Tal moderación puede ser achacada al carácter personal de la reina; por lo menos esa impresión se puede llegar a adquirir tras consultar la documentación. Sin embargo, la drástica reducción de ingresos, que durante este reinado sufre la Hacienda $\cdot$ Real, en gran medida motivada por la continua sangría, que Juan II realizó a las finanzas reales en defensa de sus intereses patrimoniales, parece que fue el principal motivo.

Durante 1433 Blanca residió en Olite hasta el 5 de mayo ${ }^{12}$, y posteriormente pasó a Tudela. Del 13 de julio al 10 de septiembre la reina

\footnotetext{
${ }^{10}$ Cuando la reina deja de residir durante un largo periodo de tiempo en Navarra, como ocurre con Leonor, esposa de Carlos III, los gastos de las infantas se incluían en el Hostal de la condesa de Foix [Archivo General de Navarra (en lo sucesivo "AGN"), Comptos Registros, $\mathrm{n}^{\mathrm{o}} 175.1,178,187,196,200$ y 204].

"La Casa Real debió organizarse de esta manera al menos desde la llegada de Juana II y Felipe III de Evreux (1328), pero los primeros cuadernos conservados son bastante más tardíos: un primer ejemplo, aunque muy sencillo todavía, puede ser un fragmento de 1350 [AGN, Comptos Registros, $\mathrm{n}^{\circ}$ 62, fol. 342r-v], aunque no empiezan a ser sistemáticos hasta los años sesenta del siglo XIV [E. RAMIREZ VAQUERO, El retorno a Navarra de la reina de Sicilia en 1415 , en "Estudios de lingüística hispánica. Homenaje a María Vaquero", San Juan de Puerto Rico, 1999, p. 502 (nota $\mathrm{n}^{\circ} 26$ )]. Con Teobaldo II se puede observar una cierta distribución de la Casa del rey [M. ${ }^{\text {a }}$ R. GARCía ARANCón, Teobaldo II de Navarra 1253-1270. Gobierno de la Monarquía y recursos financieros, [Pamplona], 1985, pp. 120-124 y 238-239]; sin embargo, no parece que alcanzara el desarrollo que adquirió con los Evreux.

${ }^{12} \mathrm{AGN}$, Comptos Registros, $\mathrm{n}^{\circ} 420$, fol. 104v.
} 
fue de romería al Pilar de Zaragoza ${ }^{13}$. Los trayectos, tanto en el reino como fuera de él, movilizaban una gran comitiva que se hacía cargo de las necesidades de la soberana y su familia. Este viaje y su posterior residencia a orillas del Ebro conllevó a planificar la administración del Hostal, donde se consumía diariamente lo que se compraba, sin dejar demasiados excedentes de almacenamiento. Un proceso bastante lógico, si tenemos en cuenta que les resultaba más cómodo llevar dinero, que cargar con innumerables cantidades de provisiones para todos sus miembros. Durante el tiempo que estuvieron en Aragón, los gastos, que hasta entonces se pagaban en moneda navarra, se desembolsaron en moneda aragonesa.

Como ya hemos podido comprobar, la organización de los hostales se fundamentaba en las necesidades que generaba la familia real. Las secciones, acuñadas, desde hace ya bastante tiempo, con el término de «tradicionales»" ${ }^{14}$, eran la Panadería, Botellería, Cocina, Frutería y la Escudería. Éstas se ocupaban de manera directa del suministro, conservación, preparación y servicio de los alimentos de la reina. La Panadería era responsable de la elaboración de los productos derivados del trigo. La Botellería de la adquisición del vino. La Cocina se encargaba de la compra de las diversas viandas y de su posterior elaboración. Contaba con un subdepartamento: la Salsería. Ésta funcionaba, en cierta manera, de forma independiente y su función se centraba en la preparación de los diferentes caldos y salsas. Sin embargo, no constituía un departamento en sí misma porque sus gastos se incluían en los de la Cocina, y las compras se realizaban desde ésta ${ }^{15}$. La Frutería abastecía de cera y fruta, y la Escudería de todo lo relacionado con las caballerías, gastos en productos de limpieza, escribanía y el pago del salario a los servidores y miembros del Hostal.

\footnotetext{
${ }^{13}$ P. Galindo Romeo, Peregrinación de Doña Blanca de Navarra en 1433 a Santa María del Pilar de Zaragoza, "Separata en Homenaje a Finke. Revista Zurita", III, fasc. 1-2 (1935), pp. 1-41.

${ }^{14} \mathrm{El}$ término "tradicionales" fue utilizado la primera vez para los hostales navarros por $\mathrm{J}$ Zabalo Zabalegui, La Administración del Reino de Navarra en el siglo XIV. Pamplona, 1973 p. 68; y, posteriormente, por M. "J. IBIRICU, El Hostal del príncipe Carlos de Viana (1451), "Príncipe de Viana", 49 (1988), p. 597. Tal denominación fue utilizada para el caso francés por M. REY en Les finances royales sous Charles VI. Les causes du déficit (1388-1413), París, 1965 , p. 25.

${ }^{15} \mathrm{El}$ mismo funcionamiento podemos ver, años más tarde, en el Hostal de Carlos, príncipe de Viana [M. a J. IBIRICU, El Hostal, pp. 610-611].
} 
De forma paralela a estos oficios existían otras secciones, denominadas en Francia como chambres $^{16}$, que completaban la estructura interna del Hostal. En la Cámara de la reina, los camareros junto con los valets, los donceles, y doncellas, las amas, las nodrizas y demás miembros con cargos afines eran los encargados de comprar medicinas, paños, telas, y de servir personalmente a la familia real ${ }^{17}$. También podemos incluir aquí a quienes cuidaban de la salud corporal de sus miembros - físicos y boticarios ${ }^{18}-$. Según lo que hasta el momento se ha podido entrever, la Cámara debía comprender el Guardarropa. Los sastres, costureros, zapateros y lavanderas se encargaban con sus trabajos de confeccionar y cuidar de la vestimenta de la reina, las infantas y de algunos miembros del Hostal ${ }^{19}$. El conjunto de

${ }^{16}$ J. FAVIER, Philippe le Bel, Librairie Arthème Fayard, 1978, p. 54.

${ }^{17}$ Como camareros, cambreros o servidores de la reina están documentados: Pedro Chimich [F. IDOATE, Catálogo del Archivo General de Navarra (en lo sucesivo "CAGN"), t. 41, n" 397/AGN, Comptos Documentos, caj. 135, $\mathrm{n}^{\circ}$ 36, fol. 1r], Juan Forment [CAGN, t. 41, $\mathrm{n}^{\mathrm{o}}$ 397/AGN, Comptos Documentos, caj. 135, $\mathrm{n}^{\circ} 36$, fol. 1r], Menautón [CAGN, t. 41, no 397/AGN, Comptos Documentos, caj. 135, $\mathrm{n}^{\circ} 36$, fol. 2v], y Juan Blanc (año 1432) [CAGN, t. 40, $n^{\circ}$ 824/AGN, Comptos Documentos, caj. 134, $\mathrm{n}^{\circ} 5$, fol. 3v]. Con el cargo de valet de Cámara se menciona a Juan Pasquier [CAGN, t. 41, n 149/AGN, Comptos Documentos, caj. $133, n^{0} 9$, VIII]. Aunque desconocemos el número exacto de camareros que tenía la reina, sabemos que durante julio de 1433, al menos nueve de ellos transportaron en barcazas, atravesando el Ebro, el equipaje para la romería que se iba a realizar a Zaragoza [P. GALINDO Romeo, Peregrinación de Doña Blanca, p. 35]. Como donceles de la reina hemos podido identificar a Sancho de Alzate, Pedro de Alzate, García de Johara, García Arnaldo de Suescun, Ramón de Agramont y Gonzalo de Los Arcos [CAGN, t. 41, $n^{\circ}$ 526/AGN, Comptos Documentos, caj. 135, $\left.\mathrm{n}^{\circ} 44, \mathrm{VI}\right]$. Más complicado resulta sacar del anonimato a las doncellas que durante este año sirvieron a Blanca de Navarra. Posiblemente fueran doña Inés (1434) [CAGN, t. 41, no 738/AGN, Comptos Documentos, caj. 134, n 22, III], Juana de Ezpeleta, Juana de Bería, María Torres, Margarita, y Catalineta, que reciben el mismo salario. Francesa Miguel de Guérez poseía el cargo de ama de la infanta Leonor [CAGN, t. 41, n ${ }^{\circ}$ 524/AGN, Comptos Documentos, caj. 133, $\left.\mathrm{n}^{\circ} 10, \mathrm{XXII}\right]$, quizás junto con Marina de Torres (año 1432) [CAGN, t. $40, \mathrm{n}^{\circ}$ 1226/AGN, Comptos Documentos, caj. 133, $\mathrm{n}^{\circ} 2$, VIII], y María Pérez de Leoz, el de ama de la infanta Blanca (año 1431) [CAGN, t. 40, no 585/AGN, Comptos Documentos, caj. 112 duplicado $2^{\mathrm{a}}, \mathrm{n}^{\mathrm{o}}$ 9, LXXII]. Como nodrizas de las infantas están documentadas: Dominga de Guenduláin, María Pérez de Anoz y Elvira Sánchez de Ostiz (año 1432) [CAGN, t. 40, $\mathrm{n}^{\circ} 1226 / \mathrm{AGN}$, Comptos Documentos, caj. 133, $\mathrm{n}^{\circ} 2$, VIII]. Eran porteros o ujieres de la Cámara de la reina, Juan de la Huerta [CAGN, t. 41, no $322 / \mathrm{AGN}$, Comptos Documentos, caj. 133, $\mathrm{n}^{\circ}$ 13, XLVII], y Enequot [AGN, Comptos Registros $\mathrm{n}^{\circ} 415$, fol. 17r]. Fernando de Axa lo era de la Cámara de las infantas [CAGN, t. 41, n ${ }^{\circ}$ 379/AGN, Comptos Documentos, caj. 135, $\mathrm{n}^{\circ} 35$, III].

${ }^{18}$ Entre los médicos - fisicos - que trataron a la reina y a su familia podemos destacar a Lorenzo de Siena, Jacob Abocax y Juan de Marsella. Como boticario de la reina se nombra a Nicolás de Echávarri [P. GALINDO ROMEO, Peregrinación de Doña Blanca, pp. 5 y 21].

${ }^{19}$ Como bordador de la reina se menciona a Copín [AGN, Comptos Registros, $\mathrm{n}^{\circ} 415$, fol. $25 \mathrm{r}$ ] y a Nicolau [AGN, Comptos Documentos, caj. 135, $\mathrm{n}^{\circ} 36$, fol. 3r]. Idéntica organización puede observarse algunos años más tarde en el Hostal de Carlos de Viana. Sin embargo, parece ser que en el siglo XIV la Cámara no absorbía las competencias del Guardarropa [M. ${ }^{a}$ J. 
servidores de menor rango parece ser que eran los libreas, o también llamados en la documentación de la época lacayones ${ }^{20}$. Los clérigos contadores, aunque no han sido identificados, eran los encargados de la economía interna ${ }^{21}$. Por encima de todos estos servidores estaba el Chambelán de la reina. Título de carácter honorífico que se concedía a los poderosos más notables del reino como recompensa por los servicios realizados y/o por la fidelidad demostrada al monarca ${ }^{22}$.

La Capilla estaba compuesta por los capellanes $^{23}$ - uno de los cuales era el limosnero ${ }^{24}-$, por los chantres y por una serie de mozos ${ }^{25}$. Este departamento era común al rey y a la reina, excepto los cargos de limosnero y de confesor ${ }^{26}$.

La administración financiera de todos los oficios y de los departamentos correspondía a la Cámara de los Dineros. Sus orígenes se remontan a principios del reinado de Carlos II. Ésta funcionaba a la vez como una caja

IBIRICU, El Hostal, p. 597].

${ }^{20}$ Toman el nombre del vestuario que los reyes, nobles, etc. daban a sus criados [Diccionario de Autoridades, voz librea]. Los lacayos eran los criados de escalera abaxo y de librea, cuyo ejercicio era seguir a su amo, cuando iba a pie, a caballo, etc. [Diccionario de Autoridades, voz lacayo]. No ha sido posible localizar quiénes pudieron servir como lacayos durante este año. Sin embargo, podemos comprobar como esta denominación se utiliza con similar significado que el de librea [CAGN, t. 42, n 1058/AGN, Comptos Documentos, caj. $\left.130, n^{\circ} 23, I I\right]$.

${ }^{21}$ M. ${ }^{a}$ J. IBIRICU, El Hostal, p. 597.

${ }^{22}$ Éste era Juan Vélaz de Medrano [CAGN, t. 41, nº 255/AGN, Comptos Documentos, caj. $135, \mathrm{n}^{\circ} 23, \mathrm{~V}$. El título de Camarera Mayor de la reina también pudo ser honorífico, aunque de menor consideración que el de Chambelán. Como Camarera Mayor se menciona a Aldonza de Tobía [CAGN, t. 41, n 527/AGN, Comptos Documentos, caj. 135, n 44, VII].

${ }^{23}$ Los capellanes de la Capilla Real eran García de Navascués, limosnero de la reina, Martín de Cemboráin, limosnero del rey, el prior de Ujué, el prior de Arróniz, Juan de Olaz, García de Abárzuza, Pedro de Egüés, el prior de Cadreita, y Simón Navar [CAGN, t. 41, no 473/AGN, Comptos Documentos, caj. 135, $\mathrm{n}^{\circ} 41, \mathrm{XX}$. Al año siguiente es mencionado como capellán de los reyes Andrés Pérez de Mallén [CAGN, t. 41, n $\mathrm{n}^{\circ} 746 / \mathrm{AGN}$, Comptos Documentos, caj. 146, $\mathrm{n}^{\circ} 10$, VIII]. Éstos desempeñaban las funciones religiosas. No deben ser confundidos con los clérigos de la Capilla, que sólo ejercían funciones contables, sin estar ordenados [M. a R. GARCía ARANCóN, "Clérigos" en la Corte de Navarra (1384-1387), "Príncipe de Viana", 52 (1991), p. 89].

${ }^{24}$ Éste era García de Navascués [ver nota $n^{0} 23$ ]. Se encargaba del reparto de las limosnas a los pobres que el rey socorría y de la administración de los establecimientos de caridad que dependían de la corona [M. ${ }^{\mathrm{a}} \mathrm{R}$. GARCía ARANCÓN, «Clérigos» en la Corte de Navarra, p. 90].

${ }^{25}$ Durante este año se gastaron 20 florines en la enseñanza de Miguel, mozo de la capilla [AGN, Comptos Documentos, caj. 134, $\mathrm{n}^{\circ} 12$, fol. 5r].

${ }^{26} \mathrm{El}$ confesor de la reina era Pedro de Beráiz, arzobispo de Tiro (año 1432) [CAGN, t. 40, $\mathrm{n}^{\circ}$ 769/AGN, Comptos Documentos, caj. 133, nº $\left.4, \mathrm{XI}\right]$. 
y como un órgano de control de los diversos servicios del Hostal. En ella se recopilaban las cuentas que suministraban los clérigos de cada uno de los departamentos, de la Cámara de la reina y de la Capilla. El máximo responsable de las cuentas del Hostal era el maestre de la Cámara de los Dineros o también llamado cambradineros ${ }^{27}$. Su tarea abarcaba todo lo referente al control de las entradas y salidas de mercaderías, el pago de éstas y la presentación de las cuentas a la Cámara de $\operatorname{Comptos}^{28}$. En un escalafón inferior estaba el contrarrolor de la expensa de la Casa de la reina ${ }^{29}$, que a su vez era ayudado en su labor por los denominados clérigos que podían pertenecer tanto a las cámaras (de la reina y de los Dineros) como a los departamentos tradicionales.

La Panadería, Botellería, Cocina, Frutería y Escudería se organizaban de forma semejante. La organización de estos últimos servicios correspondía al maestre del Hostal. En este caso el cargo estaba duplica$\mathrm{do}^{30}$. Sus competencias, a diferencia del maestre de la Cámara de los Dineros, se centraban en el funcionamiento interno de dicho Hostal ${ }^{31}$, mientras que las de este último se dirigían sobre el control económico. En el escalafón jerárquico los maestres se encontraban bajo la supervisión del Maestre del Hostal Mayor que, como el Chambelán, era un cargo honorífico. Parece que este título englobaba de igual forma a los hostales de Blanca

\footnotetext{
${ }^{27}$ El 1 de julio de 1432, por una ordenanza de la reina Blanca, se nombra maestre de la Cámara de los Dineros a Pedro Sanz de Oroz [CAGN, t. 41, n ${ }^{\circ}$ 543/AGN, Comptos Documentos, caj. 134, $\mathrm{n}^{\circ} 12$, fol. $\left.1 \mathrm{v}\right]$.

${ }^{28} \mathrm{La}$ contabilidad no sólo se reducía a los gastos, sino también a la recepción de todas las asignaciones económicas entregadas por el tesorero de Navarra - García López de Roncesvalles- para las expensas y los gajes de las gentes del Hostal [AGN, Comptos Documentos, caj. $134, \mathrm{n}^{\circ} 12$, fols. $\left.2 \mathrm{r}-3 \mathrm{r}\right]$.

${ }^{29}$ Éste era Pedro de Echarri [CAGN, t. 41, no 499/AGN, Comptos Documentos, caj. 135 $\mathrm{n}^{\circ} 48, \mathrm{XV}$. Se encargaba de reunir toda la documentación contable ordenando y organizando ordenes de pago. También preparaba los informes o expedientes que el cambradineros añadía a su cuenta general [M. a J. IBIRICU, El Hostal, pp. 628, nota n ${ }^{\circ}$ 104].

${ }^{30}$ Este año son dos las personas que comparten el cargo de maestre del Hostal: Juan de Úriz y Beltrán de Lacarra [CAGN, t. 41, no 155/AGN, Comptos Documentos, caj. 133, n⿳202, LVII].

${ }^{31}$ Como un ejemplo de sus funciones, podemos ver un documento donde los maestres del Hostal de Blanca reconocían haber recibido de Pedro de Garínoain, recibidor de La Ribera, 32 cargas de leña de chopo, 12 cargas de leña seca de cepas y de olivo para la cámara de la reina y la cocina. Igualmente, reconocen haber recibido 4 cargas de sarmientos secos «para seruicio de la dicta seynora et de las seynoras infantas sus fijas", y 10 cargas de romeros verdes "para la cambra de la dicta seynora reyna" [CAGN, t. 41, n 523/AGN, Comptos Documentos, caj. $\left.135, \mathrm{n}^{\circ} 44, \mathrm{IV}\right]$
} 
y de $\mathrm{Juan}^{32}$. En un nivel inferior se encontraban los escuderos de cada sección y los que denominamos «especialistas» (panaderos, pasteleros, salseros, cocineros, fruteros, etc.). No todos recibían el mismo salario, por lo que éste parece que estaba en función de su categoría y del puesto que desempeñaban. Incluidos dentro del amplio abanico de servidores estaban los clérigos - uno por sección-, que como ya se ha dicho anteriormente, estaban bajo las órdenes del cambradineros ${ }^{33}$.

Existían otros oficios que, aunque, M. ${ }^{\mathrm{a}} \mathrm{J}$. Ibiricu los incluye en la Cámara de la reina, a mi entender no parece que dependieran de ella. Éstos eran los que se encargaban de las diversiones de los reyes: músicos, juglares, bufones ${ }^{34}$, halconeros, los cuidadores de los perros de caza y los cazadores $^{35}$. De la misma forma, el trompeta, los veladores y los heraldos $\mathrm{u}$ oficiales de $\operatorname{armas}^{36}$ tampoco es posible enmarcarlos en ningún departamento concreto. Además, en ocasiones no siempre resulta sencillo saber si pertenecían al Hostal del rey, al de la reina o al del príncipe Carlos ${ }^{37}$.

\footnotetext{
${ }^{32}$ Entre 1432 y 1434 se denomina a Pierres de Peralta como Maestre del Hostal Mayor de los reyes. [CAGN, t. 40, n ${ }^{\circ}$ 769/AGN, Comptos Documentos, caj. 133, nº 4, XI y CAGN, t. 41, no 826/AGN, Comptos Documentos, caj. 133, n² 24, XLI].

${ }^{33}$ Cada departamento tenía un clérigo. Martín Bel lo era del Goardamangier - no existe propiamente un clérigo de Cocina- [AGN, Papeles Sueltos, I a serie, leg. 41, carp. 14]; Miguel, de la Panadería [AGN, Papeles Sueltos, I $I^{a}$ serie, leg. 41, carp. 13]; Pedro de Fourdinay, de la Botellería [AGN, Comptos Registros, no 420, fol. 3r]; Pascual, de la Frutería [AGN, Papeles Sueltos, I ${ }^{a}$ serie, leg. 41, carp. 16]; y Juan de Sevilla, de la Escudería (1432) [CAGN, t. $40, \mathrm{n}^{\circ} 727 / \mathrm{AGN}$, Comptos Documentos, caj. 132, n 6 , II].

${ }^{34}$ Entre éstos podemos incluir a Ángeles de Roncal (loca) [CAGN, t. 41, no 486/AGN, Comptos Documentos, caj. 135, $\mathrm{n}^{\mathrm{0}} 33$, III]. Estas personas fingían su locura para entretener a los miembros de la Corte. En recompensa a sus servicios recibían comida y bebida para sí y para sus cabalgaduras [M. ${ }^{\mathrm{a}}$ J. IBIRICU, El Hostal, pp. 597-598].

${ }^{35}$ No parece que la reina tuviera una especial predilección por el ejercicio de la caza y la cetrería. Parece que estos placeres eran más del gusto de Juan II. Bonanat y Juan Fernández son mencionados como halconeros del rey [CAGN, t. 41, n' 438/AGN, Comptos Documentos, caj. $133, \mathrm{n}^{\circ} 14, \mathrm{XXXVII}$ y CAGN, t. 41, n⿳ 318 / AGN, Comptos Documentos, caj. 133, $\mathrm{n}^{\circ} 8$, XXI]; y como monteros del rey, Gonzalo Fernández [CAGN, t. 41, n ${ }^{\circ} 105 / \mathrm{AGN}$, Comptos Documentos, caj. 133, no 10, XXVI]; y Álvaro de Ribera [CAGN, t. 41, n' $145 / \mathrm{AGN}$, Comptos Documentos, caj. 133, $\left.\mathrm{n}^{\circ} 15, \mathrm{VII}\right]$.

${ }^{36} \mathrm{Ya}$ desde el siglo XIV los heraldos se organizaban en tres categorías: reyes de armas (o de los heraldos), heraldos propiamente dichos y pursuivant o perseverantes. Al final de la Edad Media su función se redujo a aspectos ceremoniales o de etiqueta. [J.M. RAmOS AGUIRRE, Los oficiales de armas en la Corte de Navarra, en "Tercer Congreso General de Historia de Navarra", Área 1, Ponencia III, Pamplona, 1998, p. 3. Editado en CD-rom].

${ }^{37} \mathrm{En}$ el caso de los oficiales de armas parece que existe diferencia entre los que pertenecen a los hostales de los monarcas y los del príncipe de Viana [J.M. RAMOS AGUIRRE, Los oficiales de armas, pp. 7-8]. Como heraldos de los reyes están documentados Blanc Levrier y Pamplona [AGN, Comptos Registros, n 415 , fols. 20v-21r].
} 
Según la organización de los hostales franceses, a partir del siglo XIV, tales cargos estaban encuadrados en lo que denominan Fourrière, que reunían a servidores con funciones de las más variadas ${ }^{38}$. En Navarra sus cometidos estaban englobados en la Escudería.

\subsection{Los departamentos tradicionales}

\subsubsection{La Panadería}

La función principal de este departamento era la adquisición de trigo para su posterior transformación en pan. Salvo cuando la reina estuvo en Zaragoza, el Hostal se abasteció de las rentas que se pagaban en este cereal. Hasta principios de mayo el aprovisionamiento se realizó a través del recibidor de la merindad de Olite, mientras que cuando la Corte se estableció en Tudela lo hizo el de La Ribera. De todas formas, el trigo, con el que se elaboraba el pan que comía la reina, en muchas ocasiones, cuando residen en Tudela, era entregado por el recibidor de Olite $^{39}$. Parece que no había diferencias de calidad entre el trigo de uno u otro lugar, pero no descarto la posibilidad de que para estas fechas existiera una normativa referente al abastecimiento de algunos productos básicos, como pudiera ser el caso de este cereal, para elaborar el pan que consumían los monarcas, y que estipulara el aprovisionamiento desde Olite ${ }^{40}$. Durante el viaje por tierras aragonesas fue el panadero el encargado de comprar las piezas necesarias ${ }^{41}$, aunque por lo general, cuando estuvieron afincados en Zaragoza solamente adquirieron la materia prima. En ocasiones también gastan trigo que había sido entregado como presente por algún miembro de cierta importancia ${ }^{42}$.

\footnotetext{
${ }^{38} \mathrm{M}$. REY, Les finances royales sous Charles VI, p. 25.

${ }^{39}$ Podemos ver a dicho recibidor entregando trigo desde el 21 hasta el 30 de mayo [AGN, Comptos Registros, $\mathrm{n}^{\circ} 420$, fol. $117 \mathrm{v}-129 \mathrm{r}$ ]. Posteriormente desde el 5 al 21 de octubre [fol. 253r-266v] y otros periodos más o menos largos.

${ }^{40}$ No resulta extraño si tenemos en cuenta que es aquí -en Olite- donde residen durante gran parte del año.

${ }^{41}$ El 16 de julio, en Alagón, se pagan 30 d. jaqueses por 15 panes para la reina y las infantas, y 16 por 8 panes para la cena de las dueñas [AGN, Comptos Registros, $n^{\circ} 420$, fol. $175 r]$.

${ }^{42}$ Desde el 19 al 22 de julio, en Zaragoza, se gastaron diversas cantidades de trigo «tomado de present del protonotario" [AGN, Comptos Registros, $\mathrm{n}^{0} 420$, fol. 178v].
} 
Se detallan dos clases de pan que nos indica una diferencia de calidad. El denominado pan común se,ofrecía a quienes se benefician del pan de la Casa de la reina, como pueden ser servidores y otros personajes que se mencionan puntualmente, y que no siempre pertenecen a su séquito. Las cantidades que se consumían estaban en relación con las necesidades del momento. Así, en festividades especiales la adquisición de trigo suele ser mucho mayor de lo normal ${ }^{43}$. Diariamente, en las anotaciones del Hostal, se suman las piezas elaboradas en el día a lás sobrantes de la jornada anterior. El peso del pan estaba más o menos estáblecido. Cada unidad rondaba los 0,5 kilogramos $^{44}$. La segunda väriedad era el pan de boca; que se entregaba a la reina y a las infantas. En ningún momento mencionan cuantas unidades de este tipo elaboraban. En 1451, en el Hostal del príncipe de Viana, el peso era superior al del pan común $(0,687 \mathrm{~kg} \text {. })^{45}$. Las cantidades que se consumen diariamente, tanto en Navarra como en Aragón, eran 2 cuartales y medio $(13,75 \mathrm{~kg} \text {. })^{46}$, por lo que si el peso no variaba significativamente, el número de panes elaborados era de unos 20 .

Conjuntamente con el pan se preparaban, cada día, 36 obleas, en cuya elaboración se gastaban 15 d. carlines, cuando están en Navarra, y 5 d. jaqueses, en Zaragoza, para la compra de harina y leña ${ }^{47}$. Otro tipo de preparaciones, que también se realizaban, eran las rosquillas, hojaldres, pasteles, buñuelos y almojábanas.

Aunque a primera vista parece que cada departamento tenía una función específica y claramente diferenciada, en realidad estaban muy relacionados, adquiriendo cometidos, en lo que a preparación de alimentos

\footnotetext{
${ }^{43}$ El día de Navidad el recibidor de La Ribera aprovisionó al Hostal con 2 cahíces y 1 robo "que fue despensado en la fiesta et sala que fizo la reyna al rey y al princep ey ha dos cabaylleros, escuderos..." [AGN, Comptos Registros, $\mathrm{n}^{0}$ 420, fol. 317r]. De cada robo preparaban 44 panes [AGN, Comptos Registros, $\mathrm{n}^{\circ} 420$, fol. 1r]. Las medidas de peso eran según J. Yanguas y Miranda, Diccionario de Antigüedades, t. 2, Pamplona, 1964, p. 49: 1 cahíz $=4$ robos; 1 robo $=4$ cuartales; 1 cuartal $=4$ almudes. Las equivalencias de estas medidas con el kilogramo son: 1 robo $=22 \mathrm{~kg}$.; 1 cuartal $=5,5 \mathrm{~kg}$.; 1 almud $=1,375 \mathrm{~kg}$. [Gran Atlas de Navarra, t. 2, Pamplona, 1986, p. 268].

${ }^{44} \mathrm{~F}$. SERRANO LARRÁYOZ, La alimentación de la realeza navarra, p. 314. Algunos años más tarde, en el Hostal del príncipe Carlos, el peso era similar [M. 'J. IBIRICU, El Hostal, p. 603].

${ }^{45}$ M. a J. IBIRICU, El Hostal, p. 603.

${ }^{46}$ En mi trabajo La alimentación de la realeza navarra, p. 314, se anota, por error, que 2'5 cuartales equivalían a $12,25 \mathrm{~kg}$.

${ }^{47} \mathrm{AGN}$, Comptos Registros, $\mathrm{n}^{0} 420$, fol. $80 \mathrm{v}$ y $216 \mathrm{r}$. El 17 de marzo registraron, en la Panadería, la compra de 3 libras y 4 onzas de azúcar "pora las obleas" [ÄGN, Comptos Registros, $\mathrm{n}^{\circ} 420$, fol. 65r].
} 
se refiere, que a priori se puede creer que no le correspondían. Esta relación se da principalmente entre la Panadería y la $\operatorname{Cocina}^{48}$, y en menor medida entre esta última sección, la Botellería y la Frutería.

Otras de las responsabilidades que tienen los miembros de la Panadería, son el cuidado y reparación de sus pertenencias ${ }^{49} \mathrm{y}$, posiblemente, la limpieza de todos sus enseres. En ocasiones también anotan gastos relacionados en la confección de lencería de mesa ${ }^{50}$.

Generalmente, el personal retribuido de este departamento suele oscilar entre los nueve y los once individuos. Los salarios más elevados - 132 d./día - corresponderían a los escuderos de esta sección. No todos son fijos y durante el año fueron variando (Sancho de Alzate ${ }^{51}$, Leonet, Ogerot, Zabaleta, Martín ${ }^{52}$, Dantoni, etc.). Algo menos - 72 d.- cobran Miguel de Alfajarín, panadero ${ }^{53}$, y Pedro Sanz ${ }^{54}$. La remuneración más baja es la de Juan, el hornero ${ }^{55}: 42$ d. También hay 3 mujeres: Teresa, la panadera, María (¿pastelera?) y Teresa, la lavandera ${ }^{56}$, que reciben $66 \mathrm{~d}$.

\footnotetext{
${ }^{48}$ Podemos ver como en la Cocina se encargaban de adquirir queso de vaca, manteca [AGN, Comptos Registros, $\mathrm{n}^{\circ} 420$, fol. 6r], y miel [AGN, Comptos Registros, $\mathrm{n}^{\circ} 420$, fol. 19v] para las almojábanas. Igualmente, los pasteles, que podían ser de carne; pescado o frutas, y cuyos ingredientes básicos los compran en la Cocina, se solían preparar en la Panadería [AGN, Comptos Registros, $\mathrm{n}^{\circ}$ 420, fol. 317r]. En alguna ocasión este departamento -Panaderíaadquiere queso fresco [AGN, Comptos Registros, $\mathrm{n}^{\circ} 420$, fol. 138r], posiblemente para los buñuelos o tartas, lechugas y miel [AGN, Comptos Registros, $\mathrm{n}^{\circ} 420$, fol. 91r]. El último día de cada mes anotan la compra de sal molida [AGN, Comptos Registros, $\mathrm{n}^{\circ} 420$, fol. 25v].

${ }^{49} \mathrm{El} 31$ de mayo se pagaron $1.800 \mathrm{~d}$. por « 1 a caxa pora la Panatería como do su goarnimient" [AGN, Comptos Registros, $\mathrm{n}^{\circ} 420$, fol. 129r], y el 28 de febrero, $390 \mathrm{~d}$. "por paper et faycones d'este libro del oficio de la Panatería" [AGN, Comptos Registros, $\mathrm{n}^{\circ} 420$, fol. 50r].

${ }^{50}$ El 17 de marzo, el recibidor de la merindad de Estella recibió 900 d. «por 30 codos de lienço delgado de que fueron fechas $24^{\circ}$ seruidelletas de boca et de manos del plat» [AGN, Comptos Registros, $\mathrm{n}^{\circ} 420$, fol. 65r].

${ }^{51}$ Igualmente nombrado como Ancho o Dancho (año 1432) [CAGN, t. 40, nº 1241/AGN, Comptos Documentos, caj. 133, $\mathrm{n}^{\circ} 2$, XXXIV]. Durante el año 1433 también es mencionado como doncel [ver nota $\mathrm{n}^{\circ}{ }^{17}$ ]

${ }^{52}$ Posiblemente sea Martín Fernández de Ilurdoz que, en el año 1436, se especifica que servía como escudero de Panadería [CAGN, t. 42, n ${ }^{\circ}$ 560/AGN, Comptos Documentos, caj. $\left.139, \mathrm{n}^{\circ} 2, \mathrm{XII}\right]$.

${ }^{53} \mathrm{AGN}$, Comptos Registros, $\mathrm{n}^{0} 416$, fol. 41v. Parece que Miguel también realizaba las funciones de clérigo de Panadería [ver nota $\mathrm{n}^{\circ} 33$ ].

${ }^{54}$ Diariamente adquiría harina y leña para hacer obleas. Posiblemente no tenga nada que ver con el cambradineros de la reina -Pedro Sanz de Oroz- [ver nota $n^{\circ}$ 27].

${ }^{55}$ Durante todo el año, el último día de cada mes, se le anotaba, en el servicio de Cocina, el gasto que había realizado en la compra de salvado para las gallinas.

${ }^{56} \mathrm{AGN}$, Comptos Registros, n 420, fol. 106r.
} 


\subsubsection{La Botellería}

El cometido de esta sección era la compra del vino que se iba a consumir en la Casa de la reina. Al igual que en todos los demás departamentos, tales adquisiciones se realizaban cuando las reservas se habían acabado o estaban bajo mínimos.

Las variedades más habituales que aparecen en la mesa real son los tintos, denominados como bermejo, colorado y pardillo $^{57}$, y los blancos. En menor medida se mencionan vinos dulces como el moscatel o la malvasía $^{58}$ (ambos blancos) y el vino cocido o cocho. Durante los dos meses que la reina estuvo en Zaragoza, y, posteriormente, cuando se afincó en Tudela, también compraron vino griego o vin grec $^{59}$. Estas compras se hacían en carapitos, cuartones y pintas ${ }^{60}$; las cantidades, como ya hemos dicho, variaban en virtud de las necesidades del momento. Además de adquirir vino, los miembros de la Botellería se encargan de comprar la vajilla $^{61}$, del mantenimiento de sus enseres ${ }^{62}$, del alquiler de monturas para el transporte del vino adquirido ${ }^{63}$ y de la distribución de los caldos, tanto

\footnotetext{
${ }^{57}$ Este adjetivo puede calificar a oscuro [Diccionario de Autoridades, voz pardo].

${ }^{58}$ Bajo este nombre se incluye una cantidad considerable de viñedos que no presentan un denominador común. Por este motivo se prefiere hablar de malvasías, de las que existen variedades con uvas blancas, negras, de sabor aromático o simple, dulce o seco. Sin embargo, el que se ofrece en la mesa de la reina era "vino blanco de maluesía" [AGN, Comptos Registros, $n^{\circ} 420$, fol. 152r].

${ }^{59}$ Este vino se elaboraba con uva especial de origen griego, pero que a finales del siglo XIV ya se plantaba en el ámbito mediterráneo [J.V. GARCía MARSILla, La jerarquía de la mesa. Los sistemas alimentarios en la Valencia bajomedieval, Valencia, 1993, p. 201]. Además surgió la costumbre de denominar indistintamente vinos griegos a todos los importados, no sólo de Grecia sino también de Creta y de las islas del mar Egeo. Se trataba sobre todo de moscateles con un alto contenido alcohólico que, sin tendencia a la acidez, se revelaron óptimos para el transporte.

${ }^{60}$ Las equivalencias son: 1 carapito $=11,77$ litros; 1 cuartón $=2,9$ litros; y la pinta $=0,7$ litros [Gran Atlas de Navarra, t. 2, Pamplona, 1986, p. 268].

${ }^{61}$ El 9 de abril (Jueves Santo) adquieren a Sevilla, moro de Tudela, «32 picheres de tiera, pieça $2 \mathrm{~s}$., valen $64 \mathrm{~s}$. delibrados a los pobres, a él por 36 gobeletes de tiera, pieca $3 \mathrm{~d}$., valen $9 \mathrm{~s}$., pora los pobres, a él por 8 agoamaniles, pieça $12 \mathrm{~d}$., valen $8 \mathrm{~s}$., a él por dos pieças grandes vidryadas, pieça 7 s., valen 14 s." [AGN, Comptos Registros, no 420 , fol. 86v].

${ }^{62} \mathrm{El} 15$ de septiembre se anotan los gastos de arreglar un odre [AGN, Comptos Registros, $\mathrm{n}^{\circ} 420$, fol. $\left.86 \mathrm{v}\right]$.

${ }^{63} \mathrm{El} 26$ de marzo, el recibidor de La Ribera recibe $180 \mathrm{~d}$. «por el loguero de una azémilla que trayó vino cocho de Tudela a Olit» AGN, Comptos Registros, $\mathrm{n}^{\circ} 420$, fol. 73v].
} 
a los beneficiarios del Hostal como a la Cocina para la elaboración de diversos preparados ${ }^{64}$.

Durante 1433 podemos establecer 3 centros de importancia donde estuvo instalada la Corte: Olite y Tudela, en Navarra, y Zaragoza, en Aragón. Mientras el Hostal estuvo fijo en un lugar, las compras de vino, por lo general, se circunscribían al área territorial. De todas formas, la facilidad para transportar este artículo conllevaba que en ocasiones se trajera de lugares algo más alejados. Cuando la reina residió en Olite los caldos también se obtuvieron de Larraga, Puente la Reina y Lerín (tinto), Tudela (cocho), Estella (moscatel), Caparroso y Marcilla (blanco). En mayo, el Hostal se trasladó a Tudela. Durante el trayecto las adquisiciones se realizaron en los lugares por donde pasaron: Caparroso y Valtierra. Una vez que la comitiva se instaló en Tudela la forma de suministro fue similar a la de Olite. Ocasionalmente se compró vino de Estella (malvasía) y de Borja (blanco).

A mediados de julio y hasta la primera semana de septiembre aproximadamente, el séquito real abandonó el reino y se trasladó a Zaragoza. Sin embargo, el abastecimiento del Hostal continuó realizándose según las pautas ya comentadas. Durante el trayecto de ida y de regreso adquirieron, en los lugares por donde atravesaron (Pedrola, Alagón, Casetas y Luceni), las cantidades que necesitaban. Otros puntos de suministro, aparte de Zaragoza (tinto, blanco y vino griego), fueron Borja (tinto) y Cariñena (tinto y blanco).

Cuando el séquito regresó a Tudela, si excluimos las aportaciones del propio lugar y de su área de influencia (tinto y blanco), las poblaciones expendedoras de caldos volvieron a ser Caparroso (tinto), Estella (tinto), y de forma extraordinaria Olite (tinto). La proximidad de Tudela con el reino de Aragón influyó, en cierta manera, para que se importaran vinos de Tarazona (tinto) y Zaragoza (vino griego y malvasía).

Los tintos y blancos fueron los que en más cantidad se bebieron. El precio de los primeros suele oscilar dependiendo del mes y/o del lugar en donde son adquiridos. De enero a abril, posiblemente en Olite o en su zona de influencia, el carapito de tinto oscilaba entre los 60 y los $96 \mathrm{~d} .{ }^{65}$ En el

\footnotetext{
${ }^{64} \mathrm{El} 3$ de mayo, cuando se hace el recuento del gasto en vino de la semana se anota: «et por la cozina por esta semana postremerament pasada 2 quoartones et por la panpanada por esta semana postremerament pasada 2 quoartones" [AGN, Comptos Registros, $\mathrm{n}^{\circ} 420$, fol. 104r].

${ }^{65} \mathrm{AGN}$, Comptos Registros, $\mathrm{n}^{\mathrm{0}} 420$, fol. $2 \mathrm{r}, 5 \mathrm{r}$ y $50 \mathrm{r}$.
} 
mismo mes en Larraga, durante marzo en Lerín, y en abril y mayo en Puente la Reina, la misma cantidad, por regla general, no sobrepasaba los $60 \mathrm{~d} .{ }^{66}$. En mayo, en Caparroso y Valtierra, el precio alcanzó los $96 \mathrm{~d} .^{67}$. En Tudela, durante junio y julio, éste fluctuó entre los 60 y los 72 d., mientras que por el mes de septiembre y octubre llegó hasta los $108 \mathrm{~d} .^{68}$, estabilizándose en los dos últimos meses del año en unos $84 \mathrm{~d} .^{69}$. De forma excepcional, en octubre, se transportó vino de Olite y Caparroso. Su coste era extremadamente elevado $-120 \mathrm{~d} . /$ carapito $^{70}-$, por lo que es posible que en el precio estuviera incluido el transporte. El vino blanco era algo más caro. De enero a junio, ambos inclusive, valía entre unos 108 y $128 \mathrm{~d}$. el carapito (periferia de Olite y Tudela, Caparroso, Marcilla y Valtierra) ${ }^{71}$. En julio se adquirió vino de Borja que, a moneda navarra, oscilaba entre los 144 y $180 \mathrm{~d}^{72}$. En octubre, noviembre y diciembre el precio de este caldo, en Navarra, se redujo sensiblemente, hasta los $96 \mathrm{~d}^{73}$.

En menor medida aparecen mencionados los caldos dulces y el vino cocido. Se consumían menos y estaban destinados a la familia real y su ámbito. No es de extrañar, por tanto, que sus precios fueran más elevados. En el mes de abril, en Estella, el carapito de moscatel costaba $120 \mathrm{~d}$., y el de malvasía, en junio, $168 \mathrm{~d} .^{74}$. El vino griego se importa desde Zaragoza. Sabemos que su coste era extremadamente alto ${ }^{75}$. Por último, en febrero, el recibidor de La Ribera abasteció al Hostal de vino cocido. Su precio ascendía a $156 \mathrm{~d}$. el carapito.

\footnotetext{
${ }^{66} \mathrm{AGN}$, Comptos Registros, $\mathrm{n}^{0} 420$, fol. 28r, 32r, 34v, 52v, 57r , 61v, 65r y $81 \mathrm{r}$.

${ }^{67} \mathrm{AGN}$, Comptos Registros, $\mathrm{n}^{\circ} 420$, fol. 104v y $105 \mathrm{v}$.

${ }^{68} \mathrm{AGN}$, Comptos Registros, $\mathrm{n}^{\circ} 420$, fol. 143r y $233 \mathrm{v}$.

${ }^{69} \mathrm{AGN}$, Comptos Registros, $\mathrm{n}^{\circ} 420$, fol. 276r y $302 \mathrm{v}$.

${ }^{70} \mathrm{AGN}$, Comptos Registros, $\mathrm{n}^{\circ} 420$, fol. 250r y $256 \mathrm{v}$.

${ }^{71} \mathrm{AGN}$, Comptos Registros, $\mathrm{n}^{\circ} 420$, fol. 2r, 37v, 82r, 99v y $105 \mathrm{v}$.

${ }^{72} \mathrm{AGN}$, Comptos Registros, $\mathrm{n}^{\circ} 420$, fol. 162r y 171v. Los vinos procedentes de Aragón, tanto blancos como tintos, eran bastante más caros que en Navarra debido al cambio monetario entre un reino y otro. Durante este año, 1 dinero jaqués equivalía a 3,42 dineros carlines. El 5 de octubre se pagaron, en Tarazona, por 10,5 carapitos de vino colorado $31 \mathrm{~s}$. $6 \mathrm{~d}$. jaqueses "que a moneda de Nauarra valen 108 s." [AGN, Comptos Registros, $\mathrm{n}^{\circ} 420$, fol. 253r].

${ }^{73} \mathrm{AGN}$, Comptos Registros, $\mathrm{n}^{\circ} 420$, fol. 271r, 276r y 311r.

${ }^{74} \mathrm{AGN}$, Comptos Registros, $\mathrm{n}^{\circ} 420$, fol. $79 \mathrm{r}$ y $152 \mathrm{r}$.

${ }^{75} \mathrm{Se}$ desembolsa $5.007 \mathrm{~d}$. a Juan de Belorado «que a pagado en Caragoça por $1^{\text {a }}$ pipa et $1^{\text {a }}$ redoma de vino grec et malvesía en que hay 13 carapitos 1 quoartón el coal costa 11 florines d'oro et 3 sueldos jaqueses que valen 20 libras 17 s. 3 d." [AGN, Comptos Registros, n ${ }^{\circ} 420$, fol. 263r]
} 
Los precios de estos vinos en el reino vecino eran, en proporción, similares a los navarros. De todas formas, no debemos olvidar que la estancia en Aragón se redujo solamente a los meses de verano ${ }^{76}$.

Los valores que se han establecido pueden quedar en la mera descripción si no intentamos explicar el porqué de las diversas oscilaciones que se dan durante este año.

De todos es sabido que el ciclo agrario para la vendimia comienza en septiembre y llega a su fin por el mes de noviembre. Así pues, podemos deducir que los vinos más tempraneros estaban listos para el consumo en enero. En un principio sorprende la oscilación tan grande del precio entre los tintos de Olite, Caparroso y Valtierra (60-96 d./carapito) y los de Larraga, Lerín y Puente la Reina (60 d./carapito) durante los 5 primeros meses del año. Si descartamos que los precios de los primeros estuvieran inflados por el coste del transporte, ya que por lo general los más baratos son los que de más lejos se adquieren ${ }^{77}$, podemos pensar que es debido a cuestiones de calidad. Otro hecho es que en Larraga, Lerín y Puente la Reina se adquirieron cantidades muy elevadas ${ }^{78}$. ¿Pudo ser ésta la causa que motivara la reducción de los precios en estas poblaciones? ${ }^{79}$ Cuando más se pagó fue entre septiembre y octubre, ya que el vino viejo escaseaba y la oferta era menor. A final de año los precios volvieron a descender paulatinamente poco a poco hasta los niveles de enero. El vino blanco se mantuvo algo más estable a lo largo de todo el año. Es posible que debido a la demanda y a una producción mucho más limitada. Durante los meses de abril y mayo el que se compró en Caparroso y Marcilla valía lo mismo que

\footnotetext{
${ }^{76}$ Sobre estos precios podemos remitirnos a F. SERRANO LARRÁYOZ, La alimentación de la realeza navarra, pp. 315-318.

${ }^{77}$ No debemos olvidar que el vino de Caparroso y Valtierra fue adquirido, en mayo, en las propias localidades, cuando la reina se dirigía a Tudela.

${ }^{78}$ En Larraga compraron a María Salvador, García Gil y a Miguel de Galar unas cantidades que rondaban los 294 litros por persona. Algo parecido ocurrió en Lerín y Puente la Reina [AGN, Comptos Registros, $\mathrm{n}^{\circ} 420$, fol. 28r, 32r, 34v, 52v, 57r, 61v y 81r].

${ }^{79}$ Esta apreciación parece confirmarla el hecho de que el 1 de abril, en Puente la Reina, se pagó a 96 d. el carapito por la compra de 8 carapitos (94,16 litros) [AGN, Comptos Registros, $n^{\circ} 420$, fol. 79 r].
} 
el moscatel de Estella (120 d./carapito $)^{80}$. No debemos descartar que, al igual que lo hemos intuido para los tintos, debido a las relativamente importantes cantidades que fueron compradas en Estella -141,24 litros-, el coste del moscatel se abaratase.

La elección y posterior adquisición de vino en las poblaciones donde no residía la reina se realizaba por medio de enviados ${ }^{81}$. El transporte se hacía a través de mulas de carga ${ }^{82}$; y el coste corría a cargo de la administración del Hostal que una vez recibido el vino desembolsaba las cantidades adelantadas por el intermediario ${ }^{83}$.

La clasificación en diferentes grupos que en su momento hizo $\mathrm{M}^{\mathrm{a}}$ J. Ibiricu para los proveedores del Hostal de Carlos de Viana, se puede trasladar para este periodo en su totalidad:

a) Personas que se dedican en exclusiva a la venta de vino.

b) Individuos mencionados aisladamente de quienes se conoce un oficio diferente al de vender vino.

c) Personas que no tienen como oficio habitual la venta de vino ${ }^{84}$.

No siempre el vino que se consumía en la Corte provenía de compras. Suponemos, aunque la documentación no dice nada al respecto, que parte de éste se elaboraba con uva de las viñas regias. También, en más de una ocasión los vinos habían ingresado en las bodegas reales como presente o regalo de algunos súbditos ${ }^{85}$.

\footnotetext{
${ }^{80} \mathrm{AGN}$, Comptos Registros, $\mathrm{n}^{\circ} 420$, fol. 79r, 82r y 99v.

${ }^{81}$ En febrero, Juan de Agramont recibió 924 d. por buscar vino en Mendigorría, Puente la Reina y Lerín durante el mes de diciembre del año anterior [AGN, Comptos Registros, $n^{\circ} 420$, fol. $30 \mathrm{v}]$.

${ }^{82}$ De este modo, en el mes de marzo, el recibidor de La Ribera recibió 180 d. por el alquiler de una «azémilla que trayó vino cocho de Tudela a Olit" [AGN, Comptos Registros, nº 420, fol. 73v].

${ }^{83} \mathrm{El} 15$ de febrero, Juan Arreche cobró 48 d. «que a pagado por aparellar 2 odres et por el pasage del ponte de Caparroso» [AGN, Comptos Registros, $n^{\circ} 420$, fol. 39r].

${ }^{84} \mathrm{M}$. ${ }^{\mathrm{a} J}$. IBIRICU, El Hostal, p. 608.

${ }^{85}$ Sirva de ejemplo como, el 12 de marzo, bebieron " 2 quoartones et meyo de vino blanco de muscatel del present de Lope de Baquedano" [AGN, Comptos Registros, $\mathrm{n}^{\circ} 420$, fol. 61r]; y el 22 de septiembre, "1 quoartón et meyo de vino grec tomado de (sic.) protonotario" [AGN, Comptos Registros, $\mathrm{n}^{\circ} 420$, fol. 239v].
} 
Los gastos de mantenimiento en este departamento no fueron muy elevados. En ocasiones adquirían materiales para la Botellería ${ }^{86}$, y en otras se arreglaban los desperfectos que éstos sufrían ${ }^{87}$.

El número de servidores con remuneración diaria rondaba los seis. Juan de Luxa, escanciador, percibía 180 d. Juan de Agramont, también escanciador, Carlos de Agramont y Carlos de Ezpeleta 132 d., mientras que Pedro de Fourdinay, clérigo de la Botellería y Pascual de Peña, ayuda de la Botellería $^{88}, 72 \mathrm{~d}$.

\subsubsection{La Cocina}

La principal responsabilidad de la Cocina era la provisión diaria, la administración, la preparación y la conservación de los alimentos que iba a consumir la familia real. Era, por su complejidad, el departamento, de los relacionados con la elaboración de los alimentos, más grande de todo el Hostal.

En esta sección estaba incluida la Salsería. Funcionaba de forma autónoma aunque no constituía un departamento independiente. La Cocina estaba bajo el control de un maestre de guarniciones o gardemanger, que se encargaba de aprovisionar a esta última de los productos que habían sido comprados con anterioridad. Todos los gastos de la Salsería, a excepción de los del vino ${ }^{89}$, se englobaban en la Cocina.

Los artículos que se adquirieron fueron muy variados y abundantes. El aprovisionamiento diario se realizaba a través de compras. En otras ocasiones, pero en menor proporción, al igual que ocurre con el vino, también se abastecían por medio de regalos. El funcionamiento interno de las diferentes secciones del Hostal era bastante semejante. Los servidores se

\footnotetext{
${ }^{86}$ Se pagó 390 d. «por 1 libro pora l'oficio de la Boteyllería en el quoal ay 4 manos et meya de paper con su cobertura de pargamino" [AGN, Comptos Registros, $\mathrm{n}^{\circ} 420$, fol. 50r]. Para transportar el vino de un lugar a otro compraban «cuerdas d'esparto pora ligar los odres» [AGN, Comptos Registros, $\mathrm{n}^{\circ} 420$, fol. 37v].

${ }^{87}$ Así, el 29 de junio fueron entregados, a Lorenzo de Ayegui, 96 d. que había adelantado «por apareyllar 2 toneles» [AGN, Comptos Registros, $\mathrm{n}^{\circ} 420$, fol. 157v]. No fue infrecuente la pérdida de vino por causas imprevistas. Era bastante corriente que durante los transportes se perdieran ciertas cantidades [AGN, Comptos Registros, $\mathrm{n}^{\circ} 420$, fol. $45 \mathrm{r}$ ]. En palacio también ocurrían accidentes: "et meyo quoartón de vino blanco de maluesía que se deramó en el dreçador en la cambra de la reyna" [AGN, Comptos Registros, $n^{\circ} 420$, fol. 320r]

${ }^{88} \mathrm{AGN}$, Comptos Registros, $\mathrm{n}^{0} 420$, fol. $3 \mathrm{r}$.

${ }^{89}$ Este artículo lo recibían de la Botellería [AGN, Comptos Registros, $\mathrm{n}^{\circ} 420$, fol. 122v].
} 
encargaban de los arreglos ${ }^{90}$, la renovación de la vajilla ${ }^{91}$, y del aprovisionamiento de carbón ${ }^{92}$ y leña ${ }^{93}$.

Por lo que hemos podido comprobar, el funcionamiento de este servicio no difería en absoluto si lo comparamos con el del Hostal del príncipe Carlos de Viana, que M. ${ }^{\mathrm{a}} \mathrm{J}$. Ibiricu ha tratado en su estudio referente al año 1451. En la Cocina trabajaban una serie de servidores, que, a tenor de su remuneración diaria, podemos comprobar que desempeñaban funciones diferenciadas. Había un elevado número de proveedores que no recibían ningún tipo de gajes en metálico, es decir, que no pertenecían al personal fijo, pero que aparecen en numerosas oćasiones sirviendo a la Casa Real.

Los servidores fijos, que mayor remuneración percibían erani Martín Bel, clérigo del gardemanger, los cocineros Martın de Burgos y Juan, el joven, y Juan Lorenzo, el salsero: 72 d. diarios. Pejenaut, el carnicero, y Gonzalo, el pollero, cobran 48 d.; mientras que Dariet, el aguador, sólo recibe $42 \mathrm{~d}^{94}$. A final de cada mes, a Martín de Burgos y a Ogerot, el joven, - a este último desde mayo- se les paga $120 \mathrm{~d}$., a cada uno, excepto en el mes de julio, para zapatos, por los servicios realizados.

Entre los oficios que se encontraban adscritos a este departamento estaba el de aguador. Se encargaba de transportar el agua a la cocina.

\footnotetext{
${ }^{90} \mathrm{El} 4$ de abril se sacó punta al cuchillo del guardamanger [AGN, Comptos Registros, $\mathrm{n}^{\circ}$ 420, fol. 82r]. El 19 de junio, en Tudela, compraron clavos para reparar una cámara donde guardar las gallinas [AGN, Comptos Registros, $\mathrm{n}^{\circ} 420$, fol. 148r]. Los días anteriores a festividades importantes los gastos en reparación eran superiores. Así, el 24 de diciembre limpiaron y arreglaron los desperfectos de la cocina [AGN, Comptos Registros, $\mathrm{n}^{\circ} 420$, fol $316 \mathrm{v}]$.

${ }^{91}$ Podemos describir el material de cocina que se adquirió durante todo el año: el $17 \mathrm{de}$ febrero, unas "aganillas para trayer agoa" [AGN, Comptos Registros, $n^{\circ} 420$, fol. $41 \mathrm{r}$ ]; el 5 de marzo, 1 majador de boj [AGN, Comptos Registros, $n^{\circ} 420$, fol. 55r]; el 9 de abril (Jueves Santo), 1 pichel de tierra "para la cozina", 2 ollas grandes de tierra, 15 docenas de escudillas y 30 platos de tierra "para los pobres" [AGN, Comptos Registros, $\mathrm{n}^{\circ} 420$, fol. $87 \mathrm{r}$ ]; el 8 de octubre, 1 orzo para las aceitunas [AGN, Comptos Registros, $\mathrm{n}^{0} 420$, fol. 256r]; el 1 de diciembre, 1 olla grande de tierra "para cozer la vianda de la reyna" [AGN, Comptos Registros, $\mathrm{n}^{\circ} 420$, fol. 302r].

${ }^{92} \mathrm{El}$ carbón se compraba por cestas [AGN, Comptos Registros, $\mathrm{n}^{\circ} 420$, fol. 4r], sacos [AGN, Comptos Registros, $n^{\circ} 420$, fol. 276r], o cargas [AGN, Comptos Registros, $n^{\circ} 420$, fol. $299 \mathrm{v}$ ]. Parece que la carga de carbón equivalía a 3 robos más o menos [E.J. HamiLtoN, Money, Prices, and Wages in Valencia, Aragon, and Navarre, 1351-1500, CambridgeMassachusetts, 1936, p. 153].

${ }^{93}$ Ver nota $\mathrm{n}^{0} 31$.

${ }^{94} \mathrm{AGN}$, Comptos Registros, $\mathrm{n}^{0} 420$, fol. $4 \mathrm{r}$.
} 
Diariamente se anota en la Escudería los gastos en cebada que consumían las cabalgaduras de las que se servía para realizar su trabajo.

Martín de Álava no recibía gajes desde la Cocina sino desde la Escudería. Su labor se centraba fundamentalmente en el aprovisionamiento de todo tipo de aves y otros productos (gallinas, pollos, capones, ánsares y huevos). Pór este motivo se encargaba del alquiler de las bestias que transportaban dichas aves y de su alimentación durante el trayecto ${ }^{95}$. Este cometido lo realizaba sólo en Navarra, puesto que cuando la reina marchó a Zaragoza, quien se responsabilizaba era Martín Bel. Este último llevaba el control de los gastos más perecederos de la Cocina como el arreglo de la vajilla, y la compra de carbón, miel, queso, sal, manteca, tocino, hortalizas, etc. para la despensa regia.

Juan de Villagarcía, portero real ${ }^{96}$, se ocupaba del abastecimiento diario de hortalizas durante los 4 primeros meses del año. No cobraba gajes en la Escudería, por lo que no se le puede considerar como servidor fijo. Además su función se realiza solamente cuando la reina está en Olite. En Tudela, antes de partir a Zaragoza, y en Aragón el encargado era, como en el caso anterior, el clérigo del gardemanger. Parece ser que, con el fin de simplificar el funcionamiento de este departamento durante la estancia fuera del reino, acaparó todas las funciones relacionadas con el aprovisionamiento de la Cocina. En los 3 últimos meses del año, en Tudela, el responsable es un tal Perico. Este último tampoco cobraba ningún tipo de salario ni en Cocina ni en Escudería.

La responsabilidad última de los diversos pagos, como ya se ha dicho antes, correspondía al cambradineros. Podemos comprobar como las expensas eran anotadas a los servidores de Cocina encargados de estos menesteres $^{97} \mathrm{o}$ a los propios proveedores.

\footnotetext{
${ }^{95}$ AGN, Comptos Registros, $\mathrm{n}^{\circ} 420$, fol. $35 \mathrm{r}, 106 \mathrm{r}$ y $255 \mathrm{r}$.

${ }^{96}$ En 1432 ocupaba el cargo de portero real [CAGN, t. 40, $n^{\circ}$ 1076/AGN, Comptos Documentos, caj. $133, \mathrm{n}^{\circ} 7, \mathrm{XIX]}$.

${ }^{97}$ Parece improbable que la mayoría de los gastos corrieran a cargo de los servidores del Hostal. Posiblemente éstos ya habían recibido del cambradineros las cantidades necesarias para las compras. Sin embargo, algunas veces se suele anotar que el sirviente «a pagado" por ciertos productos [AGN, Comptos Registros, $\mathrm{n}^{\circ} 420$, fol. 9r, 28r, 87r, 148r y 279v]. En estos casos sí que es posible que el dinero fuera adelantado por el servidor.
} 


\section{A. Productos de origen animal}

a) Las carnes rojas

La carne, entendida desde un punto de vista amplio, fue símbolo del status social, y alimento por excelencia de la realeza; que por su elevado precio no era accesible diariamente más que a unos pocos. Tradicionalmente, desde la Alta Edad Media, según la tradición germánica, venía considerándose como signo de vitalidad, de fuerza y de poder ${ }^{98}$.

El carnero fue el cuadrúpedo que más se consumió. Además era una de las carnes más caras del mercado. La adquisición se realizaba por piezas enteras, medias piezas o cuartos, y el precio oscilaba entre los $384 \mathrm{~d}$. de enero y febrero y los $336 \mathrm{~d}$. del resto del año ${ }^{99}$. En otras ocasiones, las menos, se pagaba a peso, entre 28 y $30 \mathrm{~d}$. la libra ${ }^{100}$. Durante la estancia en Aragón siempre se especificaba lo que pesaba. El coste de la libra carnicera aragonesa era de $8 \mathrm{~d}$. jaqueses ${ }^{101}$. La importancia de este cuadrúpedo está evidenciada por el uso de un léxico específico relativo a las partes en que se divide el animal para su consumo (espaldas, riñones ${ }^{102}$, patas $^{103}$, piernas ${ }^{104}$ y turmas o criadillas ${ }^{105}$ ).

\footnotetext{
${ }^{98} \mathrm{M}$. MONTANARI, El hambre y la abundancia, pp. 23-25.

${ }^{99} \mathrm{AGN}$, Comptos Registros, $\mathrm{n}^{\mathrm{0}} 420$, fol. 2v, 3r, 30v, 31v, 104r, 133r, 160 y 253v Debemos tener en cuenta que el ciclo reproductivo del ganado y de los animales de corral comienza en primavera, por lo que la escasez de éstos en los meses del invierno produciría el aumento de los costes. De todas formas, tampoco debemos olvidar que las características propias de cada animal (peso) influiría en el precio de venta.

${ }^{100} \mathrm{AGN}$, Comptos Registros, no 420, fol. 250r y 276r. 1 libra de carne $=13$ onzas (1 onza $=0,031 \mathrm{~kg}$.); 1 libra de pescado $=18$ onzas; 1 libra normal $=0,372 \mathrm{~kg}$. (las equivalencias al peso actual fueron asignadas en 1852) [Gran Atlas de Navarra, t. 2, Pamplona, 1986, p. 269].

${ }^{101} \mathrm{~F}$. SERRANO LARRÁYOZ, La alimentación de la realeza navarra, p. 319.

${ }^{102}$ El 16 de junio, en Tudela, se pagaron $138 \mathrm{~d}$. por " 2 espaldas de carnero et $1^{\text {a }}$ reynonada" [AGN, Comptos Registros, $\mathrm{n}^{\circ} 420$, fol. 145v].

${ }^{103}$ Se pagaban por unidades o por libras. El precio era similar al resto del carnero [AGN, Comptos Registros, $\mathrm{n}^{\circ} 420$, fol. $252 \mathrm{r}$ y $252 \mathrm{v}, 279 \mathrm{v}$ ].

${ }^{104}$ AGN, Comptos Registros, $n^{\circ} 420$, fol. 150r.

${ }^{105}$ El par valía 24 d. [AGN, Comptos Registros, $\mathrm{n}^{\circ} 420$, fol. 129v].
} 
El cabrito también aparece con frecuencia en la mesa, aunque en un número de días algo inferior al carnero. Se compraba por piezas y, durante el año, el precio osciló entre los 84 y los $168 \mathrm{~d}^{106}$. En Zaragoza cada unidad valía $120 \mathrm{~d}$. jaqueses ${ }^{107}$.

Menor presencia en la dieta tuvieron las carnes de origen bovino. El valor de la carne de vaca no varió mucho; entre 20 y 24 d. la libra ${ }^{108}$. En ocasiones se detalla la compra de cañada (tuétano de vaca) ${ }^{109}$. Algo más caro estaba el becerro. Se compraba por cuartos, aunque alguna vez suelen anotar su peso en libras (30 d./libra) ${ }^{110}$. En Aragón la libra de vaca y de becerro costaban 4 y 10 d. jaqueses respectivamente ${ }^{111}$. La relativa estabilidad de los precios de estos productos y su menor presencia en la dieta podemos atribuirla a una menor demanda, motivada por la utilización de estos animales como bestias de labor más que destinados al consumo humano ${ }^{112}$.

La importancia que el cerdo tuvo en la alimentación de la sociedad altomedieval $^{113}$ quedó reducida, a mediados del siglo $\mathrm{XV}$, en lo que se refiere a las clases pudientes, por otras especies como el carnero y el cabrito. No quiere decir esto que se dejara de consumir, pero su función en la dieta no fue ni mucho menos tan preponderante como en siglos anteriores. Se aprovechaba tanto el magro como el tocino ${ }^{114}$. Este último valía entre

${ }^{106} \mathrm{AGN}$, Comptos Registros, $\mathrm{n}^{\circ} 420$, fol. 1r, 28r, 31v, 104r y 316r.

${ }^{107} \mathrm{~F}$. SERRANO LARRÁyOZ, La alimentación de la realeza navarra, p. 319.

${ }^{108} \mathrm{AGN}$, Comptos Registros, no 420, fol. 1r, 28r y 157r.

${ }^{109} \mathrm{AGN}$, Comptos Registros, $\mathrm{n}^{\circ} 420$, fol. $2 \mathrm{v}$.

${ }^{110} \mathrm{AGN}$, Comptos Registros, no 420, fol. 157r, 171v y 277v.

${ }^{11} \mathrm{~F}$. SERRANO LARRÁYOZ, La alimentación de la realeza navarra, p. 319.

${ }^{112} \mathrm{P}$. AIROLDI, La tavola del conte: spese per il cibo alla Corte di Filippo i di Savoia (12691274), en R. Comba, A. M. Nada Patrone E I. Naso (dir.): La mensa del Principe. Cucina e regimi alimentari nelle corti sabaude (XIII-XV), Cuneo-Alba-Rocca de' Baldi, 1996, p. 16.

${ }^{113} \mathrm{P}$. AIROLDI, La tavola del conte, p. 15.

${ }^{114} \mathrm{El} 20$ de julio y el 10 de agosto se compraron perniles de tocino, de 5 y 5,5 libras aragonesas respectivamente ( $16 \mathrm{~d}$. jaqueses/libra) [AGN, Comptos Registros, $\mathrm{n}^{\circ} 420$, fol. $179 \mathrm{v}$ y 201v]. 
los 16 y los $18 \mathrm{~d}$. la libra ${ }^{115}$. También se elaboraban embutidos: meli$z^{116}{ }^{16}$ y longanizas ${ }^{117}$.

b) Las carnes blancas

De la importancia de las aves en el escalafón alimentario bajomedieval queda constancia con sólo comprobar su abundante presencia en la compra diaria. La facilidad de aprovisionamiento permitía su excelente comercialización. La gallina es la que más veces aparece mencionada en la mesa real. La necesidad de estar bien abastecidos implicaba que en la Cocina anotaran los gastos realizados en el alquiler de las bestias que las transportaban desde donde se adquirían hasta donde estaba afincado el Hostal. Los lugares de recogida fueron muy numerosos: Villamayor de Monjardín, Artajona, la Valdorba, Valtierra, Larraga, San Martín de Unx, Murillo el Fruto, Añorbe, Mélida, Falces, Miranda, Oteiza, Villatuerta, Ribaforada, Cirauqui, Mañeru, Ayegui, Cascante, Murchante, Cabanillas, Pitillas, valle de Unciti, Santesteban, Mendigorría, y por supuesto Olite y Tudela ${ }^{118}$. Es corriente el arrendamiento de recintos cerrados para depositarlas, como casas y cambras $^{119}$. Cuando el estado de estos lugares no era el óptimo se realizaban las reparaciones necesarias ${ }^{120}$. A últimos de mes se pagaba por el salvado que había servido para alimentar dichas aves ${ }^{121}$. El valor de cada gallina por regla general era de $30 \mathrm{~d}$., aunque dependiendo del tamaño su coste podía casi superar el triple del precio medio. Suele coincidir que las

\footnotetext{
${ }^{115} \mathrm{AGN}$, Comptos Registros, $\mathrm{n}^{\mathrm{0}} 420$, fol. $77 \mathrm{r}$ y $92 \mathrm{v}$. Este producto se utilizaba corrientemente como grasa y condimento [A. RIERA I MELIS, Jerarquía social y desigualdad alimentaria en el Mediterráneo Noroccidental en la Baja Edad Media. La cocina y la mesa de los estamentos privilegiados, “Acta Historica et Archaeologica Mediaevalia", $16-17$ (1995-1996), p. 188].

${ }^{116} \mathrm{El} 24$ de enero se pagaron $24 \mathrm{~d}$. "por estentinos para fazer melizas" [AGN, Comptos Registros, $\mathrm{n}^{\circ} 420$, fol. 20v]. Las mellizas eran cierto género de salchichones hechos con miel, de donde tomaron su nombre [Diccionario de Autoridades, voz melliza].

${ }^{117}$ La pieza costaba 18 d. [AGN, Comptos Registros, n ${ }^{\circ} 420$, fol. 45v].

${ }^{118} \mathrm{AGN}$, Comptos Registros, $\mathrm{n}^{\circ} 420$, fol. 81r, 30v, 35r, 137r, 255r, 166v, 251r, 115r, $144 \mathrm{r}, 262 \mathrm{v}, 265 \mathrm{r}, 237 \mathrm{v}, 244 \mathrm{v}, 151 \mathrm{v}, 29 \mathrm{v}$ y $316 \mathrm{v}$.

${ }^{119} \mathrm{El} 31$ de marzo, en Olite, se pagaron $240 \mathrm{~d}$. «por el loguero de $1^{\text {a }}$ casa en que estaban las gayllinas del primero día de ienero postremerament pasado" [AGN, Comptos Registros, $\mathrm{n}^{\circ}$ 420, fol. 78 r] .

${ }^{120} \mathrm{El} 19$ de junio, en Tudela, se gastaron $72 \mathrm{~d}$. "por apareiar una cambra et por clauos espueros por tener las gallinas" [AGN, Comptos Registros, $n^{\circ} 420$, fol. 148r].

${ }^{121}$ El precio era de $48 \mathrm{~d}$. el robo [AGN, Comptos Registros, $\mathrm{n}^{\circ} 420$, fol. 50v].
} 
piezas más caras se destinaban a los enfermos ${ }^{122}$, posiblemente para preparar caldo ${ }^{123}$.

Otros ejemplares que también adquirieron, aunque en menor cantidad y en menor número de días, fueron los pollos, pollas, capones y gallos. Al igual que pasaba con las gallinas, los pollos y pollas se compraban en diferentes localidades como Larraga y Miranda ${ }^{124}$. Cada ejemplar valía por término medio $15 \mathrm{~d} .{ }^{125}$ y $36 \mathrm{~d} .{ }^{126}$ respectivamente pero, como ya se ha podido comprobar con otros productos, los precios no siempre guardaban esta correspondencia ${ }^{127}$. Una variedad de pollo que también se compra es el capón. Su precio era bastante elevado. Durante los meses de invierno y primavera la pieza valía $120 \mathrm{~d} .{ }^{128}$, mientras que a principios del verano su coste, en ocasiones, se redujo a la mitad ${ }^{129}$.

En las poblaciones del reino de Aragón, excepto en Zaragoza, cada pollo no llegaba a valer los $12 \mathrm{~d}$. jaqueses. En Pedrola (14 de julio), por dos ejemplares grandes se pagaron 22 d. jaqueses. En Alagón (16 de julio), tres pares valían 60 d. jaqueses, y en Casetas (18 de julio), por una pieza, se pagaron $10 \mathrm{~d}$. jaqueses. En Zaragoza el precio por unidad podía superar el sueldo jaqués. El coste de las pollas variaba según su tamaño, aunque por término medio la pieza valía igual que la gallina: $24 \mathrm{~d}$. jaqueses. Los capones, al igual que en Navarra, también eran caros. En Zaragoza pagaron $57 \mathrm{~d}$. jaqueses por unidad ${ }^{130}$.

\footnotetext{
${ }^{122} \mathrm{El} 21$ de diciembre se pagaron $240 \mathrm{~d}$. "por tres galinas para la seynora reyna que estaua enoiada" [AGN, Comptos Registros, $\mathrm{n}^{\circ} 420$, fol. 314v]. Sin embargo, el 24 del mismo mes, 5 unidades, "para la infanta dona Blanca que estaua enferma", costaron $150 \mathrm{~d}$. [AGN, Comptos Registros, $\mathrm{n}^{\circ} 420$, fol. 316v].

${ }^{123} \mathrm{~F}$. SERRANO LARRÁYOZ, La alimentación de la realeza navarra, p. 319.

${ }^{124} \mathrm{AGN}$, Comptos Registros, $\mathrm{n}^{\circ} 420$, fol. 98v-99r.

${ }^{125} \mathrm{AGN}$, Comptos Registros, $\mathrm{n}^{\circ} 420$, fol. 133r y $157 \mathrm{r}$.

${ }^{126} \mathrm{AGN}$, Comptos Registros, $\mathrm{n}^{\circ} 420$, fol. 104r y 104v.

${ }^{127}$ El 2 de julio, en Tudela, 2 pollos valían 66 d. [AGN, Comptos Registros, $n^{\circ} 420$, fol. $161 \mathrm{r}$; y al inicio del viaje a Zaragoza uno cuesta $12 \mathrm{~d}$. [F. SERRANO LARRÁYOZ, La alimentación de la realeza navarra, p. 320]. De igual forma, el 26 de abril, en Olite, por 8 pollas se pagaron $336 \mathrm{~d}$., y el 12 de julio, en Tudela, por 2 unidades $144 \mathrm{~d}$. [AGN, Comptos Registros, $\mathrm{n}^{\circ} 420$, fol. 98v y 275r].

${ }^{128} \mathrm{AGN}$, Comptos Registros, $\mathrm{n}^{\circ} 420$, fol. 1r, 47r y 80r.

${ }^{129} \mathrm{AGN}$, Comptos Registros, $\mathrm{n}^{\circ} 420$, fol. 133v.

${ }^{130} \mathrm{~F}$. SERRANO LARRÁYOZ, La alimentación de la realeza navarra, p. 320.
} 
Los gallos, comprados con fines terapéuticos (caldo), costaban 72 y 78 d. cada uno ${ }^{131}$.

c) Las carnes de caza

La caza era para la aristocracia militar europea del Medievo una actividad fundamental. No sólo estaba destinada a conseguir una presa para luego ser cocinada y presentada en la mesa como ejemplo de triunfo, sino que era un útil ejercicio de entrenamiento para la guerra. A partir del último tercio del siglo XIV, por lo menos en lo que al reino de Navarra parece ser, la montería dejó de tener la función de preparación para el campo de batalla, predominando el aspecto lúdico que ésta conllevaba. La condición de mujer y la delicada salud de Blanca, a la que tantas veces se ha hecho y se hará referencia, pudo influir en gran medida en un cierto desinterés en la práctica de la caza mayor. La cetrería, de seguimiento más pausado, es posible que fuera más del gusto de la reina ${ }^{132}$.

La carne de caza mayor apenas aparece registrada en las cuentas del Hostal. No es de extrañar por ser un producto que, por lo general, no se suele comprar sino que se adquiría directamente o como presente ${ }^{133}$. En una ocasión se menciona el ciervo, cuyo precio, en Tudela, era de $16 \mathrm{~d}$. la libra ${ }^{134}$. El resto de las adquisiciones eran artículos de caza menor. Debemos destacar la presencia de perdices (30 d./unidad) ${ }^{135}$, tórtolas (18 d./unidad $)^{136}$, perdigones $(30 \mathrm{~d} . / \text { unidad })^{137}$, pájaros $(12 \mathrm{~d} . / \text { unidad })^{138}$

\footnotetext{
${ }^{131}$ AGN, Comptos Registros, $\mathrm{n}^{\circ} 420$, fol. 256v, 300v y 319v

${ }^{132} \mathrm{El} 4$ de abril se anota la cantidad de carne que consumieron los halcones [AGN, Comptos Registros, $\mathrm{n}^{\circ} 420$, fol. 82r].

${ }^{133} \mathrm{P}$. AIROLDI, La tavola del conte, p. 17; y M. TALAMONA, Consumi alimentari alla Corte di Filippo i di Savoia-Acaia (1295-1301), en R. Comba, A. M. Nada Patrone e I. Naso (dir.): La mensa del Principe. Cucina e regimi alimentari nelle corti sabaude (XIII-XV), Cuneo-AlbaRocca de' Baldi, 1996, p. 49.

${ }^{134} \mathrm{AGN}$, Comptos Registros, $\mathrm{n}^{\circ} 420$, fol. $154 \mathrm{r}$.

${ }^{135} \mathrm{El}$ ciclo reproductivo de estos animales provocó durante los primeros meses del año (enero y febrero) un aumento de los precios ( $48 \mathrm{~d}$./unidad) debido a su escasez. Una vez pasado el periodo de cría, su valor comenzó a descender (30 d./unidad por mayo), manteniéndose más o menos estable desde principios de septiembre hasta final de año [AGN, Comptos Registros $n^{\circ} 420$, fol. 24r, 29v, 129v, 250r, 276r y 302r].

${ }^{136} \mathrm{AGN}$, Comptos Registros, $\mathrm{n}^{\circ} 420$, fol. $228 \mathrm{v}$ y $252 \mathrm{r}$.

${ }^{137} \mathrm{AGN}$, Comptos Registros, $\mathrm{n}^{\circ} 420$, fol. $243 \mathrm{v}$.
} 
y conejos ( $24 \mathrm{~d} . /$ unidad $)^{139}$. En menor medida también se presentaron en la mesa ánsares $(120 \mathrm{~d} . / \text { unidad })^{140}$, palomas $(24 \mathrm{~d} . / \text { unidad })^{141}$, palominos $(12 \mathrm{~d} . / \text { unidad })^{142}$ y gazapos (18 d./unidad $)^{143}$.

Se debe tener en cuenta que los precios que aportamos no son inalterables y que a lo largo del año las oscilaciones que sufren suelen ser debidas principalmente a dos cuestiones. Por un lado al tamaño del animal y por otro al periodo estacional en el cual se realizaban las compras. No hace falta decir, que cuando finalizaba la época de cría de todos estos animales su costo en el mercado era inferior al resto del año.

\section{d) El pescado}

En la primera mitad del siglo XV la observancia del precepto eclesiástico de la abstinencia había influido en gran parte las actitudes alimentarias de la sociedad laica, creando un ciclo alimentario que podemos denominar «breve» (2 días por semana) y otro «de larga duración» (la Cuaresma), que condicionaba la rutina y la calidad de la alimentación. Las indisposiciones físicas de Blanca y de las infantas a lo largo de todo el año nos permiten observar que cuando estaban dolientes no cumplieron el mandato eclesiástico. Tales excepciones no afectaban al resto de los miembros del Hostal que no comieron carne durante la Cuaresma, todos los viernes y sábados, y las vigilias de las principales festividades anuales (Ascensión, San Juan Bautista, Santiago, La Asunción, Todos los Santos y Navidad). Durante el Adviento, sin embargo, no observamos ningún tipo de modificación en el régimen alimentario.

\footnotetext{
${ }^{138} \mathrm{AGN}$, Comptos Registros, $\mathrm{n}^{\circ} 420$, fol. $107 \mathrm{v}$. Generalmente no suelen detallar las piezas que compran. Pero hay que suponer que debían ser pequeños debido a su bajo precio y a las grandes cantidades que solían adquirir [A. CASTELLANO GUTIÉRREZ, La mesa real de Navarra. Algunos datos para su estudio, según las cuentas del Hostal de 1408, "Príncipe de Viana", 53 (1992), p. 593].

${ }^{139} \mathrm{AGN}$, Comptos Registros, no 420 , fol. 276r, 299v y 300v.

${ }^{140} \mathrm{AGN}$, Comptos Registros, $\mathrm{n}^{\circ} 420$, fol. 4r. En el caso de que fueran más grandes de lo normal el precio aumentaba. Así, "por 2 ánsares gordos" pagaron 288 d. [AGN, Comptos Registros, $\mathrm{n}^{\circ} 420$, fol. 37v].

${ }^{141} \mathrm{AGN}$, Comptos Registros, $\mathrm{n}^{\circ} 420$, fol. $244 \mathrm{v}$

${ }^{142}$ AGN, Comptos Registros, $n^{\circ} 420$, fol. 227r.

${ }^{143} \mathrm{AGN}$, Comptos Registros, $\mathrm{n}^{\circ} 420$, fol. $158 \mathrm{v}$ y $168 \mathrm{r}$.
} 
La presencia en la mesa de pescado fresco de mar era de por sí un rasgo distintivo que no todas las clases sociales se podían permitir. Su transporte desde el Mar Cantábrico y su posterior comercialización se realizaba gracias a la contratación de mulateros, o a través, como ocurría con el pescado de río, de los mercados locales.

La variedad más apreciada era la merluza. Ésta se adquiría fresca, remojada y seca. Se compraba por $\operatorname{costales}^{144}$ o piezas pero siempre anotando el peso correspondiente. No existían excesivas diferencias entre el precio de la fresca y la seca, entre los 20 y los 24 d. por libra ${ }^{145}$. Excepcionalmente, junto con la merluza, adquirieron golondrinas de mar (chicharra), a $20 \mathrm{~d}$. la libra ${ }^{146}$.

El consumo de congrio fue importante. Generalmente se compró seco; posiblemente por la facilidad con la que podía conservarse. No obstante en alguna ocasión se consigue fresco. El precio del seco oscilaba entre los 48 (diciembre) y los $72 \mathrm{~d}$. (enero y febrero) ${ }^{147}$, mientras que el fresco (abril) valía $30 \mathrm{~d}$. la libra ${ }^{148}$. Debemos tener presente que la posibilidad de adquirir esta variedad de pescado fresco en primavera era mucho más fácil que en invierno, por lo que su valor no es de extrañar que fuera menor en esa época del año.

Compraron sardinas y arenques, aunque por lo general no conocemos su precio debido a que fueron registrados los gastos pero no las cantidades. Sólo en una ocasión especifican que pagaron $2.610 \mathrm{~d}$. por un barril que contenía 586 unidades de estos últimos ${ }^{149}$. Se distinguen tres

\footnotetext{
${ }^{144} \mathrm{El} 4$ de junio, en Tudela, pagaron $3.741 \mathrm{~d}$. por un costal «en que ay $43^{\circ}$ pares, pesant 17 dozenas 1 libra, por dozena 18 s. 3 d." [AGN, Comptos Registros, $\mathrm{n}^{\circ} 420$, fol. 135r y $135 \mathrm{v}]$.

${ }^{145} \mathrm{AGN}$, Comptos Registros, $\mathrm{n}^{\circ} 420$, fol. 13r, 26r y 134v. El 4 de septiembre fueron compradas, en Zaragoza, 19 libras de merluza remojada, a 5 d. jaqueses la libra [AGN, Comptos Registros, $\mathrm{n}^{\circ} 420$, fol. 223r]. El remojo era el proceso a que se sometía el pescado para eliminar la sal que había servido de conservante [M. ${ }^{a}$ del R. RELAÑo MARTínEZ, El comercio de pescado en Córdoba durante la segunda mitad del siglo XV, en J. Hinojosa Montalvo y J. Pradells Nadal (dir.): "1490: en el umbral de la modernidad. El Mediterráneo europeo y las ciudades en el tránsito de los siglos XV-XVI", t. 2, Valencia, 1994, p. 570].

${ }^{146} \mathrm{AGN}$, Comptos Registros, $\mathrm{n}^{\circ} 420$, fol. 103r.

${ }^{147} \mathrm{AGN}$, Comptos Registros, $\mathrm{n}^{\circ} 420$, fol. $25 \mathrm{r}, 49 \mathrm{v}$ y $316 \mathrm{v}$.

${ }^{148}$ El 3 de abril se pagaron, a Juan de Nagusia, $1.800 \mathrm{~d}$. por 60 libras de «congrio fresco de mero" [AGN, Comptos Registros, $\mathrm{n}^{\circ} 420$, fol. 81r].

${ }^{149} \mathrm{AGN}$, Comptos Registros, $\mathrm{n}^{\circ} 420$, fol. $54 \mathrm{v}$.
} 
variedades de arenques: normales, blancos ${ }^{150}$ y viejos ${ }^{151}$. Esta última parece responder a su conservación (similar a lo que hoy en día son las sardinas viejas) más que a una variedad biológica. Aunque la documentación nada dice al respecto, la forma más común de conservar ambas especies sería al salazón. Las sardinas también se adquirieron frescas ${ }^{152}$.

El besugo y el delfín son mencionados en bastantes menos ocasiones. Se vendían por peso o piezas. La libra del primero valía entre $18 \mathrm{~d}$. y 22 $\mathrm{d}^{153}$, mientras que la del segundo entre 24 y los $26 \mathrm{~d}^{154}$.

De las variedades de agua dulce que se degustaron se citan las anguilas. En algunas ocasiones especifican el tamaño ${ }^{155}$. Se pagaba por piezas y por libras $(24 \mathrm{~d} \text {./libra })^{156}$. Otras especies que se mencionan son los barbos, colaques, barbilones, y tencas. Estas dos últimas costaban igual que las anguilas.

Cuando la reina reside en Tudela, aparte de adquirir truchas en Navarra, también las compran en Tarazona ${ }^{157}$. No sabemos si por el aprecio que pudieran profesar a este pescado o por meras coyunturas de mercado. Se pagaban por piezas y sus precios variaban según el tamaño del animal. Otra variedad era la lamprea; suponemos que no es la especie marina del mismo nombre porque quien suele encargarse del aprovisionamiento es el recibidor de La Ribera. Se transportaba desde Tudela a Olite, por lo que su pesca pudo realizarse en el río Ebro. Se pagaban por piezas, y su coste era elevado: $180 \mathrm{~d}$. por unidad ${ }^{158}$.

e) Otros productos de origen animal: huevos, leche y queso

La compra de huevos fue habitual durante todo el año. La prohibición eclesiástica de tomarlos durante la Cuaresma no se cumplió. Su precio

\footnotetext{
${ }^{150} \mathrm{AGN}$, Comptos Registros, $\mathrm{n}^{\circ} 420$, fol. 56r y $81 \mathrm{r}$.

${ }^{151} \mathrm{AGN}$, Comptos Registros, $\mathrm{n}^{\circ} 420$, fol. $88 \mathrm{r}$.

${ }^{152} \mathrm{AGN}$, Comptos Registros, $\mathrm{n}^{\circ} 420$, fol. 128r y $162 \mathrm{r}$.

${ }^{153} \mathrm{AGN}$, Comptos Registros, no 420 , fol. 1v y $26 \mathrm{r}$.

${ }^{154} \mathrm{AGN}$, Comptos Registros, $\mathrm{n}^{\circ} 420$, fol. $81 \mathrm{r}$ y $61 \mathrm{v}$.

${ }^{155} \mathrm{El} 23$ de junio compraron anguilas gruesas y aynguiletas [AGN, Comptos Registros, $\mathrm{n}^{\mathrm{o}}$ 420, fol. 152v].

${ }^{156} \mathrm{AGN}$, Comptos Registros, $\mathrm{n}^{\circ} 420$, fol. 136r.

${ }^{157} \mathrm{AGN}$, Comptos Registros, $\mathrm{n}^{\circ} 420$, fol. $252 \mathrm{r}$.

${ }^{158} \mathrm{AGN}$, Comptos Registros, $\mathrm{n}^{\circ} 420$, fol. $82 \mathrm{r}$ y $103 \mathrm{r}$.
} 
variaba según su tamaño, y cada unidad podía costar 1,2 ó $3 d^{159}$. Se utilizaban en la preparación de gran cantidad de platos.

El consumo de leche (¿de vaca?) durante el Medievo estaba limitado por la imposibilidad de conservar convenientemente un alimento que fácilmente podía deteriorarse. Posiblemente por esto, las cantidades que se desembolsaron fueron reducidas y fijas: $12 \mathrm{~d} .{ }^{160}$ Se ha podido observar cómo su compra se realiza principalmente en los meses de invierno y primavera, incluida la Cuaresma, reduciéndose de manera considerable durante el resto del $a_{n} o^{161}$. Su utilización, al igual que ocurría con los huevos, parece que estaba relacionada con las elaboraciones culinarias.

El queso, de fácil conservación y transporte desde los lugares de elaboración a los de venta, estuvo presente en la mesa durante todo el año excepto en el periodo cuaresmal. No suelen especificar con qué tipo de leche se había elaborado. Algunas veces, sin embargo, sí que se detalla que eran de vaca. Se compraba por piezas y su valor era prácticamente el mismo durante todo el año $(24 \mathrm{~d} \text {./unidad })^{162}$. Era un ingrediente imprescindible en numerosas recetas.

\section{B. Legumbres, verduras y hortalizas}

La función de estos alimentos, en la dieta de las clases privilegiadas, era la de acompañar a las carnes y a los pescados ${ }^{163}$. La mayoría de las veces se anota el término genérico de hortaliza. No se registran las cantidades y su gasto casi siempre ronda los $12 \mathrm{~d}$. diarios. Hay veces en que se compraba junto con otras verduras y en estos casos el desembolso llegaba

\footnotetext{
${ }^{159}$ AGN, Comptos Registros, ${ }^{\circ} 420$, fol. $98 v, 172 v$ y $296 r$.

${ }^{160} \mathrm{AGN}$, Comptos Registros, $\mathrm{n}^{\circ} 420$, fol. 28r, 133r y 155r. Esto no quiere decir que en ocasiones no gastaran algo más [AGN, Comptos Registros, $n^{\circ} 420$, fol. 17r].

${ }^{161} \mathrm{La}$ tradición médica italiana abogaba por el consumo de leche en invierno, cuya conservación podía prolongarse algo más que el resto del año, y en primavera, cuando la calidad era mejor debido a la frescura de los pastos de los cuales se alimentaba el ganado [P. AIROLDI, La tavola del conte, p. 20].

${ }^{162} \mathrm{AGN}$, Comptos Registros, $\mathrm{n}^{\circ} 420$, fol. 3r, 28r, 104r, y $144 \mathrm{r}$.

${ }^{163} \mathrm{No}$ así en la dieta de las clases sociales más desfavorecidas, en donde las legumbres y hortalizas suplieron en gran medida a la carne de calidad, cuyo consumo no se podían permitir de forma continuada [A. RIERA I MELIS, "Panem nostrum quotidianum da nobis hodie". Los sistemas alimenticios de los estamentos populares en el Mediterráneo Noroccidental en la Baja Edad Media, en J. I. de la Iglesia Duarte (coord.): "La vida cotidiana en la Edad Media" (VIII Semana de Estudios Medievales de Nájera), Logroño, 1998, p. 41].
} 
a ser el doble e incluso el triple ${ }^{164}$. La presencia de estos alimentos en el mercado estaba en función de los ciclos estacionales. Así pues, la denominación de hortaliza bien pudo englobar a las cebollas, ajos, etc., que en ningún momento se mencionan y que podían adquirirse durante todo el año.

Los puerros aparecen en marzo ${ }^{165}$. y los berros y berzas a principios de noviembre ${ }^{166}$. Durante los nueve primeros meses se mencionan las espinacas y acelgas. Las primeras, cuando se pagan por separado de la hortaliza, cuestan $3 \mathrm{~d}$. el manojo ${ }^{167}$. El espárrago se consume en los meses de primavera (abril) y verano. Parece que cuando compraban cantidades importantes se adquirían por cestas ${ }^{168}$. Producto de verano y otoño eran las calabazas ${ }^{169}$. En una ocasión compran rábano balisco ${ }^{170}$. No sabemos de cuantos se abastecieron pero su gasto fue elevado: $72 \mathrm{~d}$. En verano también se mencionan berenjenas y pepinos ${ }^{171}$. Las lechugas y verdolagas, pese a no adquirirse en esta sección sino en la Panadería, debemos agruparlas con el resto de vegetales. Se compraban junto con la miel $^{172}$.

La variedad de legumbres es algo más escasa. Las arvejas secas estuvieron presentes durante todo el año $^{173}$ y las verdes en mayo y julio $^{174}$. Por lo general, no suelen anotarse las cantidades de las que se

\footnotetext{
${ }^{164} \mathrm{AGN}$, Comptos Registros, $\mathrm{n}^{\circ} 420$, fol. 1r-v , 2v, 54v, 253v y $297 \mathrm{r}$.

${ }^{165} \mathrm{AGN}$, Comptos Registros, $\mathrm{n}^{\circ} 420$, fol. 54v.

${ }^{166} \mathrm{AGN}$, Comptos Registros, $\mathrm{n}^{\circ} 420$, fol. 277r y $297 \mathrm{r}$.

${ }^{167} \mathrm{El} 6$ se junio se pagaron $18 \mathrm{~d}$. «por 6 manoyllos d'espinagas" [AGN, Comptos Registros, $\mathrm{n}^{\circ} 420$, fol. 137r].

${ }^{168} \mathrm{AGN}$, Comptos Registros, $\mathrm{n}^{0} 420$, fol. 94r.

${ }^{169} \mathrm{AGN}$, Comptos Registros, $\mathrm{n}^{\circ} 420$, fol. 253v.

${ }^{170} \mathrm{AGN}$, Comptos Registros, $\mathrm{n}^{\circ} 420$, fol. 58v. El término rábano vagisco es similar al de rábano rusticano (nombre vulgar de la especie Cochlearia Armoracia) [Enciclopedia Universal Ilustrada Espasa-Calpe voz rábano].

${ }^{171} \mathrm{~F}$. SERRANO LARRÁYOZ, La alimentación de la realeza navarra, p. 324.

${ }^{172}$ AGN, Comptos Registros, no 420 , fol. 91r. [Ver también F. SERRANO LaRRÁyOz, La alimentación de la realeza navarra, p. 324].

${ }^{173}$ AGN, Comptos Registros, no 420 , fol. 25v; y F. SERrano LARrÁyOz, La alimentación de la realeza navarra, p. 324.

${ }^{174} \mathrm{AGN}$, Comptos Registros, $\mathrm{n}^{\circ} 420$, fol. $112 \mathrm{r}$ y $162 \mathrm{r}$. M. ${ }^{\mathrm{a}} \mathrm{J}$. IBIRICU afirma que las arvejas eran guisantes [M. ${ }^{a}$ J. IBIRICU, El Hostal, p. 615]. Sin embargo, esta acepción del término arveja parece más propia de países latinoamericanos como Argentina, Colombia y Chile. Parece que ésta es una variedad de algarroba [Diccionario de la Lengua Española. Real Academia Española, vigésima primera edición, voz algarroba y arveja].
} 
proveyeron. En octubre, sin embargo, se aclara que 1,5 libras valían 18 d. ${ }^{175}$. En menor medida compraron, a $12 \mathrm{~d}$. la libra, habas verdes (mayo) $)^{176}$. También adquirieron lentejas ${ }^{177}$ y garbanzos ${ }^{178}$.

\section{Las grasas}

El uso del aceite como ingrediente culinario fue muy importante. Pero no debemos engañarnos y pensar que hubo un total predominio de éste frente a otras grasas. Además, en Cuaresma, no sustituyó por completo, como cabría esperar, a las grasas de origen animal, que por lo menos en teoría no se podían utilizar ${ }^{179}$. En ningún momento especifican la variedad de este producto, pero parece que era de oliva. Resulta interesante comprobar como en muchas veces la compra de aceite coincidió con viernes o sábado, es decir, cuando la presencia de pescado era obligada en la dieta (frituras). Se compraba por libras y su precio variaba entre 22-24 d. (enero), 33 d. (febrero), 22 d. (marzo), 20 d. (mayo) y 14 d. (junio) ${ }^{180}$. En julio, en Zaragoza, la libra valía 4 d. jaqueses ${ }^{181}$. El gasto variaba en virtud de las diferentes necesidades. No siempre se utilizaba como ingrediente culinario sino que también se usó para iluminar las estancias, las luminarias de la capilla ${ }^{182}$ y para elaborar cera. En este último caso la sección encargada de adquirirlo era la Frutería ${ }^{183}$.

Las grasas de origen animal estaban representadas por el ya mencionado tocino, la manteca de cerdo y el saín. El uso de estas dos últimas predomina en los meses de invierno. En primavera y otoño también

${ }^{175}$ AGN, Comptos Registros, no 420 , fol. 253v.

${ }^{176}$ El 1 de mayo, en Olite, se pagaron por 28 libras de habas verdes 336 d. [AGN, Comptos Registros, $\mathrm{n}^{\circ} 420$, fol. 103r]. La cantidad fue importante, por lo que la presencia en la mesa de este artículo sería más abundante de lo que en un principio se puede pensar.

${ }^{177} \mathrm{~F}$. SERRANO LARRÁYOZ, La alimentación de la realeza navarra, p. 324.

${ }^{178} \mathrm{AGN}$, Comptos Registros, $\mathrm{n}^{\circ} 420$, fol. 316v

${ }^{179} \mathrm{El} 13$ de marzo, en plena Cuaresma, se compró manteca [AGN, Comptos Registros, $\mathrm{n}^{\mathrm{o}}$ 420, fol. 61v]; y, 2 días antes, saín [AGN, Comptos Registros, $\mathrm{n}^{\circ} 420$, fol. 57v].

${ }^{180} \mathrm{AGN}$, Comptos Registros, $\mathrm{n}^{\circ} 420$, fol. 1v, 14r, 33r, 53v, 104v y 155r

${ }^{181} \mathrm{~F}$. SERRANO LARRÁYOZ, La alimentación de la realeza navarra, p. 325.

${ }^{182} \mathrm{El} 7$ de febrero se compraron 2 libras "para la capilla et a la cambra" [AGN, Comptos Registros, $\mathrm{n}^{\circ} 420$, fol. 33r].

${ }^{183} \mathrm{AGN}$, Comptos Registros, $\mathrm{n}^{\circ} 420$, fol. 159r. 
las compraron, pero en menos ocasiones ${ }^{184}$. La manteca se vendía a $6 \mathrm{~d}$. la pelota. El precio del saín fresco era de $18 \mathrm{~d}$. la libra ${ }^{185}$, mientras que el denominado viejo valía $30 \mathrm{~d}^{186}$. También adquirieron saín regalado (derretido) para freír. Su valor era de $24 \mathrm{~d}$. la libra ${ }^{187}$.

Da qué pensar la diferencia de precio entre la manteca y el saín. Posiblemente el alto coste de este último se debiera a que era un producto elaborado que se ponía en algún tipo de adobo como medio de conservación ${ }^{188}$.

\section{Especias y condimentos}

Las especias, un producto caro que provenía de Oriente, eran la manifestación de las posibilidades económicas y de la posición social de quien las consumía. Tradicionalmente se ha considerado que su utilización estaba relacionada con la mala conservación de los alimentos, principalmente la carne, y que su función consistía en enmascarar su mal sabor. Sin embargo, debe tenerse en cuenta que la matanza de los animales que se iban a consumir se hacía prácticamente en el día, por lo que tal problema no existía realmente ${ }^{189}$. Así pues, su uso parece ser que obedece al gusto por lo raro y lo exótico, es decir como símbolo de ostentación de las clases privilegiadas ${ }^{190}$, sin olvidar que su función culinaria era la de crear un contraste de sabores gratos al paladar de los comensales $^{191}$. Las clases

\footnotetext{
${ }^{184} \mathrm{AGN}$, Comptos Registros, $\mathrm{n}^{\mathrm{0}} 420$, fol. 57v, 61v y 229v.

${ }^{185} \mathrm{AGN}$, Comptos Registros, $\mathrm{n}^{\circ} 420$, fol. $45 \mathrm{v}$.

${ }^{186} \mathrm{AGN}$, Comptos Registros, $\mathrm{n}^{\circ} 420$, fol. $3 \mathrm{v}$.

${ }^{187} \mathrm{AGN}$, Comptos Registros, $\mathrm{n}^{\circ} 420$, fol. $47 \mathrm{r}$.

${ }^{188}$ Por lo menos así parece que era a mediados del siglo XVI. Juan de Mezquia compró a un paisano de Ciordia, Juan de Guibela, "un sayn de puerco entero que pesaba honze libras y media nabarras", cuando "abrió el dicho sayn para derretir" y vio que tenía 6 libras de sal, mandó a un hijo a reclamar el caso [AGN, Tribunales Reales. Consejo Real, $n^{\circ} 1344$, fol. $12 v-$ $13 \mathrm{r}]$.

${ }^{189}$ Aunque de forma excepcional sí que suelen comprar alguna gallina afogada (ahogada) y algún carnero muerto [AGN, Comptos Registros, $\mathrm{n}^{\circ} 420$, fol. 265 y 2v].

${ }^{1 \%} \mathrm{M}$. MONTANARI, El hambre y la abundancia, pp. 67-68.

${ }^{191} \mathrm{M}$. Talamona, Consumi alimentari, p. 52.
} 
sociales menos favorecidas debían contentarse con las hierbas aromáticas, un producto local y de fácil accesibilidad ${ }^{192}$.

El azúcar se utilizó abundantemente ${ }^{193}$. Se compraba en la Cocina pero parte se entregaba a la Panadería para la elaboración de obleas, rosquillas, etc. Los cocineros reales lo utilizaban en la preparación de diversas salsas, cremas, caldos, frutas confitadas y dulces. Se pagaba por libras u onzas ${ }^{194}$. El precio era alto $(210 \mathrm{~d} \text {./libra })^{195}$. Otras especias eran la pimienta (144-168 d./libra) ${ }^{196}$, la canela y el jengibre (312-348 d./libra) ${ }^{197}$, los clavos de girofle (360-576 d./libra) ${ }^{198}$ y la nuez moscada (480 d./libra) ${ }^{199}$. La más cara de todas era el azafrán (2.304 d./libra $)^{2(1)}$.

Durante los meses invernales se produjo un alza considerable en los precios de algunos de estos productos. La libra de azafrán, en enero, llegó a valer $3.168 \mathrm{~d} .{ }^{201}$, y la de pimienta, en diciembre, $384 \mathrm{~d}{ }^{202}$. Es posible que debido a dificultades relacionadas con la producción y/o el abastecimiento.

El precio de la mostaza en grano se mantuvo más o menos estable durante todo el año: $36 \mathrm{~d}$. el almud ${ }^{203}$. En los meses estivales fue importante la compra de oruga y agraz, pero no sabemos las cantidades de las que se aprovisionaron. El gasto en oruga suele anotarse, en Navarra, a finales

\footnotetext{
${ }^{192}$ A.M. NADA Patrone, Il cibo del ricco ed il cibo del povero. Contributo alla storia qualitativa dell alimentazione. L'area pedemontana negli ultimi secoli del Medio Evo, Turín, 1981, pp. 159-160.

${ }^{193} \mathrm{~A}$ pesar de que el azúcar no sea una especia, y se considere un condimento, se incluye en este apartado por tener unas características comunes con las especias propiamente dichas, como son su elevado precio, su exotismo, su venta por los especieros y su utilización en numerosos platos.

${ }^{194} \mathrm{El} 10$ de julio se compró un pan de azúcar «pesante 4 libras 8 onzas» [AGN, Comptos Registros, $\mathrm{n}^{\circ} 420$, fol. 169v].

${ }^{195} \mathrm{AGN}$, Comptos Registros, $\mathrm{n}^{\circ} 420$, fol. $31 \mathrm{v}$ y $47 \mathrm{r}$.

${ }^{190} \mathrm{AGN}$, Comptos Registros, $\mathrm{n}^{\circ} 420$, fol. 103v, 135r y 294v.

${ }^{197} \mathrm{AGN}$, Comptos Registros, $\mathrm{n}^{\circ} 420$, fol. 169v y 103v.

${ }^{198} \mathrm{AGN}$, Comptos Registros, $\mathrm{n}^{\circ} 420$, fol. 135r y 169v.

${ }^{199} \mathrm{AGN}$, Comptos Registros, $\mathrm{n}^{\circ} 420$, fol. $29 \mathrm{v}$.

${ }^{2(0)} \mathrm{AGN}$, Comptos Registros, $\mathrm{n}^{\circ} 420$, fol. 41r, 103v, 135r y 169v.

${ }^{201} \mathrm{AGN}$, Comptos Registros, $\mathrm{n}^{\circ} 420$, fol. $24 \mathrm{v}$.

${ }^{212} \mathrm{AGN}$, Comptos Registros, $\mathrm{n}^{\circ} 420$, fol. 309v.

${ }^{203} \mathrm{AGN}$, Comptos Registros, $\mathrm{n}^{\circ} 420$, fol. 20v y $261 \mathrm{v}$.
} 
de mes $^{204}$, mientras que el agraz, sólo documentado en Aragón, a medida que se consume ${ }^{205}$. El vinagre puede que fuera un ingrediente tanto de la salsa de mostaza como de la de oruga, ya que, en ocasiones, se pagaba junto con estos productos ${ }^{206}$. De forma esporádica compraron pámpanos ${ }^{207} \mathrm{y}$ comino (48 d./libra) ${ }^{208}$.

El anís, la alcaravea y la alegría (ajonjolí) siempre se adquieren juntas, gastándose una media de 30 a $36 \mathrm{~d}$. cada vez. Nunca anotan las cantidades de las que se abastecieron. Su compra coincide siempre en periodos de abstinencia, por lo que su uso parece que estaba destinado a ciertas elaboraciones con pescado ${ }^{209}$.

El orégano y el perejil solamente se mencionan cuando la reina residía Zaragoza ${ }^{210}$. Otros condimentos eran la sal, la miel, el vinagre y los denominados sabores. La facilidad con la que se podía conservar la miel hace que esté presente en las preparaciones culinarias a lo largo de todo el año. Su precio era de unos 9 d. la libra ${ }^{211}$.

La sal y el vinagre fueron de uso diario. La primera se vendía por cuartales. El precio más bajo se pagó en abril (27 d./cuartal) y el más

${ }^{204} \mathrm{AGN}$, Comptos Registros, $\mathrm{n}^{\circ} 420$, fol. $158 \mathrm{v}$.

${ }^{205} \mathrm{~F}$. SERRANO LARRÁYOZ, La alimentación de la realeza navarra, p. 325. Las primeras compras de agraz se realizaron en agosto [AGN, Comptos Registros, $\mathrm{n}^{\circ} 420$, fol. 208v]. El agraz era un caldo que se utilizaba como condimento. Este se realizaba a base de uvas verdes (agraces) de las cuales toma su nombre. No parece en estos casos que se tratara de verjus; un condimento cuyas fases de elaboración desconocemos, y que también se componía de uvas sin madurar.

${ }^{206} \mathrm{AGN}$, Comptos Registros, $\mathrm{n}^{\circ} 420$, fol. $129 \mathrm{v}$ y $158 \mathrm{v}$. Sabemos que la salsa de mostaza, a mediados del siglo XV, también se preparaba con mosto de uva [F. SERRANO LARRÁYOZ, Banquetes de los príncipes de Viana a mediados del siglo XV. "Príncipe de Viana", 59 (1998), nota $\left.n^{\circ} 36\right]$

${ }^{207}$ Es el sarmiento verde, tierno y delgado de la vid. De aquí se saca un zumo llamado pampanada que puede suplir al agraz porque tiene un sabor parecido [AGN, Comptos Registros, $\mathrm{n}^{\circ} 420$, fol. $174 \mathrm{v}$ y $\left.178 \mathrm{v}\right]$.

${ }^{208}$ AGN, Comptos Registros, $\mathrm{n}^{\circ} 420$, fol. $87 \mathrm{r}$.

${ }^{209} \mathrm{AGN}$, Comptos Registros, $\mathrm{n}^{\circ} 420$, fol. 56r, 74v, $81 \mathrm{r}$ y $87 \mathrm{r}$. Sobre el uso culinario de la alcaravea ver L. ABU-SHAMS, Descripción de las especias más utilizadas en Alandalus y su uso actual en la cocina marroquí, en "Aragón en la Edad Media. Homenaje a la profeșora Carmen Orcástegui Gros", XIV-XV, vol. 1, 1999, p. 28.

${ }^{210} \mathrm{~F}$. SERRANO LARRÁYOZ, La alimentación de la realeza navarra, p. 325.

${ }^{211}$ AGN, Comptos Registros, $\mathrm{n}^{\circ} 420$, fol. 277r. También debemos tener presente que la miel no sólo se adquiría en la Cocina, sino que hay ocasiones en que su compra se realizaba desde la Panadería [ver nota $n^{\circ} 48$ ]. 
elevado en septiembre $(64 \mathrm{~d} . / \text { cuartal })^{212}$. El resto del año los precios variaron entre los 40 y $48 \mathrm{~d}^{213}$. El gasto en vinagre se anotaba a final de mes $^{214}$. Su precio, en julio, era de $48 \mathrm{~d}$. el carapito ${ }^{215}$.

En varias ocasiones adquieren sabores por $30 \mathrm{~d}$. Su función era la de potenciar el sabor de los alimentos que podían resultar algo insípidos ${ }^{216}$.

\section{E. Otros}

Con la excepción del trigo, del cual ya se ha comentado su utilidad al estudiar la Panadería, el único cereal que se compró para consumo humano fue el arroz. Se menciona durante todo el año, aunque las cantidades que se adquirieron no fueron muy elevadas. Sobre su función culinaria, podemos decir que aparte de servir como guarnición de algunos platos era un ingrediente importante en la elaboración de salsas. En el mes de enero su precio alcanzó las cotas más elevadas (30 d./libra) ${ }^{217}$. Durante el resto del año la libra oscilaba entre 20 y $24 \mathrm{~d}^{218}$, descendiendo hasta los 18 en noviembre y diciembre ${ }^{219}$.

La importancia de la almendra en la preparación de salsas es quizás superior a la del arroz. Durante febrero y mayo la libra valía $24 \mathrm{~d}^{220}$, y comenzó a encarecerse en junio ( $30 \mathrm{~d}$./libra $)^{221}$. En los meses restantes no superó los $48 \mathrm{~d}$. excepto en noviembre: julio (30-36 y $48 \mathrm{~d} . / \mathrm{libra})^{222}$, septiembre $(36 \text { d./libra })^{223}$, octubre $(36-48 \text { d. })^{224}$, noviembre $(48-72$

\footnotetext{
${ }^{212}$ AGN, Comptos Registros, n 420 , fol. $85 \mathrm{r}$ y $247 \mathrm{v}$.

${ }^{213}$ AGN, Comptos Registros, $n^{\circ} 420$, fol. 133r, 142v y $272 r$.

${ }^{214} \mathrm{AGN}$, Comptos Registros, $\mathrm{n}^{\circ} 420$, fol. 50v, 78r, 101r y 248r.

${ }^{215} \mathrm{AGN}$, Comptos Registros, $\mathrm{n}^{\circ} 420$, fol. 168v.

${ }^{216} \mathrm{El} 30$ de mayo se pagaron 30 d. "por sabores para las farinas" [AGN, Comptos Registros, $\mathrm{n}^{\circ} 420$, fol. 128r]; y el 24 de diciembre "por sabores para las papas" [AGN, Comptos Registros, $\mathrm{n}^{\circ} 420$, fol. 316v]. El término papas puede referirse a puches (gachas). Éstas se elaboraban con una harina que se hacía de espelta y de trigo, más gruesamente molida que la ordinaria (crimno) [Diccionario de Autoridades, voz papa, puche y crimno].

${ }^{217} \mathrm{AGN}$, Comptos Registros, $\mathrm{n}^{\circ} 420$, fol. $24 \mathrm{v}$.

${ }^{218}$ AGN, Comptos Registros, no 420, fol. 48v, 104r, 135r, 168r y $245 \mathrm{v}$.

${ }^{219} \mathrm{AGN}$, Comptos Registros, no 420, fol. 298v y 316v.

220"AGN, Comptos Registros, n" 420, fol. 40r y $104 \mathrm{r}$.

$22 \mathrm{AGN}$, Comptos Registros, n० 420, fol. 157v.

22:AGN, Comptos Registros, $\mathrm{n}^{\circ} 420$, fol. 163r y $168 \mathrm{r}$.

${ }^{223} \mathrm{AGN}$, Comptos Registros, $\mathrm{n}^{\circ} 420$, fol. 247v.
} 
d./libra) $)^{225}$ y diciembre $(36 \mathrm{~d} \text {./libra })^{226}$. En el tiempo que la reina estuvo en Zaragoza (julio, agosto y septiembre), la libra costaba $12 \mathrm{~d}$. jaqueses ${ }^{227}$.

Con una frecuencia nada despreciable se compró pasta (fídeos). Éste era un producto de lujo, y según los estudios que se han realizado hasta el momento no parece que tuviera la importancia que adquirió en otros territorios como Italia, Francia, y la Corona de Aragón. En Navarra valía entre 30 y $48 \mathrm{~d}$., y en Zaragoza $8 \mathrm{~d}$. jaqueses la libra ${ }^{228}$.

Excepcionalmente se registró la compra de dátiles; quizás debido a que se iban a utilizar como ingrediente de alguna salsa o para elaborar algún dulce. Su coste fue elevado: 288 d. la libra ${ }^{229}$.

\subsubsection{La Frutería}

Esta sección se encargaba del abastecimiento de fruta, cera y de candelas de sebo que utilizaban para la iluminación del Hostal. El aprovisionamiento de cera y fruta se realizaba en la medida en que las provisiones iban disminuyendo. La adquisición de estos dos productos en un único departamento bien pudiera deberse, como indica M. ${ }^{\mathrm{a} J}$. Ibiricu, a la complementariedad en las compras. Durante los meses invernales los gastos en cera fueron superiores a los realizados en verano. Sin embargo, las expensas en fruta eran mucho más elevadas durante los meses estivales que en invierno ${ }^{230}$.

Diariamente se registraba la cera que sobraba del día anterior y la que se entregaban a los miembros e invitados de la Casa Real. Las existencias se anotaban por peso (libras) mientras que las cantidades expendidas se apuntaba por medio de artículos elaborados (cirios, torchas, morteros... $)^{231}$. Cada fin de mes compran aceite, para lavar la cera, y leña.

\footnotetext{
${ }^{224}$ AGN, Comptos Registros, $\mathrm{n}^{\circ} 420$, fol. $251 \mathrm{r}$ y $252 \mathrm{r}$.

${ }^{225}$ AGN, Comptos Registros, $n^{\circ} 420$, fol. 276r y $298 \mathrm{v}$.

${ }_{226} \mathrm{AGN}$, Comptos Registros, n' 420 , fol. $317 \mathrm{v}$.

${ }^{227} \mathrm{~F}$. SERRANO LARRÁYOZ, La alimentación de la realeza navarra, p. 328.

${ }^{228}$ AGN, Comptos Registros, no 420, fol. 277r, 319v; y F. SERRANO LaRRÁyoz, La alimentación de la realeza navarra, p. 329.

${ }^{229} \mathrm{AGN}$, Comptos Registros, $\mathrm{n}^{\circ} 420$, fol. $43 \mathrm{r}$.

${ }^{231} \mathrm{M}$. a J. IBIRICU, El Hostal, p. 620.

${ }^{231}$ Este tipo de anotaciones se pueden comprobar diariamente [AGN, Comptos Registros, $n^{\circ}$ 420 , fol. $50 \mathrm{v}, 78 \mathrm{r}]$
} 
Todo esto era utilizado en el proceso de fabricación de las diversas categorías de velas que se realizaban en la Frutería ${ }^{232}$.

Como en los otros departamentos, éste se encargaba de la adquisición y en caso de ser necesario, de la reparación de los instrumentos de trabajo $^{233}$.

Desde un punto de vista dietético la fruta era considerada de manera bastante peyorativa. Los tratados médicos del Medievo y de siglos posteriores desaconsejaban su ingesta, aunque reconocían la atracción que éstas tenían en la mesa, y por tanto realizaban una serie de excepciones en el caso de las ciruelas, pasas, higos, etc. ${ }^{23.4}$ Un ejemplo de estas ideas se puede observar, durante la primera mitad del siglo XIV, en las Leyes Palatinas de Jaime III de Mallorca:

\begin{abstract}
Aunque el comer fruta no fuese muy recomendado por los médicos, es evidente que las mismas frutas son producidas naturalmente para provecho del hombre, y son muy adecuadas al buen gusto humano. Por esto, en las regiones en que se cosechan en cantidad suficiente, según una saludable costumbre, se sirven normalmente tanto en la comida como en la cena ${ }^{235}$.
\end{abstract}

El aprovisionamiento, mientras la Corte estuvo en Navarra, se realizó, por lo general, a través de personas, en su gran mayoría mujeres, que no pertenecían al servicio interno del Hostal ${ }^{236}$. En Olite (enero a junio), el papel fundamental corre a cargo de una tal Gracia. Sin embargo,

\footnotetext{
${ }^{232}$ AGN, Comptos Registros, no 420, fol. 159r y 176v.

${ }^{233}$ El 27 de marzo, en Olite, el recibidor de La Ribera pagó 240 d. "por 3 talegas de lienço para la fruyta que trayleron los moros, la quoal fue deliurado a la canbra" [AGN, Comptos Registros, $n^{\circ} 420$, fol. $74 \mathrm{v}$. El 31 de mayo Pedro Sanz pagó 1.800 d. «por 2 cofres por el oficio de la Fruytería" [AGN, Comptos Registros, n 420, fol. 129v]; y el 8 de julio, en Tudela, se pagaron $720 \mathrm{~d}$. a Mahoma Benent "por unas balanças para la fruyta" [AGN, Comptos Registros, $\mathrm{n}^{\circ} 420$, fol. $167 \mathrm{r}$ ]. También pueden mencionarse los $16 \mathrm{~d}$. jaqueses que, mientras estaba la reina en Zaragoza, se pagó un carretero "por su trabajo et por fazer trayer la çera del peso a la Fruytería" [AGN, Comptos Registros, no 420, fol. 204r]; o los 540 d. jaqueses por 60 libras de pabilo [AGN, Comptos Registros, n⿳ 420 , fol. 226r].

${ }^{234} \mathrm{~J}$. Cruz CRUz, Dietética medieval. Apéndice con la versión castellana del "Régimen de Salud" de Arnaldo de Vilanova, Huesca, 1997, pp. 235-255.

${ }^{235} \mathrm{M}$. Pascual Pont, La traducción de las leyes palatinas de Jaime III, en Jaime III rey de Mallorca. Leyes Palatinas, Palma de Mallorca, 1991, p. 112.

${ }^{236}$ No parece que fueran ellas las encargadas de llevar personalmente la fruta al Hostal. Posiblemente su labor fuera la de hacer de intermediarias entre los vendedores y la Frutería. El 8 de octubre, en la Panadería, se entregaron 3 panes al hombre "que trayo las peras" [AGN, Comptos Registros, $\mathrm{n}^{\circ} 420$, fol. 255v].
} 
durante los meses en que la reina permaneció en Zaragoza, el encargado de comprar todos los artículos fue el clérigo de la Frutería. En Tudela (junio, parte de julio y de septiembre hasta diciembre) tal responsabilidad recayó sobre una Juana, principalmente, y María, aunque también se registran otros proveedores como Teresa de Cascante, Estefanía, Pedro de Cabanillas, etc. Debemos destacar la presencia de abastecedores de origen musulmán: Sevilla y Mahoma Malmaduro.

Se ha podido observar que la fruta fresca, en gran parte, llegaba de la Ribera navarra y de Aragón ${ }^{237}$. Coincide con las zonas de mayor índice de población musulmana, en donde la importancia de la agricultura de regadío predominaba sobre la de secano.

Los servidores fijos que reciben remuneración diaria, por lo general suelen ser cuatro personas, aunque en ocasiones, por necesidades internas, suele recibir gajes algún compañero más. Mateo y Ogerot recibían los salarios más altos: 132 d. diarios. Pascual, clérigo de la Frutería, y Garchot recibían $72 \mathrm{~d}$.

\section{A. Frutos secos}

La posibilidad de conseguirlos durante todo el año era relativamente fácil debido a su buena conservación. Sin embargo, aunque se adquieren con cierta regularidad, su consumo se centra principalmente en los meses en los que era complicado abastecerse de fruta fresca.

El precio de las castañas, en diciembre, era de $96 \mathrm{~d}$. la docena ${ }^{238}$. No parece que las adquirieran en mucha cantidad puesto que los gastos que anotan no son importantes. También se mencionan las avellanas. Se pagaron por libras (18 d./libra), en mayo ${ }^{239}$, y por robos ( $240 \mathrm{~d} . /$ robo), en diciembre $^{2+1}$. Fuera de temporada compraron uvas $(18 \mathrm{~d} . / \text { libra })^{2+1}$, e higos.

\footnotetext{
${ }^{237}$ Parece confirmarse que, durante la Baja Edad Media, la zona productora y abastecedora de productos horto-frutícolas para el reino de Navarra fue la Ribera navarra y Aragón. Para el siglo XIV podemos ver L.R. VILLEGAS, Datos sobre la alimentación en la frontera navarrocastellano-aragonesa en el siglo XIV, en "Manger et boire au Moye Âge", t. 2, Niza, 1984 ,

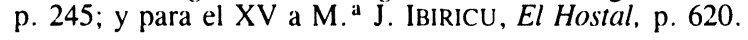

${ }^{238} \mathrm{AGN}$, Comptos Registros, $\mathrm{n}^{\circ} 420$, fol. 317r. La docena era una medida de peso. Sus medidas son las siguientes: 1 docena $=12$ libras; 1 libra $=4$ cuartos.

${ }^{239} \mathrm{AGN}$, Comptos Registros, no 420, fol. 103r.

${ }^{2+1} \mathrm{AGN}$, Comptos Registros, no 420, fol. 316v.
} 
Éstos últimos también se pagaban por libras (12 d./libra), en febrero ${ }^{242}$, y por docenas, (108 d./docena), en marzo ${ }^{243}$. Una compra que parece estar dirigida a abastecer la cocina eran las nueces ${ }^{244}$. Con este fin debieron de adquirir dátiles y piñones $(28 \mathrm{~d} \text {. jaqueses/libra })^{245}$. También se abastecen de bellotas, aunque no sabemos ni la cantidad ni su $\operatorname{precio}^{246}$. Su compra quizás se deba relacionar con la elaboración de harina para preparar algún plato (¿gachas?).

\section{B. Fruta fresca}

La estancia de la reina Blanca en Zaragoza, durante los meses estivales, motivó que en su gran mayoría éstos artículos fueran de origen aragonés. Durante este tiempo las variedades que se presentaron en la mesa fueron numerosas. Los higos, a tenor de las compras realizadas, eran los más apreciados. Se sabe que en alguna ocasión se trajeron de Burjassot (Valencia). Muy estimados eran también los duraznos, presegos, brevas y la uva. Se registra un tipo de esta última, que por su denominación puede hacer referencia a su variedad o a su lugar de origen: la uva de yllarol o yllaruell. También comieron melones. Su precio no era fijo, y oscilaba, al parecer, según su peso. El desembolso que la Frutería realizó en manzanas y limones, sobre todo en estos últimos, fue importante. Se adquirieron en grandes cantidades, posiblemente para que el Hostal estuviera abastecido sin necesidad de comprarlos diariamente, ya que se podían conservar durante cierto tiempo una vez adquiridos. Otras frutas que se mencionan son las ciruelas, peras, granadas (milgranas) y membrillos (codoynas) ${ }^{247}$.

\footnotetext{
${ }^{241}$ En varias ocasiones especifican que eran uvas pasas [AGN, Comptos Registros, no 420 , fol. $80 \mathrm{v}]$.

${ }^{2+2}$ AGN, Comptos Registros, $n^{\circ} 420$, fol. 42r.

${ }^{2+3} \mathrm{AGN}$, Comptos Registros, $\mathrm{n}^{\circ} 420$, fol. 63v.

${ }^{2+4} \mathrm{El} 10$ de julio se pagaron $18 \mathrm{~d}$. "por nuezes secas para la cozina" [AGN, Comptos Registros, $\mathrm{n}^{\circ} 420$, fol. 169v]; y, el 28 de junio, $72 \mathrm{~d}$. "por $1^{\text {a }}$ cesta de nuezes para confites" [AGN, Comptos Registros, no 420 , fol. 157r].

${ }^{2+5} \mathrm{El} 7$ de septiembre se pagaron 280 d. jaqueses "por 10 libras de dátiles et pinnones, libra 7 d.» [AGN, Comptos Registros, n ${ }^{\circ} 420$, fol. 226r].

${ }^{2+6} \mathrm{AGN}$, Comptos Registros, $\mathrm{n}^{\circ} 420$, fol. 169v.

${ }^{247}$ Para no resultar repetitivo en la enumeración de los diferentes precios de los artículos adquiridos en Navarra y Aragón he preferido omitir los aragoneses. Estos últimos pueden consultarse en F. SERRANO LARRÁyOz, La alimentación de la realeza navarra, pp. 327-329.
} 
En Navarra, por el mes de marzo, el Hostal se aprovisionó de naranjas. Su precio era de 192 d. el centenar ${ }^{248}$. En mayo compraron cerezas y guindas ${ }^{249}$. Las primeras se pagaron por libras $(12 \mathrm{~d} . / / \mathrm{libra})^{250}$ y por cestas ${ }^{251}$, mientras que de las segundas sólo especifican el pago por libras (8 d./libra $)^{252}$. A principios del mes de junio se mencionan las ciruelas de San Juan ${ }^{253}$, moras ${ }^{254}$, cermeñas ${ }^{255}$ y acediellas ${ }^{256}$. Antes de partir a Zaragoza, en julio, también compraron peras ${ }^{257}$, brevas ${ }^{258}$ y arañones $^{259}$. En septiembre, se adquieren higos ${ }^{260}$, duraznos ${ }^{261}$ y membrillos $^{262}$. También se proveyeron de $\operatorname{granadas}^{263}$ y peras ${ }^{264}$, en octubre, y de manzanas ${ }^{265}$, en noviembre. Resulta imposible detallar que fruta era más cara o más barata, puesto que en la mayoría de los casos no especifican la relación cantidad-precio.

\footnotetext{
${ }^{2+8}$ AGN, Comptos Registros, $n^{0} 420$, fol. 63v.

${ }^{2+9} \mathrm{El} 24$ de mayo se anota la compra de cerezas cellinas. [AGN, Comptos Registros, $\mathrm{n}^{\circ} 420$, fol. $121 \mathrm{v}]$.

${ }^{250} \mathrm{AGN}$, Comptos Registros, $\mathrm{n}^{\circ} 420$, fol. $121 \mathrm{v}$.

${ }^{25}{ }^{2}$ El 1 de mayo el recibidor de La Ribera pagó 980 d. "por dos cestas chicas de cerezas traydos de Çaragoça con el loguero del hombre que fue por de Tudela a Çaragoça et venir a Olit" [AGN, Comptos Registros, n ${ }^{\circ} 420$, fol. 103r].

${ }^{25}$ AGN, Comptos Registros, no 420 , fol. 120v.

${ }^{253} \mathrm{AGN}$, Comptos Registros, $\mathrm{n}^{\circ} 420$, fol. 136v. La denominación debe referirse al tiempo en que esta variedad solía madurar.

${ }^{254}$ AGN, Comptos Registros, no 420 , fol. 151v.

${ }^{255} \mathrm{AGN}$, Comptos Registros, no 420, fol. 140r.

${ }^{256} \mathrm{AGN}$, Comptos Registros, no 420 , fol. 151v.

${ }^{257} \mathrm{AGN}$, Comptos Registros, $\mathrm{n}^{\circ} 420$, fol. 160r.

${ }^{258} \mathrm{AGN}$, Comptos Registros, $\mathrm{n}^{\circ} 420$, fol. 162r.

${ }^{259} \mathrm{AGN}$, Comptos Registros, $\mathrm{n}^{\circ} 420$, fol. 169v. No parece que fueran lo que hoy en día conocemos como arañón o endrina. Éste se utiliza para la elaboración del licor denominado pacharán, que se obtiene por la maceración de endrinas en aguardiente anisado. Posiblemente se refiera a un tipo de ciruela silvestre.

${ }^{260} \mathrm{AGN}$, Comptos Registros, $\mathrm{n}^{\circ} 420$, fol. $243 \mathrm{r}$.

${ }^{201} \mathrm{AGN}$, Comptos Registros, $\mathrm{n}^{\circ} 420$, fol. 245r.

262 AGN, Comptos Registros, $\mathrm{n}^{\circ} 420$, fol. $245 \mathrm{v}$.

${ }^{263} \mathrm{El} 17$ de noviembre el clérigo de la Frutería pagó 270 d., «en Azagra, por milgranas» [AGN, Comptos Registros, $\mathrm{n}^{\circ} 420$, fol. 289v].

${ }^{20+4} \mathrm{AGN}$, Comptos Registros, no 420 , fol. 261v.

${ }_{26.5}$ AGN, Comptos Registros, no 420, fol. 290v.
} 


\section{Otros}

Otra serie de artículos que adquiría la Frutería eran las zanahorias y las aceitunas. La compra de las primeras se realizaba durante los meses invernales ${ }^{266}$. Su función parece que era servir en la cocina como ingrediente en la elaboración de potajes, salsas, guarniciones, etc. Las olivas se consiguieron durante los últimos meses del año, y se pagaron por cánta$\operatorname{ros}^{267}$. Las cantidades eran considerables pero su consumo no parece que fuera muy alto. Posiblemente fueran utilizadas en la cocina como las zanahorias. Debido a su larga conservación no es de extrañar que se compren en contadas ocasiones ${ }^{268}$.

\subsubsection{La Escudería}

Los servidores de este departamento eran los encargados del aprovisionamiento de paja, cebada y avena para las cabalgaduras, las mulas, las acémilas, el rocín de la pollería y de todo lo necesario para el mantenimiento de sus arreos, incluso de las medicinas necesarias para el restablecimiento de las bestias enfermas ${ }^{269}$. A finales de mes se anotaba la compra de papel, pergamino, tinta, cera gomada y todo tipo de artículos de escritorio cuyos destinatarios eran los diferentes departamentos, así como los secretarios y oficiales de la Cámara de los Dineros ${ }^{270}$. También adquirían escobas y material de limpieza para las distintas dependencias en donde se

\footnotetext{
${ }^{2606} \mathrm{AGN}$, Comptos Registros, $\mathrm{n}^{\circ} 420$, fol. 1r y 290v.

${ }^{267} \mathrm{El} 11$ de diciembre "por 3 cántaros et $1^{\text {a }}$ chica de oliuas traydas de Turryllas" se pagaron 648 d. [AGN, Comptos Registros, $n^{\circ} 420$, fol. 308v].

${ }^{21}{ }^{8} \mathrm{El}$ modo de conservar las aceitunas no debía diferir de como se ha realizado tradicionalmente hasta hace unos años. El 7 de octubre se compraron "oliuas para adobar" [AGN, Comptos Registros, $\mathrm{n}^{\circ} 420$, fol. $\left.255 \mathrm{r}\right]$.

${ }^{269} \mathrm{AGN}$, Comptos Registros, $\mathrm{n}^{\circ} 420$, fol. $78 \mathrm{v}$.

${ }^{270} \mathrm{El} 28$ de febrero, Pedro Sanz de Oroz, cambradineros, pagó por «3 robas de paper para los officios et secretarios por todo este mes $13 \mathrm{lbs} .10 \mathrm{~s}$., a él por 3 libras de cera gomada para los secretarios $39 \mathrm{~s}$., a él por tinta espensada en todo este mes $24 \mathrm{~s}$, a él por agujetas para enfillar las escroas 2 s.,(...) a él por 1 liuro paral officio de la Escudería en el quoall ha 8 manos de paper et por la facón por todo $55 \mathrm{~s}$., a él por otro liuro por el contarrolor en que ay 4 manos de paper et por la faycón por todo $32 \mathrm{~s}$. $6 \mathrm{~d}$., a él por 1 liuro para la Cambra a los Dineros $45 \mathrm{~s}$., a él por 4 liuros chicos para la Cambra a los Dineros, pieza $32 \mathrm{~s}$, valen $6 \mathrm{lbs}$. 8 s." [AGN, Comptos Registros, n ${ }^{\circ} 420$, fol. 51 r]
} 
hospedaba la reina ${ }^{271}$. Registran los gastos de los servidores y sus caballerías cuando éstos realizaban viajes en beneficio del Hostal ${ }^{272}$, y los pagos al zapatero del príncipe Carlos por zapatos confeccionados, cada mes, para las infantas y Juan Cardona ${ }^{273}$. Para las festividades de cierta importancia se aprovisionaban de junco con el fin de recubrir el suelo de las distintas estancias reales ${ }^{274}$.

Hasta mediados de septiembre el abastecimiento de cebada y avena se realizaba por medio de compras. Durante los meses en que la Corte estuvo en Olite los encargados de entregar estos productos fueron principalmente los recibidores de Olite y Sangüesa. En ocasiones también es mencionado el de Estella. Poco antes de partir hacia Tudela, el 1 de mayo, estas funciones pasaron a García López de Roncesvalles, tesorero de Navarra. Su labor finalizó al inicio del viaje de la reina a Zaragoza. En Aragón la responsabilidad recayó sobre maestre Bernart, el cual no cesó en sus funciones hasta el regreso a Navarra de la comitiva. Una vez que la reina volvió a instalarse en Tudela esta labor la realizaba el recibidor de $\mathrm{La}$ Ribera. A partir del 19 de septiembre se recurrió al cereal adquirido a través de rentas ${ }^{275}$.

Es posible, como dice M. ${ }^{\mathrm{a}} \mathrm{J}$. Ibiricu, que la gran diversidad de los productos que adquieren en la Escudería se deba a la existencia de una mayor relación con la administración general, y, por tanto, dicha sección se encargaría de suministrar al Hostal los artículos que no se podían incluir

\footnotetext{
${ }^{271}$ El último día de cada mes se pagaba, a Fernando, "por escobas por todo este mes", y Pedro Sanz de Oroz pagaba por jabón "deliurado a la cambra" [AGN, Comptos Registros, $\mathrm{n}^{\circ}$ 420 , fol. $159 \mathrm{v}]$.

272El 31 de marzo se pagó a Lopecoso, Juan, Beltrán y Arreche «por ciertos viages que an fecho a Estella et a Tudela et a Lerín, por paja et ostalaje por todo 31 s.» [AGN, Comptos Registros, $\mathrm{n}^{\circ} 420$, fol. 78v]. El 31 de octubre, Lopecoso, Juan y Arreche recibieron $348 \mathrm{~d}$. «por ciertos viajes que an fecho por vino a Olit et Esteila et a Caparroso et a Taracona" [AGN, Comptos Registros, $\mathrm{n}^{\circ} 420$, fol. $275 \mathrm{v}$ ].

${ }^{273}$ Era sobrino de los reyes, y residía en el Hostal [CAGN, t. 41, no 1029 / AGN, Comptos. Documentos, caj. 146, $\left.\mathrm{n}^{\circ} 41\right]$.

${ }^{274} \mathrm{El} 15$ de diciembre se pagaron $864 \mathrm{~d}$. "por 12 cargas de junco compradas en Tudela para seruicio de la seynora reyna, a goarnir las cambras del castiello de la dicta seynora reyna, con el príncipe et las infantas dolan (sic.) alojar para la fiesta de Navidat" [AGN, Comptos Registros, $\mathrm{n}^{\circ} 420$, fol. $\left.311 \mathrm{r}\right]$.

${ }^{275}$ No nos debe extrañar si tenemos en cuenta que las pechas de cereal se pagaban a finales de septiembre, en torno al día de San Miguel. La compra de avena y cebada desde el mes de enero nos induce a pensar que la cosecha del año anterior no debió ser muy abundante.
} 
específicamente en ningún otro departamento, así como llevar la contabilidad y pagar los salarios de los servidores ${ }^{276}$.

La función administrativa de la Escudería se basaba en el pago diario de los gajes y de las pensiones trimestrales a los servidores. También se anotaban los salarios retrasados y las nuevas contrataciones ${ }^{277}$, aunque no se registran los de los miembros que pertenecían a la Panadería, Botellería, Cocina y Frutería, cuyos salarios ya se mencionan en sus respectivos departamentos. La supervisión de estas labores parece que correspondía al cambradineros y al contrarrolor.

La relación habitual en que eran registradas las diversas personas que reciben salarios seguía, salvo excepciones, un orden jerárquico. En contadas ocasiones especifican el cargo de estas personas, por lo que resulta complicado identificar su función en el Hostal. En primer lugar anotaban los individuos de más renombre, cuyos sueldos eran también los más elevados. Parece, al igual que en el resto de los otros servicios, que las personas de rango similar tenían idéntica remuneración. El arzobispo de Tiro, confesor de la reina, era, cuando estaba presente, quien recibía el mayor salario: 312 d. diarios. Le siguen en importancia los de Beltrán de Ezpeleta, Juan Asiáin, Francés de Veintemilia, Leonel de Garro y Juan de Artieda que reciben 240 d.; Anglesa de Navarra, hija de Leonel de Navarra, 216 d.; Juan de Úriz, Beltrán de Lacarra, maestres del Hostal, Pedro de Val, consejero y protonotario real ${ }^{278}$, y Gil Pérez de Sarasa, tesorero de Navarra ${ }^{279}$ cobra-

\footnotetext{
${ }^{276} \mathrm{M} .^{\text {a }}$ J. IBIRICU, El Hostal, p. 625.

${ }^{277}$ Un ejemplo de estos retrasos:

"... a Johan García de Liçasoayn por sus gages de 15 días de abril et de 31 día de mayo et 30 días d'este mes [junio] que son 76 días que a quedado por olbido et se recobra aquí a $10 \mathrm{~s}$. por día..." [AGN, Comptos Registros, $\mathrm{n}^{\circ} 420$, fol. 159r].

Un ejemplo de las contrataciones:

«... a Johanot d'Ezpeleta el quoal retiene la seynora reyna por su cambrero a gages continuos de $6 \mathrm{~s}$. por día, comencando el primero día de ienero de la data d'este ayno lo quoal parece por 1 mandamiento firmado de la seynora reyna, fecho en Olit, XV días de febrero l'ayno mil CCCCXXXIII, en que se contenía que se contase et se recobrase del dicto día en adelant a los sobredictos 6 s. ..." [AGN, Comptos Registros, n' ${ }^{\circ} 420$, fol. 54r].

En las cuentas del Hostal son pocas las anotaciones que reflejan el desembolso de pensiones trimestrales a los servidores. El 30 de junio se anota: «... a 4 azemilleros por sus quoarteles de tres messes postremerament passados, a cada $1^{\circ}$ por mes $20 \mathrm{~s}$..." [AGN, Comptos Registros, $\mathrm{n}^{\circ} 420$, fol. $\left.159 \mathrm{v}\right]$. Sin embargo, en el registro del tesorero los datos son más abundantes [AGN, Comptos Registros, $\mathrm{n}^{\circ} 415$, fol. 20v-21r].

${ }^{278} \mathrm{AGN}$, Comptos Registros, $\mathrm{n}^{\circ} 415$, fol. $22 \mathrm{r}$.
} 
ban 192 d.; doña Catalina de Beaumont y otras dueñas 180 d.; García de Navascués, limosnero, 144 d. En alguna ocasión también cobran gajes personas que no eran miembros fijos como Juan García de Lizasoáin, oidor de Comptos ${ }^{280}: 120 \mathrm{~d}$.

\section{A. Secretarios}

En la Escudería también se pagaban los salarios de los secretarios. $\mathrm{Al}$ parecer trabajaban para el Hostal y sus funciones eran principalmente notariales. Al contrario de lo que opina $\mathrm{M}^{\mathrm{a}}{ }^{\mathrm{J}}$. Ibiricu parece que quien debía responder ante la Cámara de Comptos era Pedro Sanz de Oroz, cambradineros; y no los secretarios. Sin embargo, si que hay, como ella afirma cierta independencia entre la Cámara de los Dineros y la de Comptos $^{281}$. El salario del cambradineros era de $192 \mathrm{~d}$. diarios, y el Pedro de Echarri, contrarrolor, 132 d. Los secretarios reales, de los cuales hemos podido individualizar a Simón de $\mathrm{Leoz}^{282}$, Sancho de Munárriz ${ }^{283}$, Nicolás de Echávarri ${ }^{284}$, Juan de Leet ${ }^{285}$, García de Barásoain ${ }^{286}$ y a Gil de Vera ${ }^{287}$, también recibían 132 d. Gabriel Ruiz, corrector, cobraba idéntica cantidad.

\footnotetext{
${ }^{277}$ A M. a R. GARCía ARANCÓn ["Clérigos" en la Corte de Navarra, p. 101] y a M. a J. IBIRICU [El Hostal, p. 597] les sorprende la presencia del tesorero de Navarra cobrando gajes diarios. Ambas atribuyen sus honorarios por la revisión de las cuentas del Hostal. En nuestro caso es posible que fuera por estos motivos, pero también debemos recordar que éste fue el encargado de suministrar cebada y avena antes del viaje a Zaragoza.

${ }^{280}$ AGN, Comptos Registros, ${ }^{\circ} 420$, fol. 171r, 172r; y CAGN, t. 41, n 213/AGN, Comptos. Documentos, caj. 133, $\left.\mathrm{n}^{0} 19, \mathrm{LX}\right]$

${ }^{281} \mathrm{M}$. a J. IBIRICU, El Hostal, p. 626.

${ }^{282} \mathrm{CAGN}, \mathrm{t} .41, \mathrm{n}^{\circ}$ 209/AGN, Comptos Documentos, caj. 133, n 18 , VI.

${ }^{283} \mathrm{CAGN}, \mathrm{t} .41, \mathrm{n}^{\circ} 348 / \mathrm{AGN}$, Comptos Documentos, caj. 135, $\mathrm{n}^{\circ} 32$.

${ }^{26 \times} \mathrm{CAGN}, \mathrm{t} .41, \mathrm{n}^{\circ}$ 42/AGN, Comptos Documentos, caj. 135, no 3, VII.

${ }^{28.5}$ CAGN, t. 41, no 66/AGN, Comptos Documentos, caj. 135, $n^{\circ} 4$, IX.

${ }^{261} \mathrm{AGN}$, Comptos Registros, $\mathrm{n}^{\circ} 420$, fol. 302v.

${ }^{287} \mathrm{CAGN}, \mathrm{t} .40, \mathrm{n}^{0}$ 1168/AGN, Comptos Documentos, caj. 133, $\mathrm{n}^{0} 1, \mathrm{XII}$ (año 1432).
} 


\section{B. Escuderos y servidores de la Escudería}

Se ha venido considerando hasta el momento como escuderos a todos los miembros de la Escudería que servían en ella como gentes de armas ${ }^{288}$. Desconocemos su número exacto aunque se ha podido identificar a algunos de ellos: Sancho de Sarría ${ }^{289}$, Íñigo de Legarra ${ }^{290}$, Gil Martínez de Urroz $^{291}$ y García de Johara ${ }^{292}$. Todos ellos recibían los mismos gajes: $132 \mathrm{~d}$.

Otras de las funciones de la Escudería era el cuidado, alimentación y mantenimiento de las monturas. De ello debía encargarse un número considerable de personas. Sin embargo, resulta bastante complicado saber quiénes trabajaban en los diferentes oficios. Beltrán de Labets ${ }^{293}$ y Juan de Sevilla $^{294}$, caballerizos, estaban encargados de tasar el valor de las bestias que se adquirían. El primero cobraba $132 \mathrm{~d}$. diarios, mientras que el segundo $120 \mathrm{~d}$. El sobreacemilero ${ }^{295}$ y los palafreneros ${ }^{296}$ recibían $96 \mathrm{~d}$. Idénticas cantidades cobraban Gonzalo de Los Arcos y Lope de Araxa, mensajeros ${ }^{297}$. La función de los forrajeros, como Gil Gómez y Juan de

\footnotetext{
${ }^{288}$ M. a J. IBIRICU, El Hostal, p. 626.

${ }^{289}$ Era denominado como escudero de Escudería (año 1432). [CAGN, t. 41, nº 81/AGN, Comptos. Documentos, caj. 135, $\left.\mathrm{n}^{\circ} 5, \mathrm{I}\right]$.

${ }^{290}$ En 1432 se le menciona como escudero y guarda del retrayt de la reina [CAGN, t. 40, $\mathrm{n}^{\circ}$ 897/AGN, Comptos. Documentos, caj. 133, n 1 , V]. El retrete era una habitación destinada para retirarse [Diccionario de Autoridades, voz retrete].

${ }^{291}$ Era también alcaide del castillo de Rocaforte [CAGN, t. 41, nº 121/AGN, Comptos. Documentos, caj. '133, n'17, XLVIII].

${ }^{292}$ En el mismo año es denominado como escudero y como doncel de la reina [CAGN, 1. 41, no 218/AGN, Comptos. Documentos, caj. 135, n⿳ 19, VI; y CAGN, t. 41, n 526/AGN. Comptos. Documentos, caj. 135, $\left.\mathrm{n}^{\circ} 44, \mathrm{VI}\right]$.

${ }^{293} \mathrm{CAGN}$, t. 41, no 610/AGN, Comptos. Documentos, caj. 146, no 7, V (año 1434). También es mencionado como escudero de Escudería [CAGN, t. 41, no 338/AGN, Comptos. Documentos, caj. 135, $\left.\mathrm{n}^{0} 30, \mathrm{II}\right]$.

${ }^{294} \mathrm{CAGN}$, t. 41, no 982/AGN, Comptos. Documentos, caj. 133, nº 22, XXI (año 1434). Parece que este cargo lo compaginaba con el de clérigo de la Escudería [P. GALINDO ROMEO, Peregrinación de Doña Blanca, p. 21].

${ }^{205}$ Quizás fuera Domenjón de Esconztegui (año 1432) [CAGN, t. 40, no 1243/AGN, Comptos Documentos, caj. 134, no 1, fol. 5v].

${ }^{2 \%}$ Se ha identificado a Gonzalo de Sevilla [P. Galindo Romeo, Peregrinación de Doña Blanca, p. 15].

${ }^{297} \mathrm{P}$. Galindo Romeo, Peregrinación de Doña Blanca, pp. 16-17.
} 
Alzate $^{298}$, era la de comprar la cebada con la que se alimentaban las monturas. Sus salarios eran sensiblemente más bajos: $72 \mathrm{~d}$. El herrero Juan adquiría las herraduras nuevas y arreglaba las viejas. A final de mes suelen anotarse sus gastos en medicinas para los animales ${ }^{299}$. Diariamente cobra la misma cantidad que los forrajeros. Por último, podemos citar a cuatro mozos de establo y otros tantos acemileros (Lopecoso, Juan, Beltrán y Arreche). Los mozos recibían $42 \mathrm{~d}$. y los acemileros $48 \mathrm{~d}$.

\section{Otros oficios referentes al Hostal remunerados en la Escudería}

Ya hemos hecho mención, al inicio de este trabajo, de una serie de servidores que trabajaban en las dependencias de la Cámara de la reina o relacionadas con ella y que cobraban sus gajes en la Escudería. Éstos eran los camareros, los valets, los donceles y doncellas, amas, nodrizas, ujieres o porteros, médicos, bordadores, etc. Existían otros sirvientes que también podían tener cierta relación con la Cámara de la reina. Eran, por ejemplo, Lucián Bartolomeo, tapicero real y también guarda de las aves ${ }^{3(1)}$, (54 d./día), Fernando de Redecieilla, brasero de la reina ${ }^{301}$, y Pedro Sanz, peletero, (72 d./días).

Otros oficios que según parece eran comunes a ambos monarcas eran el de aposentador real y el de repostero de camas. El primero estaba encargado de cuidar los desplazamientos regios y los alojamientos del monarca y su Casa durante los viajes ${ }^{302}$, y el segundo era un criado a cuyo cargo estaba cuidar la puerta de la antecámara y de mullir los colchones de

\footnotetext{
${ }^{298}$ P. Galindo Romeo, Peregrinación de Doña Blanca, p. 22.

${ }^{299} \mathrm{AGN}$, Comptos Registros, $\mathrm{n}^{\circ} 420$, fol. 219r.

${ }^{3(0)}$ CAGN, t. 40, no 1214/AGN, Comptos. Documentos, caj. 133, nº 1, XXIII (año 1432).

${ }^{301} \mathrm{CAGN}, \mathrm{t} .41, \mathrm{n}^{\circ} 380 / \mathrm{AGN}$, Comptos. Documentos, caj. 135, $\mathrm{n}^{\circ} 35, \mathrm{~V}$.

${ }^{302}$ M.Á. LADERo QueSADA, La Casa Real en la Baja Edad Media, "Historia. Instituciones. Documentos. Homenaje al profesor D. José Martínez Gijón”, 25 (1998), p. 341. García González de Tordesillas era el aposentador real [CAGN, t. 41, no 237/AGN, Comptos. Documentos, caj. 135, n⿳0 20, I].
} 
la cama ${ }^{303}$. También recibían salarios los conserjes de los palacios rea$\operatorname{les}^{304}(120$ d./día).

La Casa de la reina también debía de tener una serie de servidores que se encargaban del buen funcionamiento de los servicios de mesa, pero resulta complicado identificarlos. Posiblemente tuvo, al igual que su esposo, un maestresala ${ }^{305}$, coperos, reposteros ${ }^{306}$ y trinchantes ${ }^{307}$. No sabemos si durante este año la reina necesitó los servicios de los astrólogos. Sin embargo, queda constancia de que en otras ocasiones sí estuvieron presentes en la Corte $^{308}$. Este oficio no parece que perteneciera al Hostal.

\section{EN LA MESA CON LA REINA}

Poco, por no decir nada, sabemos de las reglamentaciones para servir la mesa dictadas por la realeza navarra bajomedieval. Lamentablemente no se conservan, o por lo menos no han sido localizadas, como en otros lugares, ordenanzas que nos trasmitan, el funcionamiento de los hostales navarros en general y el de Blanca en particular.

Es imposible saber con certeza cómo se desarrollaba el ritual que diariamente se realizaba durante el ofrecimiento de los alimentos a la reina y a sus hijas. Tampoco sabemos cómo estaban decoradas la sala o salas donde se celebraban las comidas y los banquetes. Suponemos que en las

\footnotetext{
${ }^{303}$ Diccionario de Autoridades, voz repostero de camas. Durante 1433 como repostero de camas se menciona a Álvaro de Astorga [CAGN, t. 41, n 291/AGN, Comptos. Documentos, caj. 133, $\mathrm{n}^{\circ} 19$, XLIV].

${ }^{304}$ Hemos identificado a Nicolás de Guérez, conserje de los palacios reales de Olite [CAGN, t. 41, n⿳0 58/AGN, Comptos. Documentos, caj. 135, n 4, II]; y a García de Arguedas, conserje de los palacios reales de Tafalla [CAGN, t. 41, $\mathrm{n}^{\circ}$ 1/AGN, Comptos. Documentos, caj. 133 $n^{\circ} 17$, XXVIII].

${ }^{305}$ En 1433 Juan Dueñas era el maestresala del rey [CAGN, t. 41, no 195/AGN, Comptos. Documentos, caj. 133, $\mathrm{n}^{\circ} 21, \mathrm{XXXVI]}$.

${ }^{306} \mathrm{CAGN}, \mathrm{t} .42, \mathrm{n}^{\circ} 472 / \mathrm{AGN}$, Comptos. Documentos, caj. 137, $\mathrm{n}^{\circ} 34$, IX. El repostero era el oficial a cuyo cargo estaba guardar la plata y el servicio de mesa, incluyendo ponerla, y también de preparar las bebidas y dulces. El copero era quien tenía por oficio el llevar la copa y dar de beber al rey [Diccionario de Autoridades, voz repostero y copero]. En 1432 Juan de Luxa era escanciador de la reina [CAGN, t. 40, n 1243/AGN, Comptos Documentos, caj. 134. $\mathrm{n}^{0} 1$, fol. $\left.5 \mathrm{v}\right]$

${ }^{307}$ Leonet de Mauleón era uno de los trinchantes de la reina [P. GALINDO ROMEO, Peregrinación de Doña Blanca, p. 12].

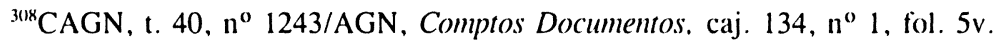


ocasiones más especiales, según la moda de la época, éstas estarían ricamente ornamentadas con el fin de exaltar el prestigio de la Corte y suscitar la admiración de los invitados ${ }^{309}$. La información contenida en la documentación consultada nos da una visión del gusto en la decoración de las estancias destinadas a este fin.

Lo habitual en estos contextos es que las viandas fueran servidas en una mesa o una serie de mesas formadas por grandes tablas de madera y apoyadas en caballetes. En los banquetes la disposición de éstas, por lo general, era en forma de $\mathrm{U}$ y los comensales se situaban en el lado externo para poder disfrutar de los espectáculos que se solía ofrecer en el centro. La mesa principal podía asentarse sobre un entarimado, y se ocupaba, según las ocasiones, por la reina, las infantas y sus invitados de honor. El resto de los comensales se colocaban en los extremos observando una estricta gradación jerárquica ${ }^{310}$. En el caso de que la mesa se dispusiera de forma alargada, se solía dejar libre uno de los lados laterales para no dificultar el servicio. Los huéspedes de mayor rango ocupaban los lugares preferentes, como son las cabeceras y el lugar central, a los lados de éstos se colocaban, según su escalafón social, el resto de los invitados ${ }^{311}$. Sabemos que era norma común la presencia de músicos y juglares para la realización de espectáculos y amenizar este tipo de veladas ${ }^{312}$.

Resulta complicado establecer quiénes acompañaban a Blanca en la mesa cuando ésta comía en la sala, puesto que no se conocen datos concretos. Es posible que junto a ella, según en qué ocasiones, se encontraran algunos de los personajes más notables de la Corte como el arzobispo de Tiro, Beltrán de Ezpeleta, etc., y un número no determinado de dueñas y

\footnotetext{
${ }^{3(1)} \mathrm{P}$. CECCHINI, La Corte squisita del duca Federico. Mense imbandite nel più bel Palazoo del Rinascimiento italiano, Bolonia, 1995, p. 15.

${ }^{31 \prime \prime}$ O. Redon, F. Sabban y S. Serventi, Delicias de la gastronomía medieval, Madrid, 1996, p. 40.

3"J.V García Marsilla, Alimentación y diferencias sociales en la ciudad de Valencia (1390-1415), en "Ir Col.loqui d'Història de l'Älimentació a la Corona d'Aragó. Edat Mitjana". t. 2, Lleida, 1995, p. 496. Sobre el ritual en la mesa podemos ver los trabajos de B.A. Henisci, Fast and Feast. Food in Medieval Society, The Pennsylvania State University Press, (sixth printing) 1997, pp. 147 y ss.; y C.A. WILSON, Ritual, Form and Colour in the Mediaeval Food Tradition, en C.A. Wilson (dir.): 'The Appetite and Eve'. Visual aspects of food and its presentation within their historic context, Edinburgh University Press, 1991, pp. 8-13.

${ }^{312}$ Un interesante trabajo sobre el papel de los juglares en la Corte navarra, en $M$." NARBona CáRCEles, La consideración del juglar en la Corte de Carlos II y Carlos III de Navarra, a través del estudio de su atuendo, en "Mito y Realidad en la Historia de Navarra" (Actas del IV Congreso de Historia de Navarra), t. 1, Pamplona, 1998, pp. 429-442.
} 
doncellas $^{313}$. También debían estar presentes, aunque en diferente mesa y posiblemente, en distinta estancia, los pobres, que en muchas ocasiones recibían alimentos. Cuando comparte la mesa con el rey o su hijo, el príncipe de Viana, éstos debieron ocupar la misma tabla que la reina ${ }^{314}$. En los periodos en los que la climatología lo permitía, las comidas se solían realizar al aire libre en las terrazas de los palacios ${ }^{315}$.

En ocasiones la reina y las infantas comían en sus habitaciones privadas $^{316}$. Las indisposiciones físicas que con frecuencia sufrían, tanto Blanca como sus hijas, pudieron motivar este hecho. El retiro no siempre implicaba más privacidad a la hora de comer, ya que en varias ocasiones se ha podido constatar la presencia de miembros del séquito. La estancia o ausencia de comensales en las habitaciones de la reina y de las infantas iría en relación con la gravedad de las dolencias que éstas tuvieran. Debemos aclarar que quienes acompañaban en estas ocasiones a Blanca o las infantas pertenecían siempre al sexo femenino. No se ha podido constatar la presencia de varones ${ }^{317}$.

Era norma común que los servidores de la mesa comieran, por lo menos en los días en que se celebraba algún festejo especial, después de haber finalizado el servicio. Su alimento eran las sobras de los banquetes $^{318}$.

\footnotetext{
${ }^{313}$ El 5 de mayo se gastaron 2 carapitos de vino de la Botellería "por las dueynas et donzeillas que cenaron en sala" [AGN, Comptos Registros, $n^{\circ} 420$, fol. 104v].

${ }^{314} \mathrm{La}$ posición de los comensales en la mesa y la generosidad en el ofrecimiento de los alimentos fueron los principales instrumentos, durante la Baja Edad Media, de la representación de las relaciones entre las personas, los grupos o las instituciones [T. de CASTRO MARTíNEZ, La alimentación en las crónicas, p. 84]. Así por ejemplo, en la Corte de Borgoña, con Carlos el Temerario (1467-1477), se comía en grupos de diez, en departamentos separados, servidos y atendidos conforme al rango y a la clase [J. HuizingA, El otoño de la Edad Media, Madrid, (decimotercera reimpresión) 1996, p. 61]. La separación de los comensales según su status social y sexo parece ser que también se daba, aunque desconocemos con qué frecuencia, en la Corte navarra [F. SERRANO LARRÁyOZ, Banquetes de los príncipes de Viana, p. 694].

${ }^{315}$ A. Castellano Gutiérrez, La mesa real de Navarra, p. 590.

${ }^{316}$ 'Sirva de ejemplo como el 5 de enero las infantas cenaron «en su cambra" [AGN, Comptos Registros, $n^{\circ} 420$, fol. $3 r$. Hay veces que se especifica que parte de los productos adquiridos se compraban para la cambra. No es de extrañar que en caso de indisposición los miembros de la familia real comieran en sus aposentos.

${ }^{317}$ Parece que el ámbito privado de la reina estaba organizado en torno a las mujeres de su Hostal. Tampoco sorprende que en caso de enfermedad, excepto a los médicos, se permitiera servir sólo al personal femenino.

${ }^{318}$ Por lo menos así era, algunos años más tarde, en la Corte de Carlos de Viana e Inés de Clèves [F. Serrano LaRráyOZ, Banquetes de los príncipes de Viana, p. 694].
} 


\subsection{La vajilla de mesa}

La vajilla cotidiana era de cerámica, a veces vidriada ${ }^{319}$, cristal $^{320}$ o estaño ${ }^{321}$, mientras que en las celebraciones más solemnes solían utilizar la de plata. En estas ocasiones no todos los presentes que acompañaban a la reina eran agasajados con el mismo servicio de mesa. El de los invitados de menor rango, como los pobres, era de cerámica $^{322}$, mientras que a la familia real debió de servirse en el de plata ${ }^{323}$.

La tipología de la vajilla utilizada por los diferentes comensales parece que no variaba en gran medida. Sobre el mantel se colocaban los platos $^{324}$, cuchillos $^{325}$, escudillas, jarras (picheles), copas y"gobeletes ${ }^{326}$. No hay mención alguna a la presencia de cucharas y saleros, pero con toda seguridad contaron con ellos. El tenedor raramente se utilizó en la Baja Edad Media. La mayor parte de los alimentos se llevaban a la boca con las manos.

${ }^{319}$ El 9 de abril (Jueves Santo) compraron "dos pieças grandes badryadas (sic)" [AGN, Comptos Registros, $\mathrm{n}^{\circ} 420$, fol. 86v].

${ }^{320}$ El 14 de agosto se registra la compra de "1 ${ }^{\text {a }}$ redonba (redoma) gran de vidrio doble" [AGN, Comptos Registros, n⿳ 420 , fol. 204v].

${ }^{321} \mathrm{El}$ primer día de febrero adquirieron 2 cofres "para lebar la vaxilla d'estayno de Olit a Tafayla" [AGN, Comptos Registros, $\mathrm{n}^{\circ} 420$, fol. 28r].

${ }^{322}$ Sirva de ejemplo como el día de Jueves Santo se adquirió una cantidad considerable de platos, escudillas, jarras... para los pobres [AGN, Comptos Registros, $\mathrm{n}^{\circ} 420$, fols. 86v-87r].

${ }^{323}$ En julio se pagó a Guillermo, platero, «por ciertos obras de plata que avía fecho por nuestro mandamiento, es a saber picheires grandes, aigueras e copas para nuestras dichas fijas et dos bacines de agoamanos para nos dicha reyna" [P. GALINDO ROMEO, Peregrinación de Doña Blanca, p. 14]. El 25 de julio, en la Botellería, compraron "1 a seda pora linpiar la plata" [AGN, Comptos Registros, $\mathrm{n}^{\circ} 420$, fol. 185r].

${ }^{324} \mathrm{No}$ son frecuentes las menciones sobre la compra de platos. Es posible que también utilizaran con una función semejante rebanadas de pan seco. El pan no sólo se consumía como tal sino que formaba parte del servicio de mesa. Durante la Edad Media una gran rebanada de pan, que se podía poner en un plato de madera o plata, recibía los trozos de carne y salsa. Después de ser utilizado en la mesa este pan se daba a los pobres o a los perros. Decimos esto porque a diario, en la Panadería, se expenden una serie de panes a los trinchantes, que muy bien los pudieron ser usados como platos. Sobre esto podemos ver, M. a Á. PÉREZ SAMPER, La mesa del rey: imagen y símbolo del poder, en "XV Congreso de Historia de la Corona de Aragón", t. 1, vol. 3, Zaragoza, 1996, p. 438; y P.W. HAMmOND, Food and Feast in Medieval England, Sutton Publishing Limited, 1996, p. 109.

${ }^{325}$ En junio Leonet de Mauleón, trinchante, recibió 1.260 d. para pagar «5 gaynibetes que para el servicio de nuestra tabla fueron comprados" [P. GALINDO ROMEO. Peregrinación de Doña Blanca, p. 12].

${ }^{326} \mathrm{E} \mathrm{El}$ gobelete es un vaso de cerámica, cobre u hojalata redondo o abarquillado y más ancho por la boca que por la base [M.' J. IBIRICU, El Hostal, p. 607] 
Al comienzo de las comidas un simple gesto de higiene - el lavarse las manos- se convirtió en un ceremonial ${ }^{327}$. Así pues, no faltaron las aigueras (aguamaniles), los bacines para recoger el agua ${ }^{328}$ y las serville$\operatorname{tas}^{329}$. Al anochecer la mesa se completaba con candelabros cuya función era la de iluminar la estancia o estancias.

Está documentado, a través de los libros de literatura de la época y de las miniaturas que los decoraban, que en Francia, Inglaterra e Italia, durante los banquetes más solemnes, en un lugar cercano a la mesa principal se colocaba un armario o tinel donde se exponía toda la vajilla trabajada con materiales preciosos. La ostentación de estas joyas, cuya función era impresionar a los invitados, era mayor cuanto más poderoso era quien ofrecía la recepción. A pesar de que la documentación consultada no nos permite saber si en la Corte de Blanca se seguían las mismas costumbres, tampoco se ha encontrado dato alguno que lo niegue. Una pieza del mobiliario que se ha podido identificar era el dreçador o mesa ajena donde se ponían los manjares a la vista antes de ser consumidos ${ }^{330}$.

\subsection{Los ritmos alimentarios}

¿A qué hora comían y cuántas veces al día lo hacían? Los textos son explícitos; las dos comidas principales del día eran el yantar y la cena ${ }^{331}$. La primera se realizaba alrededor del mediodía, mientras que la última era al anochecer. Los horarios no parece que fueran fijos. En los meses de

\footnotetext{
${ }^{327}$ J.L. Flandrin y C. Lambert, Fêtes gourmandes au Moyen Âge, París, 1998, p. 48. A pesar de que el tenedor no se usaba en la mesa sí existían las brocas, con dos o tres puntas, que servían "para tomar la vianda y ponerla delante sin tocar con las manos", y comer alimentos "adobados sin untarse" [E. de VILlENA, Arte Cisoria o Arte de cortar los alimentos (y servir la mesa). Presentación y actualización del texto J.L. Martín, Salamanca, 1997, p. 25]. En Navarra, en 1397, está documentada, en un inventario de María, condesa de Denia, la presencia de una fourcheta de plata entre la vajilla de la Panadería [AGN, Comptos Documentos, caj. 74, $\mathrm{n}^{\circ} 13$, fol. $\left.3 \mathrm{v}\right]$.

${ }^{328}$ Ver nota $n^{\circ}$ 323. El ritual de lavarse las manos se producía tanto al principio como al final de las comidas [P.W. HAMmOND, Food and Feast, p. 111]. En abril y mayo se adquirieron toallas de Flandes para el servicio de toda la familia real [AGN, Comptos Registros, no 415 , fol. $24 \mathrm{v}]$.

${ }^{329}$ Ver nota no 50.

${ }^{330}$ J.V. García Marsilla, La jerarquía de la mesa, p. 175. Había un dreçador en la habitación de la reina [AGN, Comptos Registros, n 420, fol. 320r].

${ }^{33}$ Sirva de ejemplo el día 14 de julio: «Martes, XIIII día de jullio, la reyna partió de Cortes e fue iantar, cena, a dormir a Pedrolla" [AGN, Comptos Registros, n 420, fol. 173r].
} 
verano, cuando más horas de sol hay, éstas - las comidas- se podían retrasar.

La ingesta de alimentos no sólo se reducía a estos dos momentos. Durante el viaje a Zaragoza, en varias ocasiones, tomaron pan y vino para almorzar $^{332}$. Éstos artículos servirían para dar un respiro y suplemento calórico durante el trayecto a los miembros del Hostal ${ }^{333}$. Posiblemente junto con el pan y el vino consumieron algún otro producto. De todas formas, el almuerzo no sólo se redujo a los periodos en que la Corte estaba en movimiento ${ }^{334}$.

A diario celebran lo que se denomina como colaciones. Eran unos convites a base de confites y vino ${ }^{335}$. Se diferencian claramente varios tipos. Las realizadas en el ámbito privado de la Corte, principalmente entre las dueñas, las doncellas y la reina ${ }^{336}$; las de carácter general celebradas como muestra de cortesía ${ }^{337}$, y las que podemos denominar de trabajo ${ }^{338}$. En ocasiones la Botellería corría a cargo de la provisión de vino para ciertas colaciones de individuos que no pertenecían al Hostal, pero de gran

${ }^{332}$ El 15 de julio, entre Pedrola y Alagón, se gastaron 2 cuartones de vino «po (sic.) l'almuerço de la reyna et de las infantas et dueynas et donzeylas" [AGN, Comptos Registros, $\mathrm{n}^{\circ} 420$, fol. $\left.174 \mathrm{v}\right]$.

${ }^{333}$ Para mitigar las penalidades del trayecto era frecuente la ingesta de vino "por el camino" [AGN, Comptos Registros, $\mathrm{n}^{\circ} 420$, fol. 174v].

${ }^{334} \mathrm{El} 19$ de abril, en Olite, la Cocina expendió 2 piezas de carne, posiblemente carnero, «por los que armozaron" [AGN, Comptos Registros, $\mathrm{n}^{\circ}$ 420, fol. 95r].

${ }^{335}$ Parece que con esta denominación se designaban a dos tipos de refecciones diferentes. La primera era lo que podemos denominar como un "tentempié" antes de las principales comidas del día. La segunda, en cambio, era un convite como muestra de cortesía [C. VELA I AULESA, La col.lació, un àpat medieval poc conegut, en "La Mediterrània, area de convergència de sistemes alimentaris (segles V-XVIII)", Palma de Mallorca, 1996, p. 679].

${ }^{336} \mathrm{El} 23$ de abril la Botellería gastó 2 cuartones de vino "por las colaçiones que fizieron entre día las dueynas et donzeillas en la canbra de la reyna" [AGN, Comptos Registros, n 420 , fol. 97rl. El 7 de diciembre 1 cuartón de vino "por la collación que fizieron la dueyna en la canbra de la reyna coando la reyna cenaua" [AGN, Comptos Registros, $\mathrm{n}^{\circ} 420$, fol. 305v].

${ }^{337}$ Para celebrar la llegada a Zaragoza, el 19 de julio se organizaron diversas colaçiones generales en las cuales participaron la reina, las infantas, el príncipe Carlos de Viana, las dueñas, las doncellas, los caballeros y los escuderos "así de los de casa como los de la ciudat". El 27 del mismo mes se realizó otra colación con doña Teresa de Híjar, las dueñas, las doncellas, los caballeros y escuderos [AGN, Comptos Registros, n 420 , fol. 178v y 187v].

${ }^{338}$ Como la realizada, el 6 de marzo, por "los del conseyllo et por los de la cambra de los contos" [AGN, Comptos Registros, no 420, fol. 56r]. Era corriente que después de revisar las cuentas del Hostal los maestres del Hostal y los oficiales encargados de revisarlas se reunieran para tomar algo de vino e incluso celebrarlo con una comida [AGN, Comptos Registros, $n^{\circ} 420$, fols. $289 \mathrm{r}$ y $289 \mathrm{v}]$. 
consideración social, como era el obispo de Tarazona ${ }^{339}$. No parece que hubiera un horario determinado para su celebración, sino que cualquier momento era bueno para estos menesteres.

Después de todo esto queda preguntarse cuál era la comida más importante del día. Comer menos al atardecer fue un precepto dietético aceptado unánimemente durante la Edad Media. Sin embargo, en la práctica todo dependía de otros factores, que a menudo tendían a contradecir este hecho $^{340}$. Para muchos dietistas, entre los que se incluye Arnaldo de Vilanova, la última comida debía ser la principal ${ }^{341}$.

\subsection{Aspectos religiosos}

Las obligaciones que imponía la Iglesia sobre la abstinencia de comer carne durante la Cuaresma, los viernes y las vigilias de las festividades más importantes se cumplieron con regularidad, aunque hubo ciertas excepciones. La delicada salud de Blanca, la minoría de edad de las infantas, Leonor y Blanca, de 7 y 9 años respectivamente, y las enfermedades que sufrieron, propició que, en ocasiones, el cumplimiento de no comer carne en determinados días se dejara de cumplir ${ }^{342}$. No podemos atribuir este comportamiento a una falta de piedad, sino solamente a la creencia, extendida durante toda la Baja Edad Media, de que el consumo de carne era mucho más beneficioso para la salud, en caso de enfermedad, que el pescado. El resto de los servidores del Hostal, que recibían alimentos, cumplen los preceptos religiosos a rajatabla ${ }^{343}$.

\footnotetext{
${ }^{339}$ El 6 de diciembre, en Tudela, la Botellería aprovisionó de 1 carapito y 2 cuartones "por los escollares de San Nicolás con su obispo que fizieron collación" [AGN, Comptos Registros, n" 420, fol. 305r].

${ }^{3+1} \mathrm{~J}$.L. FLANDRIN y C. LAMBerT, Fêtes gourmandes, p. 36

${ }^{3+1}$ J. Cruz Cruz, Dietética medieval, p. 107.

${ }^{3+2}$ Por ejemplo, el día de Jueves Santo, una fecha en que no se podía comer ningún tipo de alimento de origen animal, incluidos los huevos y la leche, fueron compradas 3 gallinas, 1 capón y 4 huevos [AGN, Comptos Registros, n 420, fol. 87r].

${ }^{3+3}$ Incluso un alfaquí - sabio en leyes de los musulmanes-, el viernes 19 de junio, cumplió la abstinencia junto con el resto de los servidores [AGN, Comptos Registros, n" 420 , fol. 148v].
} 


\subsection{Beneficiarios de los alimentos}

¿Eran alimentados todos los servidores y miembros del Hostal? Parece que no todos, a pesar de las razones que en otro trabajo expuse, intentando justificar justo lo contrario ${ }^{344}$. Sorprende la reducida nómina de personas que de manera continuada comían a expensas de la reina ${ }^{345}$. Quienes reciben diariamente alimentos, aparte de Blanca y las infantas, eran los servidores de los oficios más humildes dentro del escalafón cortesano: los libreas y unos indeterminados guardas. Si tenemos presente que su salario era de los más bajos, les resultaría complicado subsistir dignamente en caso de tener que pagarse su alimentación.

El ofrecimiento de pan como limosnas ${ }^{346}$ y la presencia, en numerosas veces, de pobres recibiendo comida deja constancia de la importancia que para la familia real tenía la virtud de la caridad ${ }^{347}$. Una virtud llevada a su máxima expresión el día de Jueves Santo, cuando la reina y las infantas sirvieron la mesa de los menesterosos ${ }^{348}$. La caridad alimentaria, en ocasiones, se revestía de un marcado simbolismo. Así, el 14 de noviembre alimentaron a 3 pobres del hospital de Santa Catalina y durante los días siguientes se fueron incorporando a la mesa, uno cada día, hasta alcanzar el número de 12 (en representación de los doce apóstoles) ${ }^{349}$.

En ocasiones las dueñas también fueron invitadas a comer. Sin embargo en estos casos no sólo recibían el alimento, sino que compartían

\footnotetext{
${ }^{3+4} \mathrm{~F}$. SERRANO LARRÁYOZ, La alimentación de la realeza navarra, p. 311 . A pesar de que en el registro del Hostal que hemos manejado no se hace ninguna mención, debemos tener en cuenta que los salarios que se entregaban a los servidores iban destinados a su mantenimiento personal. Los personajes de mayor consideración social recibían mayores cantidades para poder costear sus cabalgaduras y criados. Para estos asuntos los registros del Hostal de Carlos III son más explícitos.

${ }^{3+5} \mathrm{Si}$ lo comparamos, por ejemplo, con las personas que se alimentaban, un siglo atrás, en el Hostal del delfín Humberto II de Viena, hay bastante diferencia [B. LAURIOUX, Table et hiérarchie sociale à la fin du Moyen Age, en C. Lambert (dir.): "Du manuscrit à la table. Essais sur la cuisine au Moyen Âge et répertoire des manuscrits médiévaux contenant des recettes culinaires", Montreal-París, 1992, p. 89].

${ }^{3+6} \mathrm{AGN}$, Comptos Registros, n 420, fol. 80r.

${ }^{3+7}$ Sobre estas cuestiones podemos ver, en J.V. García MARSILla, La jerarquía de la mesa, p. 77-79.

${ }^{3+8}$ En la Panadería se anotaron los panes que recibieron estos pobres: "por los 13 pobres que serbió la reyna 52, por los 10 pobres que seruieron las infantas 40" [AGN, Comptos Registros, $\mathrm{n}^{\circ} 420$, fol. $\left.86 \mathrm{v}\right]$.

${ }^{3+9} \mathrm{AGN}$, Comptos Registros, no 420 , fol. $286 \mathrm{v}$ y $295 \mathrm{v}$.
} 
estancia y posiblemente, en alguna ocasión, mesa con Blanca. La generosidad alimentaria de la reina se extendía a innumerables beneficiarios puntuales. La presencia de estos en la Corte navarra se debía a múltiples motivos y el tiempo de permanencia en la Corte navarra variaba en cada caso. Podemos atestiguar, por ejemplo, las visitas de un mensajero del conde de Foix, de un escudero de la reina de Aragón, de un embajador de Castilla y otro de Segismundo de Luxemburgo, del abad de Irache y de Juan de Luna, caballero de Aragón ${ }^{350}$. Otros como Juan Cardona y el obispo de Valencia estuvieron más tiempo, y, por tanto, fueron alimentados en más ocasiones ${ }^{351}$.

También recibían alimentos, quienes eran contratados para realizar ciertos trabajos para el Hostal o los encargados de velar en la cámara de la reina, cuando ésta estaba enferma ${ }^{352}$.

En varias ocasiones se ofrecieron a miembros del clero las denominadas pitanzas ${ }^{353}$. La carne, acompañada con pan y vino, era de bastante consistencia, por lo que la forma más común de presentarla debió de ser asada. Otra de las maneras de demostrar el afecto que la reina tenía a las personas más cercanas a ella era entregando alimentos cuando contraían matrimonio $^{354}$.

Una vez que hemos establecido quiénes recibían alimentos en el Hostal, nos quedan todavía algunas preguntas que hacer. ¿Comían todos los que se beneficiaban de los alimentos en igual cantidad? ¿Su preparación y

\footnotetext{
${ }^{350} \mathrm{AGN}$, Comptos Registros, no 420, fol., 157v, 163r, 76v, 290r, 88v y 299v.

${ }^{351}$ Juan Cardona recibió alimentos desde finales de diciembre de 1432 hasta, por lo menos, finales de febrero [AGN, Comptos Registros, $n^{\circ} 420$, fol. 1v, 2r, 14r y 47r]. La presencia del obispo de Valencia está constatada en los meses de abril, noviembre y diciembre [AGN, Comptos Registros, $\mathrm{n}^{\circ} 420$, fol. 101r, 276r y 314r].

${ }^{352} \mathrm{El} 2$ de febrero recibieron vino y alimentos «los que linpiaron la calostra de Santa María" [AGN, Comptos Registros, $\mathrm{n}^{\circ} 420$, fol. 29r]; y el 19 de abril, sólo vino, a "las gentes que velaron en la cambra de la reyna et por los cabaylleros et escuderos et dueynnas et donçeillas et otros seruidores" [AGN, Comptos Registros, n 420, fol. 94v].

${ }^{353}$ Durante la estancia de la reina en Zaragoza, los canónigos del Pilar, en varias ocasiones, fueron obsequiados por la reina [F. SERRANO LARRÁYOZ, La alimentación de la realeza navarra, p. 315]. En Tudela también fueron agasajados los franciscanos (15 de noviembre), las monjas de Santa Clara (8 de diciembre) y los capellanes del Hostal (20 de diciembre) [AGN. Comptos Registros, $\mathrm{n}^{0} 420$, fol. 287v, 306r y 314r].

${ }^{354}$ El 8 de abril Pedro Sánchez recibió por su boda 1 cahíz de trigo, 12 carapitos de vino, 4 carneros, 3 cabritos y 24 gallinas. De la misma forma, el 29 de noviembre, fueron expendidos 4 carapitos de vino "por las bodas de la fija de maestre Bernart" [AGN, Comptos Registros, no 420 , fol. $85 \mathrm{v}$ y $299 \mathrm{v}]$.
} 
elaboración era la misma? Tal y como se ha ido viendo para otros aspectos, las cantidades servidas iban en relación a la condición social de quien las recibía. La respuesta a la segunda pregunta no es fácil y la documentación que ha sido consultada no permite hacer más que algunas conjeturas.

No cabe duda de que no hay distinción en la calidad de los productos, que se entregan a los servidores e invitados, pero esto no quita, para que su preparación en la cocina, pudiera variar en cierta manera. No tenemos que olvidar que tanto en el pan como en el vino había ciertas diferencias de calidad, cuando estaban destinados para la familia real y a sus allegados. Es posible que con el resto de los alimentos ocurriera algo similar.

Blanca y sus hijas eran quienes más alimentos recibían. De todas formas, las desmesuradas cantidades de algunos productos de los que se benefician originan dudas sobre su consumo real. Esto hace suponer que gran parte de lo expendido diariamente, tanto en comida como en bebida, se donaba a otros servidores del Hostal que no aparecen mencionados como beneficiarios.

\subsection{Prácticas culinarias en la Corte navarra}

La cocina cortesana tuvo durante la Baja Edad Media un rápido desarrollo. Las relaciones tanto políticas como diplomáticas, la imitación de los usos y de las costumbres de los monarcas más importantes, y el continuo movimiento de los cocineros de una Corte a otra, hizo que la gastronomía bajomedieval tuviera un carácter cosmopolita ${ }^{355}$. Ésta, durante los siglos XIV y XV, se desarrolló en un momento de ruptura con la gastronomía antigua y de contacto con la árabe a través de la Península Ibérica y Sicilia ${ }^{356}$. El estudio de recetarios redactados durante los últimos siglos de la Edad Media nos ha dejado constancia de que la cocina de Europa occidental presentaba unas características comunes, pero que quedaban matizadas por diferencias nacionales y regionales propias de cada territorio $^{357}$.

\footnotetext{
${ }^{355}$ J.V. García Marsilla, La jerarquía de la mesa, p. 163.

${ }^{356}$ O. Redon, F. SabBan y S. Serventi, Delicias de la gastronomía, p. 19.

${ }^{357} \mathrm{Un}$ interesante trabajo sobre este asunto, en J.L. FLANDRIN, Internationalisme, nationalisme et régionalisme dans la cuisine des XIV" et $X V^{\prime \prime}$ siécles: le témoignage des livres de cuisine, en "Manger et boire au Moyen Âge". t. 2, Niza, 1984, pp. 75-91.
} 
¿Puede Navarra incluirse en esta órbita? ¿Existió una cocina navarra definida durante el reinado de Blanca o, por el contrario, fue deudora de la de otros territorios? Sorprende la inexistencia, hasta el momento, de recetarios bajomedievales navarros. Tampoco encontramos en los libros de cocina catalanes (por su proximidad física) ni en los franceses (por la tradicional relación de las dos monarquías) un sólo plato que indique como procedencia el reino navarro. Téngase en cuenta que en Castilla el primer libro de cocina que se tradujo, en 1529, fue el Libro de guisados, manjares y potajes de Ruperto de Nola del Llibre del Coch, de origen catalán (ca. 1460), y se ha considerado que este retraso en su difusión por dicho reino pudo haber sido debido a un menor refinamiento de la cocina castellana frente a la catalana ${ }^{358}$. ¿Es posible que ocurriera algo similar aquí?

Las respuestas a estas preguntas son difíciles de desentrañar más que todo por la ausencia de libros de cocina, puesto que hubieran sido de gran utilidad para contestar las cuestiones que nos planteamos. Es por esto que nos tenemos que basar en las anotaciones que se registran en los libros del Hostal Real cuyas deficiencias en este tipo de datos son notables, entre otras razones porque la función de estos manuscritos era principalmente contable.

\section{A. Métodos de preparación de los alimentos}

Los cocineros contaban con toda clase de utensilios para la elaboración de las viandas. Los calderos, ollas, pucheros y todo el utillaje necesario era parte del paisaje donde se las tendrían que apañar diariamente.

De la lectura de los recetarios medievales se ha podido comprobar que las cocciones se efectuaban según el tipo de producto utilizado, o por el color o la consistencia del plato que se deseaba obtener. Su elaboración se estructuraba en varias fases: limpiar, cortar, picar, triturar, cocer, condimentar, desleír, ligar, etc. En numerosas recetas, la cocción, que en muchas ocasiones es la fase final de la preparación de un plato, era precedida de una serie de operaciones de precocción. Estas últimas afectaban principalmente a las carnes, para limpiarlas, darles consistencia, dorarlas ligeramente; pero también a ciertas verduras para fijar el color o eliminar el amargor antes de la cocción definitiva o su preparación final.

\footnotetext{
${ }^{358}$ J.V. GaRCía MaRSilla, La jerarquía de la mesa, p. 165.
} 
Cabe decir que las técnicas culinarias de la cocina medieval apenas se diferencian de las empleadas hoy en día. Están documentadas, durante el periodo que estamos estudiando, la cocción, el hervido (bouillir), las frituras y el asado.

Como demuestran algunos trabajos que tratan sobre gastronomía medieval, el léxico (verbos) utilizado durante los siglos XIV y XV designaba operaciones culinarias que servían para diferenciar todo tipo de prácticas anteriores a la cocción propiamente dicha, y que del mismo modo necesitaban del fuego; aunque hoy por hoy no suelen ser de uso frecuente. El tratamiento que se aplicaba a las carnes asadas, aunque no a todas, correspondía a una precocción (cocer o hervir) seguido del denominado propiamente asado. En los potajes medievales las cualidades intrínsecas de las carne importaban bastante menos que el interés por obtener una mezcla de gustos y de consistencias. Por este motivo se aplicaban diferentes cocciones a un mismo producto o, a la vez a varios ingredientes que se asociaban a continuación para la finalización del plato ${ }^{359}$.

En la documentación consultada, el verbo cozer, en algunas ocasiones, parece que implicaba la fase final de una preparación, aunque no siempre debió de utilizarse con este sentido ${ }^{360}$. La cocción se realizaba introduciendo el alimento en agua, aunque en ocasiones también se utilizó $v^{\text {vino }}{ }^{361}$. Sinónimo quizás sea el verbo buyllir. Pourboulir, en los recetarios franceses, correspondía a una precocción con agua más o menos larga con el fin de enternecer o simplemente cocer un alimento antes de la operación final en la cocina ${ }^{362}$. Se utilizaba con verduras, pescados o carnes. Con este sistema se extraía la grasa de las carnes para utilizarla posteriormente

${ }^{359}$ O. Redon, F. SABBAn y S. Serventi, Delicias de la gastronomia, pp. 55-57; y F. SABBAN, Le savoir-cuire ou l'art des potages dans le Ménagier de Paris et le Viandièr de Taillevent, en "Manger et boire au Moyen Age", t. 2, Niza, 1984, pp. 165-169.

${ }^{36(1)}$ Sabemos que algunas veces se cocían perniles de tocino [AGN, Comptos Registros, $\mathrm{n}^{0}$ 420, fol. 41v]. El cerdo, como el buey o el carnero eran considerados "carnes pesadas". Estas carnes se debían cocer [O. REDON, F. SABBAN y S. SERVEnTI, Delicias de la gastronomía, p. $56]$.

${ }^{301}$ El 22 de abril, la Botellería, expendió 1 cuartón de vino "por cozer yerbas" [AGN, Comptos Registros, $\mathrm{n}^{\circ} 420$, fol. $96 \mathrm{v}$. El 14 de febrero se especifica que, de la carne (posiblemente carnero) que comieron algunos miembros de la Casa Real, fueron asadas 2 piernas, 3 espaldas y un pecho; cocidas 2 lonjas (lonchas) y un pecho [AGN, Comptos Registros, $\mathrm{n}^{\circ} 420$, fol. 38v]. El 23 de abril se gastó 1 cuartón de vino por cocer una anguila [AGN, Comptos Registros, $\mathrm{n}^{\circ} 420$, fol. 98r].

${ }^{302}$ El 14 de febrero se anota que para el «buyllido de las infantas» se utilizó una pierna [AGN, Comptos Registros, n० 420, fol. 38v]. 
en los caldos. También servía para reblandecer la verdura y quitarle el amargor $^{363}$.

La fritura también se consideraba un método de cocción $^{364}$. Sin embargo, el asado fue la técnica culinaria por excelencia de la cocina medieval. Ésta era la última operación culinaria, con la excepción de los últimos retoques, que se realizaba a la vianda antes de servirse en la mesa. El tocino ${ }^{365}$, y en menor medida el queso ${ }^{366}$, se utilizaron para lardar (envolver con lardo o grasa lo que se va a asar).

Las funciones de la cocina, y por extensión de los cocineros y todos los servidores que en ella trabajaban, era muy compleja. Los métodos de preparar los alimentos no se diferenciaban, según lo que hemos podido comprobar, del resto del Occidente europeo.

\section{B. La cocina y la gastronomía}

Los estudios que, en los últimos años, se han realizado sobre este tema, entre los que podemos destacar los de C. B. Hieatt, T. Scully, y los de B. Laurioux, han dejado constancia de los pocos manuscritos medievales de cocina que se conservan en la Península Ibérica. Tan sólo en Cataluña y Portugal se ha conservado alguno ${ }^{367}$.

Resulta difícil aportar algún dato sobre la cocina y la gastronomía palaciega de Blanca de Navarra utilizando, como ya se ha mencionado 83.

${ }^{363}$ J. CRuz Cruz, La cocina mediterránea en el inicio del Renacimiento, Huesca, 1997, p.

${ }^{364} \mathrm{El} 24$ de febrero se compró saín derretido, huevos y azúcar "para las frituras" [AGN, Comptos Registros, $\mathrm{n}^{\circ} 420$, fol. $47 \mathrm{r}$.

${ }^{365} \mathrm{C}$ on este fin se utilizaba tanto en carnes como en vegetales (calabazas) [AGN, Comptos Registros, $\mathrm{n}^{\circ} 420$, fol. 150r, 276r y 250r]. En otras ocasiones -lardar - tiene el significado de echar grasa pero no de embadurnar propiamente. No parece que cuando se anota el gasto de tocino - para lardar a las arvejas- [AGN, Comptos Registros, no 420 , fol. $151 \mathrm{v}]$ éstas fueran asadas. En elaboraciones que no son asados, como guisos o potajes con verduras (acelgas, nabos, berzas, puerros, etc.), su uso también fue muy corriente [AGN, Comptos Registros, n" 420 , fol. $5 \mathrm{r}, 8 \mathrm{r}$, y $70 \mathrm{v}]$.

${ }^{360}$ AGN, Comptos Registros, no 420, fol. 304r.

${ }^{367}$ Podemos mencionar uno de los últimos trabajos de C.B. HIEATT, Making Sense of Medieval Culinary Records: Much Done, But Much More to Do, en M. Carlin and J. T. Rosenthal (dir.): Food and Eating in Medieval Europe. Londres-Ohio, 1998, pp. 101-116; T. ScUlly, The Art of Cookery in the Middle Ages, Suffolk-New York, 1995; y B. Laurioux, Le règne de Taillevent. Livres et pratiques culinaires à la fin du Moyen Âge, París, 1997, pp. 208210. 
anteriormente, sólo fuentes contables. Sin embargo, la única forma, hasta el momento, de poder hacerlo es a través de los nombres de las elaboraciones que alguna vez aparecen citadas. De todas maneras, si el título del plato en sí es una precisa fuente de información, tampoco nos debemos olvidar de los ingredientes que los integraban, cuando los conozcamos, ni de comparar su presencia o ausencia con los recetarios de cocina conocidos ${ }^{368}$.

\section{a) Los potajes}

En la Edad Media se denominaba potaje a preparaciones tan variadas cuya consistencia iba desde un ligero caldo a un estofado de caza con salsa espesa. En esta denominación, durante la Baja Edad Media, se incluían las sopas, las pastas en caldo, los purés y las carnes en salsa ${ }^{369}$.

Las menciones a los ingredientes que componían estos potajes no son muy abundantes. El carnero parece que era la carne con la que a diario se preparaban. El pollo, el vino blanco, el queso y las especias eran otros de los componentes que se incluían en sus elaboraciones. También utilizaron el pan, aunque la documentación no lo expresa directamente, para ligar las salsas y todo tipo de platos $^{370}$.

En este apartado tan heterogéneo podemos incluir las siguientes elaboraciones:

Aricot: tradicionalmente se ha considerado que los términos «héricot», «haricot» o también «hericoq» deriva de «aricoter» o «cortar en trozos pequeños». Podría ser, por tanto, un guiso de pequeños trozos de carnero $^{37 !}$.

\footnotetext{
${ }^{36 x}$ Sobre la importancia de los recursos contables para este tipo de estudios ya se ha referido B. LAURIOUX, L'histoire de la cuisine: problèmes, sources et méthodes. L'exemple du Moyen Agge (XIII'-XV' siècles), en S. Cavaciocchi (dir.): "Alimentazione e nutrizione secc. XIII-XVIIII" (Atti delle Ventottesima Settimana di Studi [Prato]), Florencia, 1997, pp. 473-476.

${ }^{369}$ Sobre los tipos de potajes ver L. PlouviER, La gastronomie dans le Viandier de Taillevent et le Ménagier de Paris, en "Manger et boire au Moyen Âge", t. 2, Niza, 1984, pp. 152-153.

${ }^{371}$ Todos los días, en la Panadería, anotaban la cantidad de pan que entregaban a la Cocina y a la Salsería.

${ }^{371}$ AGN, Comptos Registros, $n^{0} 420$, fol. 4r, 9r y 41 r. Bien pudiera ser similar a la receta denominada "héricot de mouton" en el Ménagier de Paris (en lo sucesivo MP). Era un potaje a base de carnero, cebollas, caldo de buey, macis, perejil, hisopo y salvia [O. REDON, F SABBAN y S. SERVENTI, Delicias de la gastronomía, pp. 206-207]. En el Libro de Guisados de Ruperto de NOLA (en lo sucesivo $L G$ ) hay una receta llamada "potaje que se dice nerricoque" con cierta similitud [J. Cruz Cruz, La cocina mediterránea, p. 291]; y en el Libre de Sent Soví
} 
Capirotada: se preparaba con queso ${ }^{372}$. Resulta ciertamente significativo que no haya mención de esta receta en los manuscritos franceses. Era un guisado que se hacía con verduras, huevos, ajos y otros ingredientes, para echarlo encima de otro, a fin de bañarlo o rebozarlo. Recibe esta denominación porque la forma que tomaba era a modo de capirote $^{373}$.

Cominada: su nombre viene dado por la utilización del comino. Sólo se ha podido comprobar que usaron tocino ${ }^{374}$.

Purea: es lo que hoy en día llamamos puré. Tampoco hemos identificado otros componentes a excepción del tocino ${ }^{375}$. Las verduras y hortalizas que se adquirieron debieron servir para preparar este plato.

Bruet gouge (Brouet georgé): en la Europa medieval la denominación de bruet designaba a un potaje en el que la carne o el pescado era el principal ingrediente. Dependiendo de los productos que se utilizaran para su elaboración, el grosor de las salsas podía ser mayor o menor. El presente

(en lo sucesivo SS) [L. Faraudo De Saint-Germain, El Libre de Sent Soví. Recetario de cocina catalana medieval, "Boletín de la Real Academia de las Buenas Letras de Barcelona". 24 (1951-52), p. 32] se utiliza la almendra. No es determinante para confirmar su uso en este plato, pero el 16 de febrero, día en que se preparó aricot, se compraron especias y almendras [AGN, Comptos Registros, $n^{\circ} 420$, fol. $41 \mathrm{r}$ ].

${ }^{372} \mathrm{AGN}$, Comptos Registros, $\mathrm{n}^{\circ} 420$, fol. $272 \mathrm{v}$.

${ }^{373}$ Ver Diccionario de Autoridades, voz capirotada. En el $L G$ hay una receta llamada "almodrote que es capirotada». Sus ingredientes eran perdices, queso de Aragón, ajos, manteca huevos, pan, caldo de carnero y almodrote (salsa) [J. CRUZ CRUZ, La cocina mediterránea, p. 281]. En Castilla también está documentado este plato [E. de VILLENA, Arte Cisoria, p. 58].

${ }^{374} \mathrm{AGN}$, Comptos Registros, $\mathrm{n}^{\circ} 420$, fol. 30v y 276r. Los manuscritos franceses $(M P)$ mencionan la comminée de poullaille [Le Ménagier de Paris, edición de Jerôme Pichon, París, 1847, reimpr. Ginebra, sd., pp. 161-162 (Se ha utilizado la versión que se encuentra en Internet: http://www.pbm.com/-lindahl/menagier/); y P. AEBISCIIER, Un manuscrit valaisan du Viandier attribué à Taillevent, "Vallesia", 8 (1953), p. 86 (en lo sucesivo VT)l, y también la comminée d'almandes (VT); y la comminée de poisson [Vivendier de Kassel, en B. LAURIOUX, Le règne de Taillevent, p. 372 (en lo sucesivo VK)]. Las dos primeras recetas también utilizan tocino en su preparación. Otros de los componentes eran las aves de corral, pan, jengibre, comino, agua, vino y verjus. En el $M P$ se usa azafrán, para dar color, y leche. Esta especia también se menciona en el $V K$.

${ }^{375}$ AGN, Comptos Registros, $n^{\circ} 420$, fol. 277 r. Una receta que utiliza tocino para freír las verduras es la del "porée de cresson en karesme au lait d'amandes» (Puré de berros para Cuaresma) en el MP [O. Redon, F. SABBAn y S. Serventi, Delicias de la gastronomia, pp. 150-151]. Otra versión del $V K$ sin tocino es el "porée en lait d’amandes" [B. Laurioux, Le règne de Taillevent, p. 373]. Existían, según el $M P$, tres tipos de purés: el blanco, el verde y el negro [Le Ménagier de, pp. 139-140]. 
plato se elaboraba a base de aves de corral, ternera u otro tipo de carne $e^{376}$.

Bruet camelín: elaborado con los mismos tipos de carne que el anterior bruet, y donde la canela adquiría un protagonismo especial. Para su preparación utilizaron gallinas, almendras y azúcar ${ }^{377}$.

Bruet foille: se realizaba con carnero; pero desconocemos la manera de hacerlo ${ }^{378}$.

Cimea: no sabemos si realmente debería incluirse en los denominados potajes medievales. La cimia es lo que hoy denominamos marrubio. Posiblemente, al igual que la cominada, esta hierba hubiera dado su nombre a un plato. Solo hemos podido asociar este plato con la carne (posiblemente

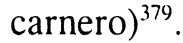

Mouton a las ierbas: como su propio nombre indica la base de esta preparación era el carnero ${ }^{380}$. La ierbas bien pudieran ser plantas aromáticas cuya proporción sería mayor que la de las especias.

Morterol: su nombre deriva de «mortero»; donde se majaba la carne que lo componía. También se utilizó leche y azúcar ${ }^{381}$.

Sopa: con esta denominación se hace referencia a los platos compuestos de rebanadas de pan y de caldo de olla u otro análogo en que se ha cocido. Fueron preparadas con queso ${ }^{382}$ y $^{p^{383}}{ }^{383}$.

\footnotetext{
${ }^{376}$ En la documentación solo se especifica que se utilizó carnero "por el brue gouge (sic.)» [AGN, Comptos Registros, $\mathrm{n}^{\circ} 420$, fol. 171v]. Según el MP, también se componía de caldo de carne, jengibre, canela, azafrán, clavos de girotle, vino, verjus y vinagre [Le Ménagier de, pp. 163-164]. Otra receta parecida se encuentra en el VT [P. AEBISCHER, Un manuscrit valaisan. p. 87].

${ }^{377}$ AGN, Comptos Registros, $\mathrm{n}^{\circ} 420$, fol. $252 \mathrm{v}, 272 \mathrm{v}$ y 273 r. En el $M P$ este potaje se llama "brouet de canelle" [Le Ménagier de, pp. 163]. En la receta francesa se mencionan otras especias como el jengibre, los clavos de girofle y los granos de paraíso. Sorprende la utilización, por los cocineros navarros, de azúcar en la preparación de este potaje.

${ }^{378} \mathrm{AGN}$, Comptos Registros, $\mathrm{n}^{\mathrm{0}} 420$, fol. 95r. Foille en la actualidad significa tonneau (tonel: recipiente) [F. Godefroy, Lexique de l'ancien français, París-Leipzig, 1901, p. 235].

${ }^{379} \mathrm{AGN}$, Comptos Registros, $\mathrm{n}^{\mathrm{0}} 420$, fol. 66r.

${ }^{3 \times 10} \mathrm{AGN}$, Comptos Registros, no 420 , fol. $3 \mathrm{v}$ y $11 \mathrm{r}$.

${ }^{381} \mathrm{AGN}$, Comptos Registros, $\mathrm{n}^{\circ} 420$, fol. $11 \mathrm{r}$ y $17 \mathrm{r}$. Una receta que incluye los ingredientes que hemos apuntado podemos verla en el $L G$ [J. CRUZ CRUZ, La cocina mediterránea, p. 275]

${ }^{3 * 2}$ AGN, Comptos Registros, no 420, fol. 45v y $294 \mathrm{r}$.

${ }^{3 \times 3}$ El día de Jueves Santo anotaron, en la Panadería, la expensa de 14 panes "por sopas e cozina" para los pobres [AGN, Comptos Registros, n" 420, fol. 86v].
} 
Adobado: parece que se refiere a una especie de guiso. Sólo se deja constancia expresa de haber usado miel ${ }^{384}$.

Fideos: su presentación era en forma de caldo. Éstos se acompañaron de tocino y queso ${ }^{385}$.

No se han hallado más denominaciones que hagan referencia a lo que llamamos potajes medievales. Sin embargo, no hay duda que existieron otros muchos platos que la documentación, aunque no informa, nos deja entrever ${ }^{386}$.

\section{b) Asados}

Sólo en ocasiones muy puntuales se especifica el asado de carnero. De todas formas, como podemos imaginarnos, esto no quiere decir que no se asaran otras carnes.

\section{c) Embutidos}

No se han encontrado muchos datos sobre los tipos de embutidos que se compraban o que se preparaban en las cocinas reales.

\footnotetext{
${ }^{384}$ AGN, Comptos Registros, $n^{\circ} 420$, fol. 2v, 9r y 53v. Puede resultar aventurado relacionar el "adobado" con lo que en el $L G$ se llama "potaje de carnero adobado que se dice janete de carnero». En esta receta se utilizan «membrillos y peras hechas en conservas con miel" [J. CRUZ CRUZ, La cocina mediterránea, p. 272]. Igualmente, en la documentación que hemos consultado hay veces en que se anota la compra de miel para membrillos, por lo que es posible que fueran utilizados en este tipo de "potaje» [AGN, Comptos Registros, n 420, fol. 251r]. De la misma forma, parece que lo que se denomina como "ygada" (elaborada con carne de carnero y miel) [AGN, Comptos Registros, $\mathrm{n}^{\circ} 420$, fol. 3v, $4 \mathrm{lr}$ y $70 \mathrm{v}$ ] se debía preparar, según el $L G$, de forma parecida al «adobado» (en esta receta se utilizaba el hígado). En el $L G$, hay otra receta de carnero "adobado" en la que también se usa miel [J. CRUZ CRUZ, La cocina mediterránea, p. 329].

${ }^{385}$ AGN, Comptos Registros, $n^{\circ} 420$, fol. $29 \mathrm{v}$ y $250 \mathrm{r}$. Con algunos de estos ingredientes. en el $L G$, hay una receta denominada "potaje de fideos" [J. CRUZ CRUZ, La cocina mediterránea, pp. 289-290]. Otra receta, de origen italiano, podemos encontrar en Libro de Arte Culinaria (en lo sucesivo $L A$ ) de Martino da COMO [J. CRUz CRUz, La cocina mediterránea. pp. 156-156]. Un estudio sobre la cocina italiana del siglo XV en C. BENPORAT, Cucina italiana del Quattrocento, Florencia, 1996, pp. 9-75. Alguna crítica a la edición de los textos culinarios de C. Benporat, en J. Cruz CruZ, La cocina mediterránea, pp. 31-32.

${ }^{386}$ En el $L A$ hay una receta llamada "guiso de calabazas" [J. CRUZ CRUZ, La cocina mediterránea, p. 159]. La adquisición, en el departamento de Cocina, de "1 a oilla de tiera para las calabaças" y de queso - este último producto en numerosas ocasiones- [AGN, Comptos Registros, $\mathrm{n}^{\circ} 420$, fol. $181 \mathrm{r}$ y $\left.250 \mathrm{r}\right]$, nos hace pensar que posiblemente se utilizaron para hacer un "potaje" parecido.
} 
Longanizas: desconocemos sus componentes. No se elaboraron en la cocina sino que fueron compradas.

Melizas: eran unos salchichones hechos con miel. Estaban compuestas de miel, pan, saín, especias e intestinos ${ }^{387}$.

\section{d) Pasteles}

Durante la Edad Media la denominación de paté (Francia) y pastello (Italia) designaba a algo envuelto en una masa. Los ingredientes que los componían eran productos cárnicos (carneros, tocino para lardar y pollas), otras veces pescado (salmón) y especias (pimienta) ${ }^{388}$.

Past en pot: sólo el carnero ha podido ser asociado a este plato ${ }^{389}$.

\section{e) Salsas}

La importancia de las salsas en la preparación de los diferentes platos está fuera de dudas. Hay veces que se daban idénticos nombres para designar un caldo o una salsa ${ }^{390}$ debido a que contenían los mismos elementos líquidos (vino ${ }^{391}$, leche de almendras y zumos de frutas) y las mismas especias.

Salsa de pago: se componía de azúcar, miel y huevos ${ }^{392}$.

\footnotetext{
${ }^{387}$ AGN, Comptos Registros, $n^{\circ} 420$, fol. 58v, 18v y 20v. El 22 de enero fueron entregadas, a Juan, el joven, especias para «melizas». Ese mismo día se compró jengibre, canela, pimienta, azúcar y arroz [AGN, Comptos Registros, $\mathrm{n}^{\circ} 420$, fol. 18v]. Es posible que fueran estos ingredientes las denominadas ese día como «especias".

${ }^{388}$ AGN, Comptos Registros, $n^{\circ} 420$, fol. 201v, 158v, 209v, 96v y 196v.

${ }^{389} \mathrm{AGN}$, Comptos Registros, $\mathrm{n}^{\mathrm{0}} 420$, fol. 12r. Seguramente era lo que el MP denomina como "pasté en pot de mouton" (paté de pierna de carnero a la cazuela). No parece que estuviera recubierto de una masa, como debía ser norma común en los pasteles, sino que la cazuela (pot) debía hacer una función similar a ésta [O. REDON, F. SABBAN y S. SERVENTI, Delicias de la gastronomía, pp. 325-327]. Otra receta de "pasté en pot" en el VK [B. LAURIOUX, Le règne de Taillevent, p. 373]; y en el $L G$ ("pastel en bote") [J. CRUZ CRUZ, La cocina mediterránea, p. 329].

${ }^{300}$ O. Redon, F. SABban y S. Serventi, Delicias de la gastronomia, p. 365. Es el caso de la "camelina".

${ }^{391}$ No sólo se utilizó en los diferentes platos sino también en la preparación de medicinas y para lavar la fruta y vegetales (higos, uvas pasas, duraznos y rábanos) [AGN, Comptos Registros, $\mathrm{n}^{\circ} 420$, fol. $29 \mathrm{r}, 57 \mathrm{v}, 63 \mathrm{r}$ y $\left.69 \mathrm{v}\right]$.

${ }^{392}$ AGN, Comptos Registros, $\mathrm{n}^{\circ} 420$, fol. $253 \mathrm{v}, 3 \mathrm{v}$ y $296 \mathrm{r}$. Ni en las recetas italianas $(L A)$ ni en las catalanas $(L G)$ mencionan la miel en la preparación de lo que llaman "salsa de pavo" [J. Cruz Cruz, La cocina mediterránea, pp. 166 y 265].
} 
Salsa camelina: se ha comprobado el uso de canela, especias, almendras y azúcar ${ }^{393}$

Salsa verde: era un clásico de la cocina medieval. Todos los manuscritos dan recetas de ella. Desgraciadamente sólo sabemos que se compuso de especias, pero nada más. Su consumo lo podemos asociar con platos asados ${ }^{394}$.

Pampanada [salsa]: ¿es verdaderamente una salsa o un condimento? El jugo que se obtiene de los pámpanos (sarmiento verde de la vid) era muy parecido al agraz. Las menciones a la utilización de la pimienta por la panpanada nos lleva a creer que pudo tratarse de una salsa ${ }^{395}$.

Oruga [salsa]: no hay ninguna mención de que se elaborara una salsa con este nombre, aunque sí la compra de esta planta ${ }^{396}$. y la miel ${ }^{397}$

Mostaza: entre los ingredientes que la componían estaba el vinagre

$\mathrm{Al}$ igual que ocurre con los potajes, debieron preparar otras salsas de las que no tenemos noticias directamente, pero que de manera indirecta podemos intentar identificarlas. Es el caso de una cuyos componentes eran la miel, el pan y los rábanos ${ }^{398}$.

\footnotetext{
${ }^{303}$ AGN, Comptos Registros, no 420, fol. 305r, 90r, 272v. La documentación manejada sólo informa que las almendras y el azúcar se usaron para preparar el "bruet camelín». De todas formas no hay por qué dudar de que se usaran también en esta salsa. Los manuscritos franceses $(M P, V K$ y $V T)$ no mencionan elementos dulces [O. REDON, F. SABBAN y S. SERVENTI, Delicias de la gastronomía, pp. 380-381; B. LAURIOUX, Le règne de Taillevent, p. 375; y $\mathrm{P}$. AEBISCHER, Un manuscrit valaisan, p. 99]. En cambio, sí que se anotan en los italianos $(L A)$ y catalanes $(L G)$ [J. CRUZ CRUZ, La cocina mediterránea; pp. 165-166 y 311].

${ }^{394}$ El Domingo de Pascua (12 de abril) se anota la expensa de especias para preparar salsa verde "para l'asa[do"] [AGN, Comptos Registros, n 420, fol. 90r].

${ }^{395}$ AGN, Comptos Registros, $n^{\circ} 420$, fol. $113 \mathrm{r}$.

${ }^{396} \mathrm{AGN}$, Comptos Registros, $\mathrm{n}^{\circ} 420$, fol. 158v. Recetas de esta salsa podemos verlas en el SS [L. Faraudo de SainT-Germain, El Libre de Sent Soví, p. 23], y en el $L G$ [J. Cruz Cruz, La cocina mediterránea, pp. 331-332].

${ }^{397} \mathrm{Ni}$ en los textos italianos ni en los franceses parece que la miel se usara en la preparación de mostaza. Sólo en los catalanes: en el SS [L. FaRAudo DE SAINT-GERMAIN, El Libre de Sent Soví, p. 23], y en el LG [J. Cruz CRUZ, La cocina mediterránea, p. 332] se ha comprobado recetas que la mencionan.

${ }^{348}$ AGN, Comptos Registros, $\mathrm{n}^{\circ} 420$, fol. 58v. Podría ser parecida a la que en el LG se denomina como «salsa de rábano vexico" [J. CRUZ CRUZ, La cocina mediterránea, p. 334].
} 


\section{f) Entremeses}

En la documentación estudiada no hay mención alguna al entremés. Esta palabra, según el contexto, podía tener diferentes significados, pudiendo designar en cada momento, un espectáculo o un plato. En Italia el intermezzo era un intermedio y no un manjar ${ }^{399}$. Sin embargo, hay una serie de platos tanto azucarados como salados, que, según la literatura culinaria francesa de la época, se presentaban después de las carnes asadas, y que bien pueden ser incluidos en este epígrafe.

Armendolat o armendolada: su composición como bien indica su nombre era a base de almendras y azúcar ${ }^{4(0)}$.

Manjar blanc: denominado por los estudiosos de la gastronomía como un elemento casi indispensable en un banquete medieval de cualquier país de Europa. Los ingredientes básicos que utilizaron para su elaboración fueron: gallinas, pollos, arroz, azúcar y almendras ${ }^{401}$.

Farraduras: hoy las denominamos gachas. Por lo insípido que podía resultar este plato se le añadía $\operatorname{miel}^{402}$ y lo que los textos denominan sabores para las farinas ${ }^{413}$.

Poca información tenemos sobre otros platos; aunque también es posible que los cocineros prepararan arroz con leche ${ }^{4(1)}$.

\footnotetext{
${ }^{349}$ O. Redon, F. Sabban y S. Serventi, Delicias de la gastronomía, pp. 37 y 420-421.

${ }^{4(x)} \mathrm{AGN}$, Comptos Registros, $\mathrm{n}^{\circ} 420$, fol. 204r y 209. Una receta de origen italiano podemos ver en el $L A$. Resulta ciertamente curioso como las recetas que aparecen en el texto catalán $(L G)$ explican preparaciones destinadas a los enfermos. Estas recetas se incluyeron en la edición castellana de 1529 pero no fueron redactadas en el manuscrito original [J. CRUZ CRUZ, La cocina mediterránea, pp. 158 y 305-306].

${ }^{+101}$ AGN, Comptos Registros, $n^{\circ} 420$, fol. 1r, 207r y 276r. Un estudio sobre los orígenes de este plato y sus similitudes y diferencias en Europa se puede ver, en A. CONTRERAS MAS y A. PIÑA FLORIT, El menjar blanc: orígenes y evolución de un plato, Palma de Mallorca, 1996, pp. $19-40$.

${ }^{412} \mathrm{AGN}$, Comptos Registros, $\mathrm{n}^{\circ} 420$, fol. 50v. En Italia $(L A)$ las gachas se elaboraban con cebada y en Cataluña $(L G)$ con harina de arroz [J. CRUZ CRUZ, La cocina mediterránea, pp. 148 y 371-372]. Sin embargo, en otro manuscrito catalán (SS) se ofrece una relación de gachas elaboradas con cebada (ordiat) y avena (avenat) [L. FARAUDO DE SAINT-GERMAIN, El Libre de Sent Soví, pp. 25-26]. En Francia hay recetas en las que se utiliza trigo (froumentée) [O. REDOn, F. SABBAn y S. SERVENTI, Delicias de la gastronomía, pp. 447-4481. Resulta curioso que en ninguna de las recetas que hemos consultado utilicen miel. No obstante, las catalanas (SS y $L G)$ mencionan el azúcar.

${ }^{+113}$ Ver nota $n^{0} 216$.

${ }^{+14}$ En varias ocasiones se especifica el gasto de azúcar para el arroz [AGN, Comptos Registros, $\mathrm{n}^{\circ} 420$, fol. $112 \mathrm{r}$ y $\left.136 \mathrm{r}\right]$
} 


\section{g) Repostería}

La repostería en la mesa de Blanca de Navarra tuvo también su importancia.

Rosquillas: se utilizó harina de trigo, huevos, azúcar y pimienta ${ }^{405}$. El día de San Blas, siguiendo una tradición que se continua hasta hoy en día, fueron bendecidas ${ }^{406}$.

Fullaldres (hojaldres): la función de estos sería la de envolver a ciertos preparados de carne o pescado. Se elaboraban con manteca ${ }^{407}$.

Buñuelos: se presentaban con miel ${ }^{408}$.

Almojávares (almojábanas): eran unos buñuelos de queso de vaca para cuya preparación se usó manteca y miel ${ }^{409}$.

Obleas: su presencia en la mesa fue diaria durante todo el año.

\section{h) Confituras}

De gran aprecio entre las clases acomodadas. Las especias y frutas se confitaban tal como las conocemos hoy en día. También existían otras variedades que se presentaban en forma de grageas o de gránulos de pasta de azúcar.

\footnotetext{
${ }^{405} \mathrm{AGN}$, Comptos Registros, $\mathrm{n}^{\mathrm{o}} 420$, fol. $29 \mathrm{v}, 310 \mathrm{v}, 304 \mathrm{v}$ y $113 \mathrm{r}$. El uso de la pimienta parece que era corriente, según el $L G$, en estas preparaciones [J. CruZ CrUZ, La cocina mediterránea, pp. 323-324].

${ }^{406} \mathrm{El} 3$ de febrero se registra el gasto de 1 cuartal de trigo (para harina) «por las rosquiellas bendichas" [AGN, Comptos Registros, $\mathrm{n}^{\circ} 420$, fol. 29v].

${ }^{407}$ AGN, Comptos Registros, $\mathrm{n}^{\circ} 420$, fol. 316v.

${ }^{408} \mathrm{AGN}$, Comptos Registros, $\mathrm{n}^{\circ} 420$, fol. $45 \mathrm{v}$.

${ }^{409} \mathrm{AGN}$, Comptos Registros, $\mathrm{n}^{\circ} 420$, fol. 3r y 6r. Eran unos buñuelos de origen musulmán [M. ${ }^{a}$ J. RUBiERA MATA, La dieta de Ibn Quzmãn. Notas sobre la alimentación andalusí a través de su literatura, en M. Marín y D. Waines (dir.): La alimentación en las culturas islámicas, Madrid, 1994, p. 130]. La influencia musulmana en la repostería peninsular se puede comprobar en una receta portuguesa denominada "almojávenas de D. Isabel de Vilhena», que se encuentra en una colección de recetas denominada en su edición moderna como Um tratado da cozinha portuguêsa do século XV (en lo sucesivo $C P$ ) [A. GOMES FILHO, Um tratado da cozinha portuguêsa do século $X V$, Río de Janeiro, 1963, p. 151]. Podemos ver otra receta catalana $(L G)$ con el nombre de «toronjas de Xativa que son almojávanas" [J. CRUZ CRUZ, La cocina mediterránea., p. 323]
} 
Sobre el primer tipo de confituras sabemos que se ofrecieron peras y frutas $^{410}$. En otra ocasión se detalla la compra de potes de calabacat (calabaza confitada) $^{411}$. También adquirieron miel para la albucarroga confit $^{412}$. Del segundo no se detallan las diferentes variedades salvo excepciones. La denominación genérica de confites, que a veces compran, nos confirma su aprecio ${ }^{413}$.

\section{i) Otros}

Albóndigas: es posible que este plato se pudiera incluir en el apartado de los potajes. Sin embargo, al no saber con certeza si se acompañaban de salsas hemos optado por no hacerlo. Se preparaban con carne de carnero ${ }^{414}$.

Fiambre: se elaboraba con carne de gallinas ${ }^{415}$.

Aguasal: no sabemos a ciencia cierta si era un plato o un método de conservación. Algunos de los componentes eran el queso, carne, tocino y conejo $^{416}$.

${ }^{410} \mathrm{AGN}$, Comptos Registros, $\mathrm{n}^{\circ} 420$, fol. 305r y 17r. También se menciona varias el uso de la miel con membrillos (pudiera ser para elaborar dulce de membrillo) y con nueces [AGN, Comptos Registros, $\mathrm{n}^{\circ} 420$, fol. $\left.251 \mathrm{r}\right]$.

${ }^{41}$ P. Galindo Romeo, Peregrinación de Doña Blanca, p. 21.

${ }^{412}$ AGN, Comptos Registros, no 420, fol. 277r. ¿Melón o sandía confitada? Albudeca (sandía) etimológicamente viene de al-buteikka [R. GARCía, Primer Diccionario General Etimológico de la Lengua Española, t. 1, Madrid, 1880, voz albudeca].

${ }^{+13}$ P. Galindo Romeo, Peregrinación de Doña Blanca, p. 21. En una ocasión se anota la compra de "12 libras de anís et ciliandre coffites (sic.), a $12 \mathrm{~s}$. libra" [AGN, Comptos Registros, $\mathrm{n}^{\circ} 415$, fol. $\left.18 \mathrm{v}\right]$

${ }^{+14}$ AGN, Comptos Registros, $n^{\circ} 420$, fol. 29r. De Portugal es una receta $(C P)$ que además de carnero también propone utilizar carne de cerdo [A. GOMES FILHO, Um tratado da cozinha. p. 147]. Otra receta de origen italiano $(L A)$ nos informa que se podían elaborar de ternera o de otra clase de carne [J. CRUZ Cruz, La cocina mediterránea, p. 136].

${ }^{415} \mathrm{AGN}$, Comptos Registros, $\mathrm{n}^{\circ} 420$, fol. $177 \mathrm{v}$. En el $L A$ se especifica una receta llamada "mortadela de carne de ternera" [J. CRUZ CRUZ, La cocina mediterránea, p. 137]. Pudiera ser que se hiciera de forma similar.

${ }^{+16} \mathrm{AGN}$, Comptos Registros, no 420, fol. 1r, 252v, 307r y 299v. Parece que era una forma de conservación, pero que requería una cierta preparación culinaria. En el $L G$ (en su versión de 1529) añade la receta de "escabeche de conejos", que muy bien pudo ser parecida a como se preparaba en Navarra [J. CRUZ CRUZ, La cocina mediterránea, p. 330]. 


\section{CONCLUSIONES}

El sistema organizativo del Hostal de Blanca de Navarra era similar, aunque con las características propias de la época, al del resto de los hostales que conocemos. El servicio personal de la reina y su organización seguían las pautas marcadas por Carlos III, su padre, que a su vez se basó en el Hostal Real de la Casa de Francia. En la denominación de algunos oficios, sin embargo, se ha podido observar cierta influencia castellana. No resulta extraño si tenemos en cuenta el origen de Leonor, su madre, y de Juan II, su esposo.

El personal femenino del Hostal era bastante numeroso, pero predominan en todos los departamentos los servidores masculinos ${ }^{417}$. De todas formas, se ha constatado que el servicio personal e íntimo de la reina, sobre todo cuando está convaleciente de sus continuas indisposiciones, era realizado por una servidumbre compuesta únicamente por mujeres.

Se ha observado que durante gran parte del año la reina comía con un grupo reducido de acompañantes. Es más, en las ocasiones en que estaba enferma, las comidas diarias no se realizaron en la sala destinada a tal efecto, sino en sus habitaciones privadas. La intimidad se abandona en las festividades, domingo de Pascua de Resurrección, Navidad, etc., celebrando banquetes con una amplia afluencia de invitados.

El pan, vino y carne eran considerados alimentos básicos. El pan blanco de trigo - elaborado y cocido en la Panadería - se presenta a diario en la mesa regia. El vino tampoco faltó en ninguna ocasión;. Los tipos eran muy variados, desde los tintos o blancos a los dulces y aromáticos como la malvasía o el moscatel. Éstos procedían, dependiendo del lugar donde residía la reina, de Navarra o Aragón. La presencia de Blanca en Zaragoza influyó en la compra de caldos de importación como el vino griego.

Las carnes que más se consumieron fueron el carnero, el cabrito, las aves de corral, principalmente gallinas y pollos, y la caza menor (perdices, tórtolas, perdigones, pájaros, conejos, ánsares, palomas, palominos, gazapos y conejos). Sin embargo, la compra de carne de caza mayor (ciervo) se registra en una ocasión. Esta ausencia se puede explicar, más que por una

\footnotetext{
${ }^{417}$ Un estudio sobre las mujeres al servicio de la reina Blanca, en M.a R. GARCía ARANCÓN, El personal femenino del Hostal de la reina Blanca de Navarra (1425-1426), en El trabajo de las mujeres en la Edad Media Hispana, Madrid, 1988, pp. 27-41.
} 
falta de aprecio, porque su adquisición habitual se realizaba a través de los cazadores reales y como presente de personajes notables.

El consumo del pescado sólo se realizaba en los periodos en que la Iglesia imponía, como método de mortificación, la abstinencia de comer carne. A pesar de todo, en la mesa se presentaban las variedades más apreciadas. Cuando la reina y las infantas se encontraban enfermas no cumplían con el mandato eclesiástico debido a que en la mentalidad de la época la carne era el mejor remedio contra las enfermedades.

También se registra la compra de huevos y queso. Con menor asiduidad, sin embargo, se menciona la leche; posiblemente por las dificultades de conservación.

Las verduras y hortalizas ocupaban un lugar importante en la dieta debido a que eran adquiridas a diario, aunque no constituyeron una parte fundamental de la alimentación. Su función era la de acompañar a las carnes y pescados. El consumo de legumbres fue más reducido. La consideración de que estos alimentos eran propios de las clases sociales más desfavorecidas debió influir en la frecuencia con la que se abastecían. El poco gasto que se constata en la adquisición de estos artículos se debe a que sus precios eran bastante bajos.

La fruta, tanto la fresca como los frutos secos, aparece con frecuencia en la mesa real. Su presencia, como la de todos los productos vegetales, variaba en función de las estaciones.

Resulta complicado intentar ver influencias y características de la cocina palaciega navarra. Sin embargo, no es menos cierto que después de realizado este estudio, se ha comprobado una serie de datos significativos respecto a la existencia o no de una cocina navarra definida durante el reinado de Blanca, o la posibilidad de que ésta fuera deudora de otros territorios.

El gusto por los sabores contrastados, es decir, lo dulce combinado con lo agrio y salado fue muy característico de la cocina medieval. La utilización de elementos ácidos, como el vinagre y el agraz fue, en la Corte navarra, muy frecuente. De igual forma, se ha observado una tendencia a utilizar los edulcorantes (miel y azúcar) con gran profusión. El uso de estos ingredientes era más habitual en los libros de cocina italianos y catalanes que 
en los franceses ${ }^{418}$. Con el fin de potenciar el sabor los cocineros utilizaban gran cantidad de especias (pimienta, jengibre, canela, clavos de girofle, nuez moscada, alcaravea y azafrán) y, en menor medida, hierbas aromáticas (anís, comino, orégano y perejil).

Es bastante significativa la ausencia de denominaciones de platos elaborados con pescado. La consideración de este alimento como sustituto de la carne pudo haber influido en cierta medida en una falta de interés en citarlos.

Se ha podido observar una gran influencia de la cocina francesa. La terminología utilizada, tanto en los métodos de preparación como en los nombres de numerosos platos, así lo indican. Las continuas relaciones, tanto desde el punto de vista político como del personal, durante toda la Baja Edad Media, entre los monarcas navarros y franceses confirman este hecho.

Durante los años que Blanca estuvo en Sicilia, el peso de la cocina italiana, y, por qué no, también de la catalana, debió ser muy importante para consolidar los gustos alimentarios de la futura reina de Navarra. No resulta, por tanto, tan sorprendente que la pasta (fideos), producto típicamente italiano, y que en Francia ya está documentado durante el siglo XIV, se empiece a mencionar en las compras de la realeza navarra tras la muerte de Carlos III $(1425)^{419}$.

La importancia de la cocina musulmana también ha podido ser constatada, no sólo por la presencia de algunos productos (berenjenas, pepinos, etc.) sino también por la denominación de algunos platos (albóndigas) y de algunos productos de repostería (almojábanas).

Así pues, a pesar de los datos tan puntuales que se han sido aportados, podemos finalizar afirmando que la cocina elaborada en la Corte de la reina Blanca no difería en absoluto de la tradición culinaria europea. La influencia externa; francesa, catalano-italiana, musulmana y, posiblemente, aunque en menor medida, castellana originó lo que podemos denominar como una cocina mixta. Ni los productos utilizados ni los platos elaborados nos ofrecen suficientes datos para demostrar la existencia de alguna

\footnotetext{
${ }^{418}$ De todas formas, debemos tener presente que, en el siglo XV, la frecuencia de empleo del azúcar aumentó de una manera considerable, en los tratados de cocina franceses, si los comparamos con los del XIV [J.L. FLANDRIN, El azúcar en los libros de cocina franceses del siglo XIV al siglo XVIII, en A. Malpica (ed.): "1492: Lo dulce a la conquista de Europa" (Actas del Cuarto Seminario Internacional sobre la caña de azúcar)". Granada, 1994, pp. 195-202].

${ }^{419} \mathrm{La}$ ausencia de pasta, en la dieta del rey Carlos III, ha sido comprobada durante el trabajo de archivo que se ha realizado para la redacción de mi tesis doctoral, todavía en curso.
} 
originalidad en la gastronomía navarra, aunque es posible que la conjunción de las diversas influencias foráneas le diera un rasgo distintivo frente a las otras cocinas europeas. 


\section{APÉNDICES}

\section{GRÁFICO 1}

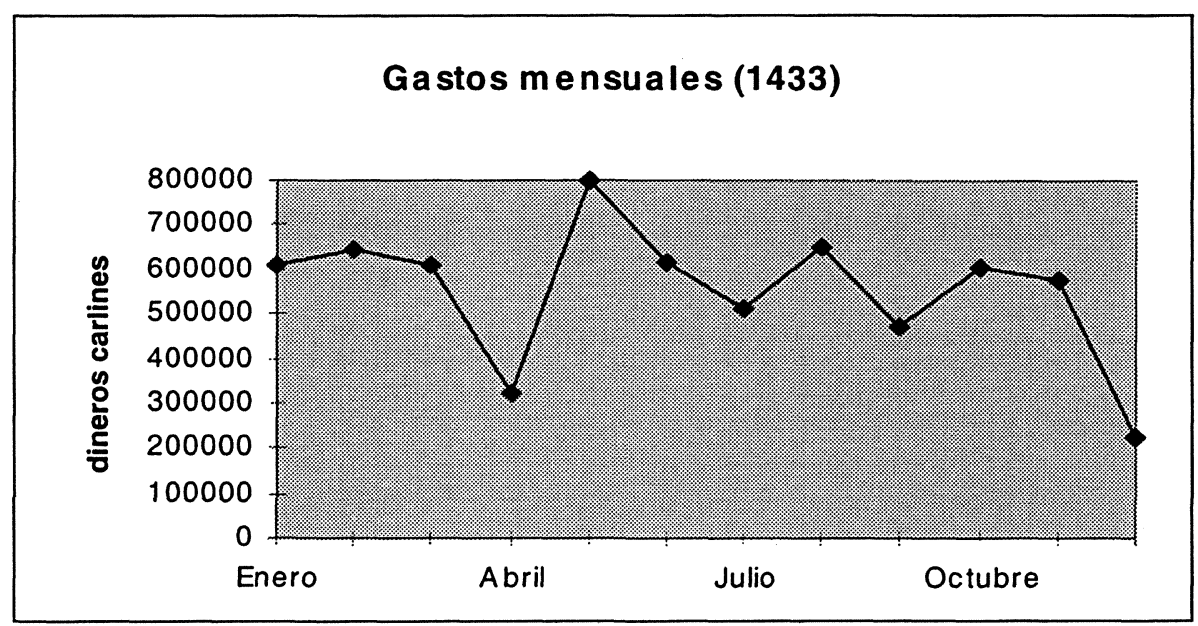

\section{GRÁFICO 2}

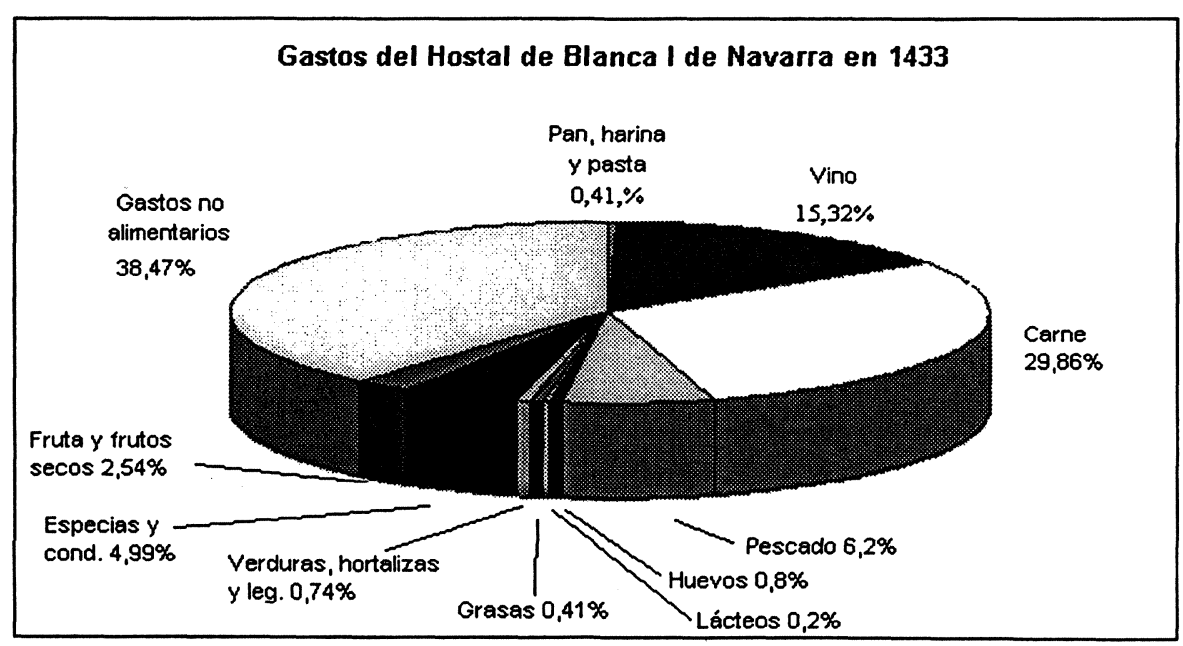


ITINERARIO DE BLANCA DE NAVARRA (1433)

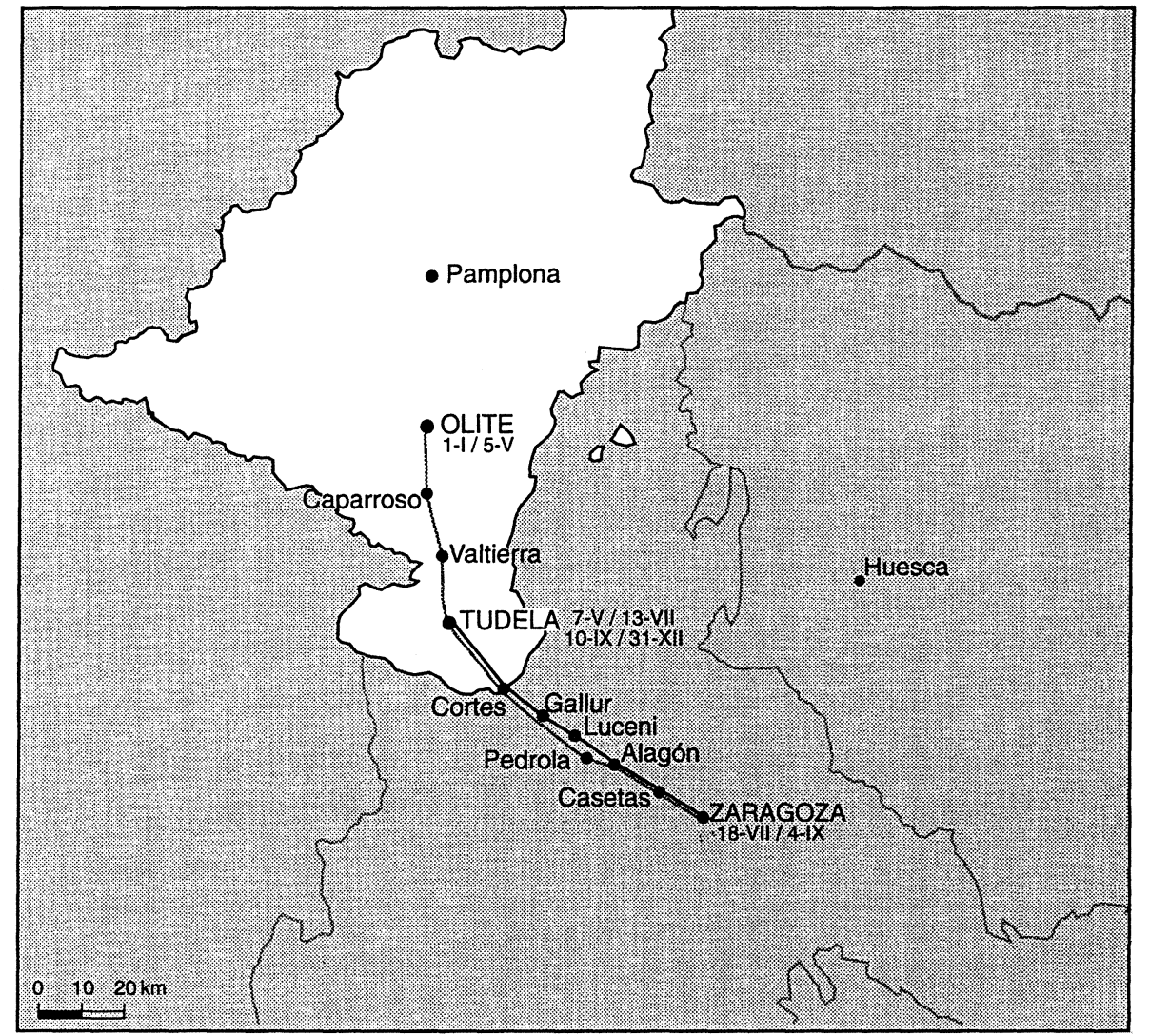

Itinerario: Olite, Caparroso, Valtierra, Tudela, Cortes, Pedrola, Alagón, Casetas, Zaragoza Casetas, Alagón, Luceni, Gallur, Cortes, Tudela 
APROVISIONAMIENTO DE VINO EN EL HOSTAL DE BLANCA DE NAVARRA (1433)

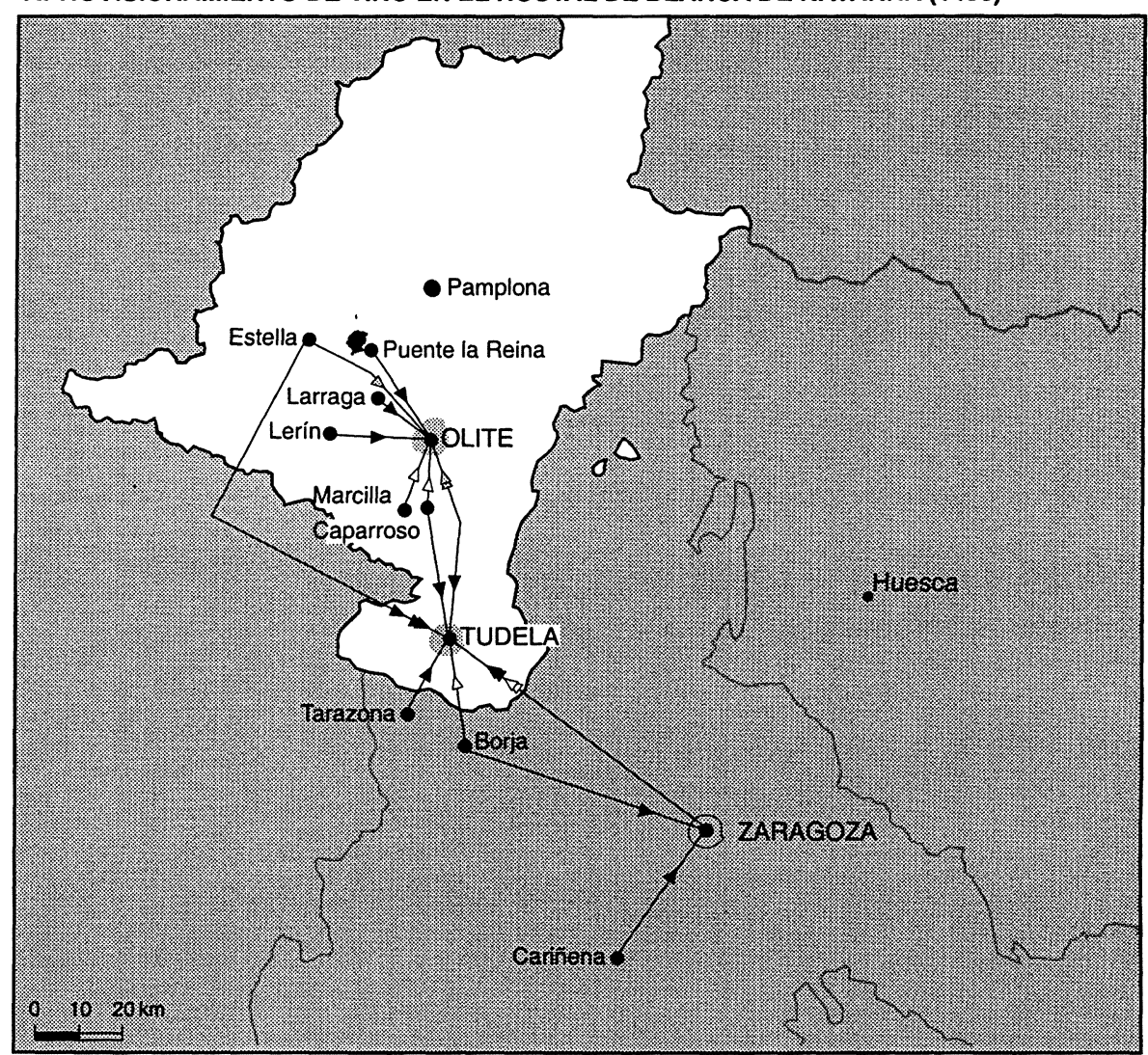

Vino blanco

Moscatel

Malvasia

$\bowtie$ Vino griego

Vino cocido

Aprovisionamiento loca 


\section{ANEXO DOCUMENTAL}

Relación de precios de los alimentos adquiridos en Navarra (1433)

\begin{tabular}{|c|c|c|c|}
\hline Producto & $\begin{array}{l}\text { Precio (d. carlín) } \\
\text { / Cantidad }\end{array}$ & Producto & $\begin{array}{c}\text { Precio (d. carlín) } / \\
\text { Cantidad }\end{array}$ \\
\hline Aceite & 14-33 d. / libra & Almendras & 24-72 d. / libra \\
\hline Anguila & 24 d. /libra & Ansar & 120 d. / unidad \\
\hline Arenque & $\begin{array}{c}00610 \mathrm{~d} . / 586 \\
\text { unidades }\end{array}$ & Arroz & 18-30 d. / libra \\
\hline Arvejas & 12 d. / libra & Avellanas & $\begin{array}{l}18 \text { d. / libra } \\
240 \text { d. / robo }\end{array}$ \\
\hline Azafrán & 2.304 d. / libra & Azúcar & 210 d. / libra \\
\hline Barbilón & 24 d. / libra & Becerro & 30 d. / libra \\
\hline Besugo & 18-22 d. / libra & Cabrito & 84-168 d. / unidad \\
\hline Canela & $312-348$ d. /libra & Capón & $60-120$ d. / unidad \\
\hline Carnero & $\begin{array}{c}\text { 336-384 d. I } \\
\text { unidad } \\
28-30 \text { d. / libra }\end{array}$ & Castañas & 8 d. / libra \\
\hline Cerezas & 12 d. / libra & Ciervo & 16 d. / libra \\
\hline $\begin{array}{l}\text { Clavos de } \\
\text { girofle }\end{array}$ & $360-576$ d. / libra & Conejo & 24 d. / unidad \\
\hline Congrio & 30-72 d. / libra & Cominos & 48 d. / libra \\
\hline Chicharra & 20 d. / libra & Dátiles & 288 d. / libra \\
\hline Delfín & 24-26 d. / libra & Espinacas & 3 d. / manojo \\
\hline Fideos & 30-48 d. / libra & Gallina & 30 d. / unidad \\
\hline Gallo & $72-78$ d. I unidad & Gazapo & 18 d. / unidad \\
\hline Guindas & 8 d. Tlibra & Habas & 12 d. / libra \\
\hline Higos & 9-12 d. / libra & Huevos & 1-3 d. / unidad \\
\hline Jengibre & 312-348 d. / libra & Lamprea & 180 d. / unidad \\
\hline Manteca & 6d. T pelota & Merluza & 20-24 d. Tlibra \\
\hline Miel & 9d. /libra & $\begin{array}{l}\text { Mostaza } \\
\text { (grano) }\end{array}$ & 36 d. / almud \\
\hline Naranjas & $\begin{array}{l}192 \mathrm{~d} . / 100 \\
\text { unidades }\end{array}$ & $\begin{array}{c}\text { Nuez } \\
\text { moscada }\end{array}$ & 480 d. / libra \\
\hline Pájaros & 12 d. T unidad & Paloma & 24 d. / unidad \\
\hline Palomino & 12 d. / unidad & Perdigón & 30 d. / unidad \\
\hline
\end{tabular}




\begin{tabular}{|c|c|c|c|}
\hline Producto & $\begin{array}{l}\text { Precio (d. carlín) } \\
\text { / Cantidad }\end{array}$ & Producto & $\begin{array}{c}\text { Precio (d. carlín) } \\
\text { Cantidad }\end{array}$ \\
\hline Perdiz & $30 \mathrm{~d} . /$ unidad & Pimienta & 144-168 d. / libra \\
\hline Polla & 36 d. $/$ unidad & Pollo & 15 d. T unidad \\
\hline Queso & 24 d. / unidad & $\begin{array}{l}\text { Saín de- } \\
\text { rretido }\end{array}$ & 24 d. / libra \\
\hline Saín fresco & $18 \mathrm{~d} . /$ libra & Saín viejo & 30 d. / libra \\
\hline Sal & 27-64 d. / cuartal & Tenca & 24 d. / libra \\
\hline Tocino & 16-18 d. / libra & Tórtola & $18 \mathrm{~d} . /$ unidad \\
\hline Uvas pasas & $18 \mathrm{~d} . /$ libra & Vaca & $20-24$ d. / libra \\
\hline Vinagre & 48 d. / carapito & $\begin{array}{l}\text { Vino } \\
\text { (blanco) }\end{array}$ & $96-128$ d. / carapito \\
\hline $\begin{array}{c}\text { Vino } \\
\text { (cocido) }\end{array}$ & $156 \mathrm{~d} . /$ carapito & $\begin{array}{c}\text { Vino } \\
\text { (malvasía) }\end{array}$ & 168 d. / carapito \\
\hline $\begin{array}{l}\text { Vino (mos- } \\
\text { catel) }\end{array}$ & 120 d. T carapito & Vino (tinto) & $60-120$ d. $/$ carapito \\
\hline
\end{tabular}

\section{RÉSUMÉ}

L'étude envisage l'approfondisement d'un sujet jusqu'au présent peu developpé, dans les lignes de recherche historique prioritaires en Navarre.

Le travail est divisé en deux sections. D'une part, l'organisation de l'Hôtel de la reine Blanche, dont on a analisé les serviteurs, les fourniseurs, les produits et les prix, parmis d'autres aspects de l'institution. De l'autre, on s'est approché à l'élement symbolique que la nourriture implique, en touchant des matières comme les vaisselles, les rythmes alimentaires, les aspects religieux et les bénéficiaires des aliments. Enfin, malgré les rares sources disponibles, on a cherché à donner aussi une vision générale des pratiques culinaires de la Cour navarraise au $\mathrm{XV}^{\mathrm{c}}$ siècle.

\section{SUMMARY}

This study tries to amplify a subject not developed enough, for the moment, in the lines of historical research that are being carried out in Navarre.

It is divided in two sections. On one hand, aspects as servants, provision, products and prices, among others, have been studied through the organisation in queen Blanca's Hostel. On the other hand, we have approached the symbolic factor that feeding implies. We have also studied questions relating to crockery, feeding paces, religious aspects and beneficiaries from food. At last, in spite of having few and dispersed data, we have tried to give a view about culinary practises in the navarresse court during the first half of the 15 th century. 